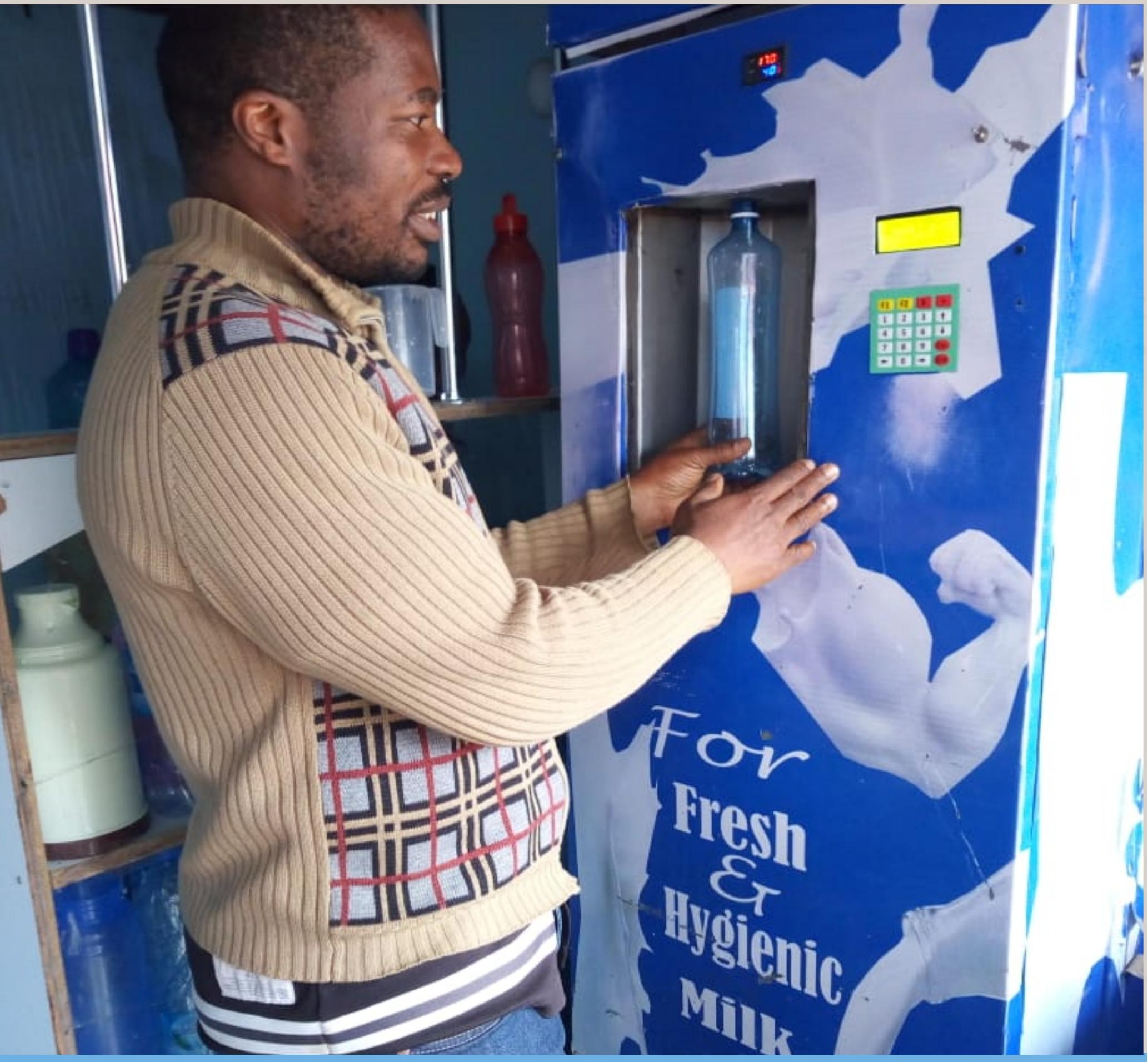

Milk Dispensing Machines in Kenya's Dairy Industry: Trends and scenario analysis

Oscar Ingasia Ayuya, Dave Mwangi Ireri, Judy Kithinji, Asaah Ndambi, Catherine Kilelu, Bockline Omedo Bebe, Paul Ndung'u and Jan van der Lee

3R Kenya Report 012 WLR Report 1253

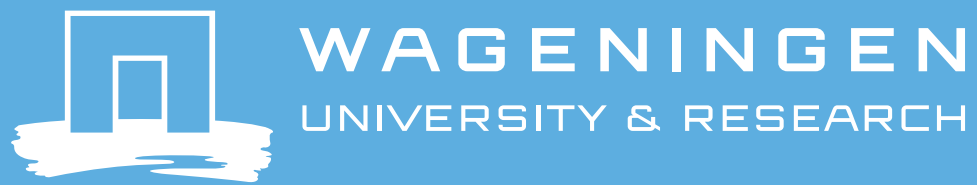





\title{
Milk Dispensing Machines in Kenya's Dairy Industry: Trends and scenario analysis
}

Oscar Ingasia Ayuya ${ }^{1,5}$, Dave Mwangi Ireri ${ }^{2,7}$, Judy Kithinji ${ }^{2}$, Asaah Ndambi ${ }^{3}$, Catherine Kilelu ${ }^{4}$, Bockline Omedo Bebe $^{5}$, Paul Ndung' ${ }^{6}$ and Jan van der Lee $^{3}$

\author{
1 AfriDev Economic Consulting Limited \\ 2 Policy and Market Options \\ 3 Wageningen UR Livestock Research \\ 4 3R Kenya Project, ACTS \\ 5 Egerton University \\ 6 Kenya Dairy Board \\ 7 Chuka University
}

This research was conducted by Wageningen Livestock Research, commissioned under the 3R Kenya project, which is funded by the Embassy of the Kingdom of the Netherlands in Nairobi, Kenya, within the framework of the Agriculture and Food \& Nutrition Security program.

Wageningen Livestock Research

Wageningen, May 2020

3R Kenya Report 012

WLR Report 1253 
Oscar Ingasia Ayuya, Dave Mwangi Ireri, Judy Kithinji, Asaah Ndambi, Catherine Kilelu, Bockline Omedo Bebe, Paul Ndung'u and Jan van der Lee, 2020. Milk Dispensing Machines in Kenya's Dairy Industry: Trends and scenario analysis. 3R Kenya research report 012/Wageningen Livestock Research, Report 1253.

\section{Summary}

This study analyses trends in the development of ATM milk retailing in Kenya, based on data collected in six counties with high ATM density. Trends include growth in the ATM businesses and related support services, consumer perceptions and demand and milk quality and safety issues in this milk market segment. Building on the trends analysis, the second part of the study explores scenarios that are likely to affect further growth of milk ATMs. The evidence is intended to inform the necessary policy and regulatory framework that can support quality-driven investments in this growing retail market segment.

This report can be downloaded for free at https://doi.org/10.18174/521451, at www.wur.nl/livestockresearch (under Wageningen Livestock Research publications) or at www.3r-kenya.org.

(C) 2020 Wageningen Livestock Research

P.O. Box 338, 6700 AH Wageningen, The Netherlands, T +31 (0)317 483953 ,

E info.livestockresearch@wur.nl, www.wur.nl/livestock-research. Wageningen Livestock Research is part of Wageningen University \& Research.

All rights reserved. No part of this publication may be reproduced and/or made public, whether by print, photocopy, microfilm or any other means, without the prior permission of the publisher or author.

Wageningen Livestock Research is NEN-EN-ISO 9001:2015 certified.

All our research commissions are in line with the Terms and Conditions of the Animal Sciences Group. These are filed with the District Court of Zwolle.

Wageningen Livestock Research Report 1253, 3R Kenya research report 012 


\section{Table of contents}

1.1 Background 11

1.2 Research objectives $\quad 12$

$\begin{array}{lll}1.3 & \text { Structure of the report } & 12\end{array}$

$\begin{array}{ll}\text { Methodology } & 13\end{array}$

2.1 Study area $\quad 13$

2.2 Sampling and data collection $\quad 13$

2.2.1 Survey of milk ATM operators and consumers 13

2.2.2 Key informant interviews $\quad 14$

$\begin{array}{ll}2.3 \text { Scenario analysis method } & 14\end{array}$

$3 \quad$ Trends and development of milk ATMs $\quad 16$

3.1 Geographical distribution of milk ATMs $\quad 16$

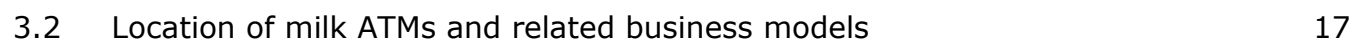

$\begin{array}{lll}3.3 & \text { ATM milk sales } & 18\end{array}$

$\begin{array}{lll}3.4 & \text { ATM milk pricing and margins } & 19\end{array}$

3.5 Milk ATM businesses and employment $\quad 21$

4 Consumer perceptions and quality aspects of ATM milk 22

4.1 Consumers' milk purchasing patterns $\quad 22$

4.2 Quality perception of ATM milk by consumers 26

4.3 Quality and safety assessment of milk dispensed in ATMs $\quad 27$

4.3.1 Results of quality and safety of milk sampled for KDB surveillance $\quad 27$

4.3.2 Selected studies on quality and safety of ATM milk 28

4.4 Best and poor practices along the milk ATM supply chain 29

$5 \quad$ Business ecosystem in the ATM market segment 32

5.1 Milk ATM technology business 32

5.1.1 Types of Milk ATM technologies offered by suppliers 32

5.1.2 Business development in the ATM milk supply chain $\quad 34$

$\begin{array}{ll}5.1 .3 \text { Suppliers of ATM milk } & 35\end{array}$

$5.2 \quad$ Milk ATM business licensing $\quad 38$

6.1 Enablers and disablers of ATM milk sector growth 40

$\begin{array}{lll}6.2 & \text { Scenario analysis } & 41\end{array}$

6.2.1 Scenario 1: Business as usual $\quad 41$

6.2.2 Scenario 2: Stronger regulatory framework leads to increased compliance with KDB regulations $\quad 43$

6.2.3 Scenario 3: Public ban on sale of raw milk in urban areas, leading to the ATM market segment encroaching on the informal market segment 
References

Appendix 1 ATM sampling technique and extended scenario methodology 50

Appendix 2 Further analysis

55 


\section{List of tables}

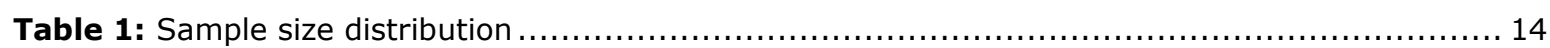

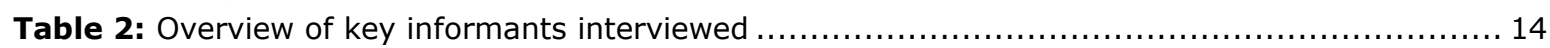

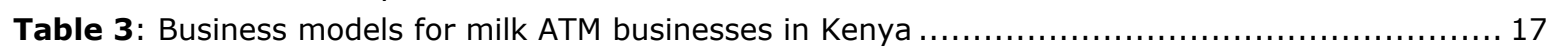

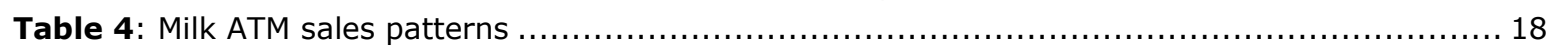

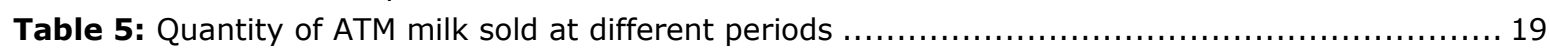

Table 6: Geographical patterns in ATM average pricing and distance by ATM operators $\ldots \ldots \ldots \ldots \ldots \ldots$

Table 7: Price comparison between ATM milk and other milk market segments..................... 20

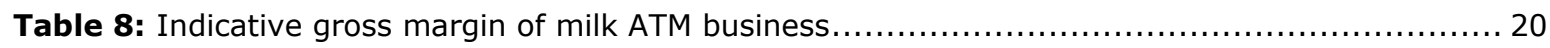

Table 9: Milk purchases and distance to ATM by male- and female-headed consumer households.... 24

Table 10: Quality perception of ATM milk by consumers....................................... 26

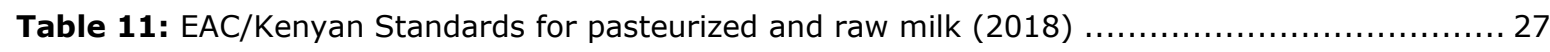

Table 12: Prevalence of detectable levels of antibiotic residues in milk from Eldoret ..................29

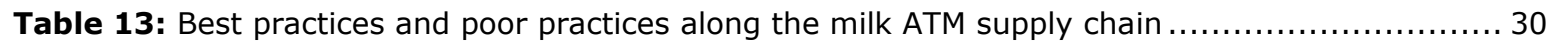

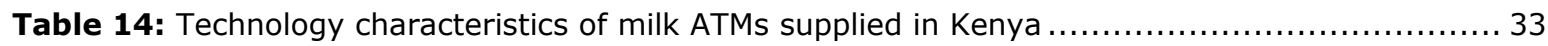

Table 15: Enablers and disablers of future development of ATM milk supply chain .................. 41

Table 16: Future projections in demand and supply of ATM milk in a business-as-usual scenario.... 42

Table 17: Scenario with compliance rate changes through a stronger regulatory framework $\ldots \ldots \ldots . . .44$

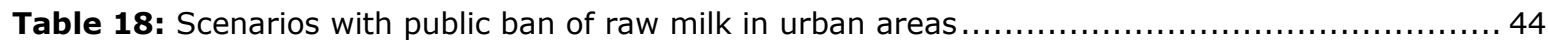

\section{List of figures}

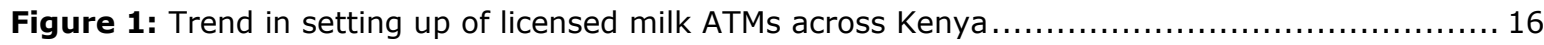

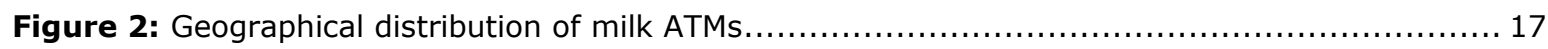

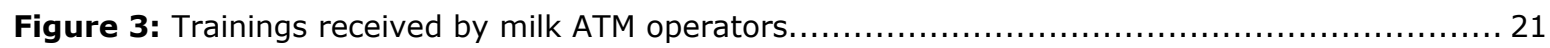

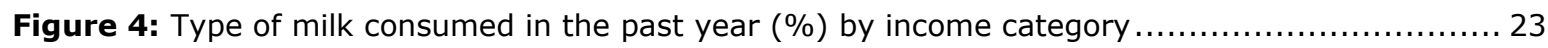

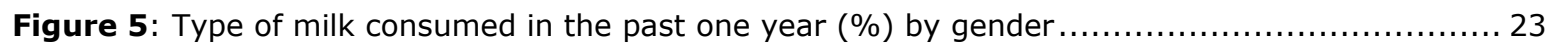

Figure 6: Consumer purchasing patterns of ATM milk (\%) by income bands....................... 24

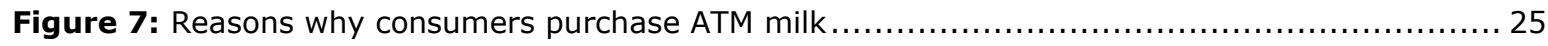

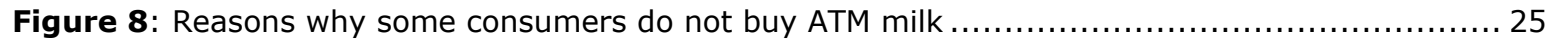

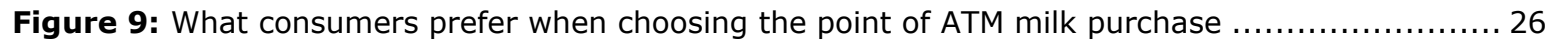

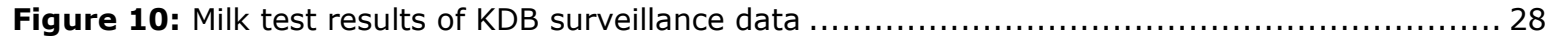

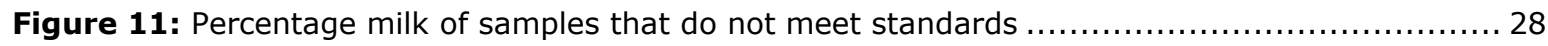

Figure 12: Assessment of total viable count (TVC cfu/ml) at different points of the ATM .............29

Figure 13: Type of businesses developed around the ATM market segment ...................... 36

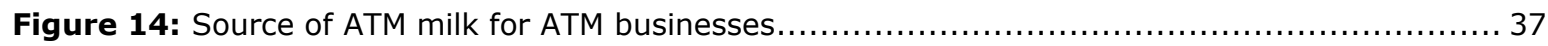

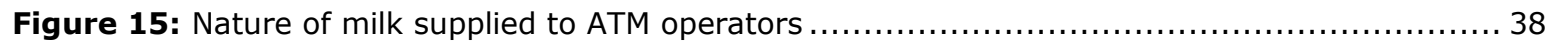

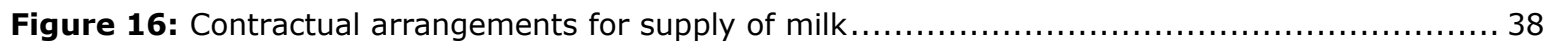

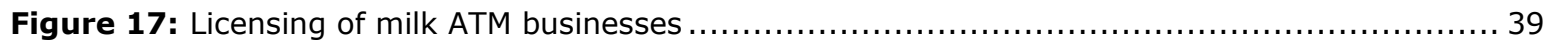

Figure 18: Trends in supply and demand of ATM milk over 10 years in business as usual scenario .. 43 


\section{List of photos}

Photo 1: Milk ATM in a mini supermarket (left) and stand-alone milk ATM business (right) ........... 18

Photo 2: Illustration of the different ATM milk prices across operators.............................. 19

Photo 3: Consumer purchasing ATM milk for home consumption (left) and a customer consuming at

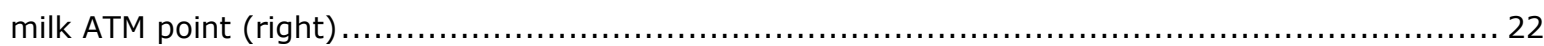

Photo 4: ATM milk operators using non-recommended milk cans in the ATM machine.................27

Photo 5: Sealed cans(left) and tamper-proof cans (right) used by some enterprises to secure the ATM

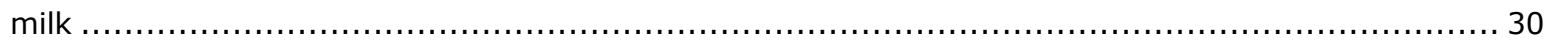

Photo 6: Medical certificate issued by county government to milk ATM operators $\ldots \ldots \ldots \ldots \ldots \ldots \ldots 31$

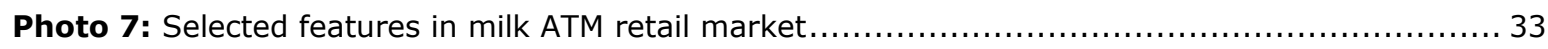

Photo 8: Businesses selling non-dairy products (left) and dairy products (right) together with ATM

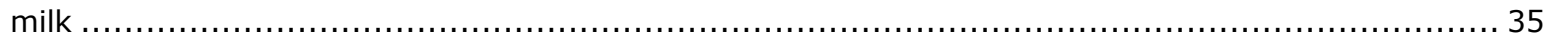

Photo 9: Suka dairies cooperatives one of the suppliers of ATM milk in Nakuru..................... 37

\section{List of acronyms and abbreviations}

$\begin{array}{ll}\text { ATM } & \text { automated teller machine (milk-vending machine) } \\ \text { CIP } & \text { cleaning-in-place } \\ \text { EAC } & \text { East African Community } \\ \text { FAOSTAT } & \text { Food and Agriculture Organization Corporate Statistical Database } \\ \text { GoK } & \text { Government of Kenya } \\ \text { GSM } & \text { global system for mobile communication } \\ \text { KDB } & \text { Kenya Dairy Board } \\ \text { KEBS } & \text { Kenya Bureau of Standards } \\ \text { KES } & \text { Kenya shillings } \\ \text { KNBS } & \text { Kenya National Bureau of Statistics } \\ \text { TBC } & \text { total bacterial count } \\ \text { TCC } & \text { total coliform count } \\ \text { TVC } & \text { total viable count }\end{array}$




\section{Acknowledgements}

This research was conducted by Wageningen Livestock Research. The study was implemented by Afridev Economic Consulting Limited, Policy \& Market Options Limited (PMO) and the 3R research team in collaboration with the Kenya Dairy Board. We are grateful to various stakeholders including selected ATM operators, ATM machine suppliers, consumers, milk processors, county public health officials and KDB inspectors for their cooperation in undertaking this study. We also thank the participants of the policy roundtable meeting where the preliminary findings of the study were presented and during which the scenarios were discussed and refined. We are also grateful to the field enumerators for their support in data collection and in providing photos used in this report.

The $3 R$ project is funded by the Embassy of the Kingdom of the Netherlands in Nairobi, Kenya, within the framework of the Agriculture and Food \& Nutrition Security program. 


\section{Summary}

Urbanization, increasing population, rising income levels and changing dietary consumption patterns are expected to increase demand for milk and dairy products in Kenya. The annual per capita milk consumption of 110 litres is projected to double by the year 2030 . Out of the 3.9 billion litres of cow milk consumed, 2.1 billion litres (54\%) is marketed. It is estimated that about $70 \%$ of the marketed milk is traded informally, mostly in raw form, while the rest is processed into milk and dairy products and marketed formally. There has been a recent technological and market development in milk retailing in the formal milk market, called the milk-vending or dispensing machine (popularly known as the milk ATM). There has been a widespread uptake of this innovative platform for milk retail in some Kenyan urban and peri-urban areas.

The Kenya Dairy Board (KDB) and stakeholders in the milk ATM supply chain are engaged in a debate on how to best develop the market segment while ensuring consumer access to quality and affordable milk. There is therefore the need for empirical evidence on the likely growth trends in consumer demand, as well as scenarios for factors that are likely to affect further growth trends. In addition, the empirical evidence should inform decisions about what interventions would be relevant and supportive to this milk retail market segment.

The research questions were:

1. What are the trends in the development of the ATM milk market segment?

2. What are key consumer patterns, quality and food safety issues related to the development of milk ATM market segment?

3. What businesses have emerged around ATM milk market segment?

4. What are the potential scenarios that might affect the development of the ATM milk segment?

This study is based on primary data collected in the period between July and August 2019 from six counties with a high density of milk ATMs according to KDB database, using mixed methods. Survey questionnaires were administered on 162 ATM operators and 490 consumers (from which 352 were considered to be of acceptable quality and analysed). Key informant interviews were conducted for qualitative information with ATM machine suppliers, ATM milk processors, the Milk ATM Association, KDB officials and KDB inspectors. Further, secondary data was obtained from the KDB database and FAOSTAT and literature was reviewed to inform scenario development.

\section{Major findings}

Trends and development of ATMs over time

- About $74 \%$ of all ATMs are in Nairobi and its environs (including Kiambu, Machakos and Kajiado counties) but we note a trend of the business spreading to other counties.

- $\quad$ The ATM milk market is expanding and accounts for about $16 \%$ of the milk traded in what is characterised as the formal market.

- The current average consumer price per litre of raw milk is KES 54, ATM milk is KES 63 and processed packaged milk is KES 93 and ultra-heated milk (UHT) is KES 110; this means that packaged pasteurized and UHT milk on average are respectively $48 \%$ and $73 \%$ more expensive than ATM milk, while ATM milk is $18 \%$ more expensive than raw milk. This positions ATM milk as an emerging alternative to processed packaged milk contributing to expanding the formal market of the Kenya dairy industry.

Consumer preferences, perceptions and quality issues related to ATM milk

- $\quad$ From the sample consumers, about $70 \%$ had consumed ATM mind only $17 \%$ of the population had consumed raw milk. The consumption patterns varied by income categories. Those categorised as high income only purchased packaged and ATM milk, while those in low and middle income categories bought all milk types

- For consumers who currently buy ATM milk, the most (43\%) notable reason for this purchase choice was the affordability of ATM milk.

- Consumer preferences of the ATM point of purchase are based on milk quality, the reliability of supply, favourable operation hours and cleanliness of the ATM premises. 
- Consumer concerns - including adulteration with preservatives, water and foreign materials - limit their confidence in ATM milk.

- Presently, consumers trust the quality of milk from ATMs more than the quality of milk from informal retail outlets (plastic), which should inform strategies to help milk from ATMs outcompete milk from informal segment outlets in price and quality.

The ATM market segment and the business ecosystem

- The average volume of ATM milk bought is 1.06 litres per buyer per day.

- Almost all (99\%) ATM operators sell pasteurized milk, and a majority of them (67\%) have contractual arrangements with a milk supplier (mainly processors, mini-processors and farmer cooperatives). However, co-pasteurization business (where ATM operators source raw milk and engage the services of a pasteurizer, for a fee) is developing, and self-pasteurization (where ATM operators own pasteurizers to pasteurize their own milk) is emerging as an alternative model of supplying milk to the ATMs.

- Importation of fully assembled ATM machines is falling, and there is an emerging trend of local fabrication of ATM machines with importation of some components.

- Imported ATM machines cost about KES 1.2 million, while locally fabricated machines cost between KES 120,000-700,000, depending on specifications and level of compliance with food safety requirements. Besides the initial investment, ATM businesses incur other costs such as licensing, branding and maintenance.

- $\quad$ Future technology demands for ATM machines, include improving their efficiency and effectiveness, include use of food-grade materials, sales record memory, GSM messaging systems, calibration accuracy, full automation and sensors indicating when the ATMs are running low.

- It is estimated that there were 2030 ATMs in Kenya in 2019, creating direct employment along the chain (each ATM employs 1.65 employees, which means 3350 employees in total, of whom $41 \%$ are female), as well as indirect employment (transporters, servicing, branding, pasteurizing, etc.).

Future development and scenarios analysis for the milk ATM supply chain

- $\quad$ Based on trends since 2005, the ATM milk market segment is projected to grow threefold in 10 years, from the current 102 million litres to 343 million litres. The best-case scenario is that it will grow by a factor of 4.38 ; in the worst-case scenario, the factor is 2.13 .

- In a best-case scenario, where compliance has grown to $79 \%$ in the tenth year, the quantity demanded and supplied would grow by a factor of 4.71 and 4.48 respectively. Higher demand and supply result from increased consumer preference for ATM milk. However, laxity in ensuring compliance by KDB would lead to mushrooming of non-compliant milk ATMs that would affect consumer confidence.

- It is projected that with the impending milk ban in trade of raw milk in urban areas, the milk ATM market segment will capture an extra $30 \%$ of urban milk consumers. The ban on trading raw milk in urban areas has the potential to grow the ATM milk segment by a factor of about 6 .

- The biggest potential for future expansion of the ATM milk market segment is by expanding into the informal market segment.

\section{Recommendations}

- GoK could fast-track policy and regulations to remove unsafe operators and improve consumer confidence in the ATM milk product in order to utilize its potential, mainly linked to its price competitiveness, to be a game changer in the process of formalization of the milk marketing sector.

- Consumer organizations and the public sector could sensitize consumers through various campaigns and public media in assuring them of the market prospects for ATM milk, if quality along the supply chain would improve.

- GoK could support KDB in strengthening its capacity in terms of enforcement officers, data management systems, ATM milk traceability systems and appropriate systems for registering and monitoring ATMs.

- With the investments already made by operators, the government regulations could facilitate the supply chain, including a phased approach to stop the use of non-food-grade materials, to safeguard the interest of the investors and move to regulated machines. On the supply side, key enablers for the supply chain are enhancing growth of co-pasteurizers and building stronger linkages between milk ATM machine operators. 


\section{Introduction}

\section{$1.1 \quad$ Background}

At approximately 110 litres per capita, Kenya's milk consumption is five times higher than the average of other sub-Saharan African countries. This pattern is expected to grow, as the per capita consumption of milk and dairy products is projected to double by the year 2030, fuelled by urbanization, rising income levels and changing dietary patterns (MoALF, 2010; Rademaker et al., 2016). Currently, the annual milk production is about 5.2 billion litres, with the bulk being cow's milk (3.9 billion litres), and this is projected to grow to about 12.6 billion litres by 2030 (GoK, 2019; KDBsupplied data, 2019). Over half of the milk produced (54\%) is marketed, of which about $70 \%$ is traded informally, mostly in raw form, while the rest is processed into milk and dairy products and sold through formal markets (Kenya Markets Trust, 2019).

Quality and safety concerns of trade in raw milk are at the centre of debate in the dairy industry, where stakeholders are divided over the push for formalization of the milk market in Kenya through processing (Makoni et al., 2014; Rademaker et al., 2016; Alonso et al., 2018). The informal market outlets in the dairy sector in Kenya are typified by high levels of non-compliance with food safety and quality standards attributed to low investment in safe milk handling and poor adherence to standards and regulations. However, the dominance of the informal market is linked to consumer preferences and purchasing power as well as insufficient price and quality advantages of processed milk (Bebe et al., 2018a; van der Lee et al., 2016). The concern over milk quality relates to the potential health risks and public health-care burden of consuming unsafe milk (Ndambi et al., 2018) but also to how it undermines the competitiveness of the Kenyan dairy sector (Makoni et al., 2014; van der Lee et al., 2016).

While the government's vision for the sector, articulated in the Kenya National Dairy Master Plan and the Draft National Dairy Policy (MoALF, 2010; GoK, 2019), is to expand a formal processed chain in the milk market and to improve milk quality, little headway has been made (van der Lee et al., 2016; Makoni et al., 2014). The market share of the formal sector has been growing slowly to reach the current estimated 30\%. Milk delivered to processors increased from 535.7 million litres in 2017 to 634.3 million litres in 2018 (KNBS, 2019). The slow growth calls for diversified approaches to upgrading of the informal sector, with the goal of expanding quality and safety-driven development with appropriate safeguards (Makoni et al., 2014; Alonso et al., 2018). Accelerating transition to a competitive, quality-driven industry requires exploring innovation and investment opportunities for sustainable and inclusive sector development that will continue to contribute to food and nutrition security, economic development and improved livelihoods.

The sector is embracing technological and marketing innovation to address quality issues along the value chain (Gachango et al., 2014; KDB, 2016). Recently, some industry actors are experimenting with integrating quality-based milk payment systems to control and improve milk quality along their supply chains (Ndambi et al., 2018, 2019). An emerging market innovation is milk retailing through vending machines (popularly known as "milk ATMs"), which are placed in strategic market locations and sell chilled, pasteurized milk. Consumers bring their own containers, so they get affordable access to processed milk that can be bought in flexible volumes as demanded (Bebe et al., 2018a; Kosgey et al., 2018). The spread of milk ATMs has provided business opportunities to entrepreneurs in urban centres, which indicates the potential for growing the formal market segment.

The current KDB strategic plan (KDB, 2016) recognizes ATMs as a technological and business innovation that can contribute to delivering quality milk in the market. This mainly relates to pasteurization and minimizing milk handling, which should enhance hygiene and assure quality and safety to consumers (Bebe et al., 2018a). However, the growth in milk ATM businesses has occurred in a context of regulatory gaps that has resulted in various compliance issues that raise concerns about the safety of milk dispensed in ATMs (Bebe et al., 2018a; Kosgey et al., 2018). Currently, the $\mathrm{KDB}$ is reviewing the regulations with the objective of enhancing compliance and to improve consumer confidence in the industry. The emergence of milk ATMs as outlets for marketing processed and affordable milk has the potential to transform and expand the formal market system. However, 
systematic information on current trends, drivers and factors that could inform the development of the ATM market segment is scant.

\subsection{Research objectives}

Though the milk ATM market segment in Kenya is expanding and gaining attention in the industry, there is limited empirical evidence about the growth trends, consumer perceptions and demands and what scenarios and policy options are likely to affect its further development. This knowledge gap informs the 3R Kenya study presented in this report.

Specifically, the study aimed to answer the following research questions:

1. What are the trends in the development of the ATM milk market segment?

2. What are the key consumer patterns, and quality and food safety issues related to the development of the milk ATM market segment?

3. What businesses have emerged around the ATM milk market segment?

4. What are the potential scenarios that might affect the development of the ATM milk segment?

The insights of this study are intended to inform decisions about what interventions would be relevant to and supportive of investment in this milk retail market segment.

\subsection{Structure of the report}

The remainder of this report is structured as follows. Chapter 2 explains the research methodology. Chapter 3 describes trends in the development of the ATM milk market segment and Chapter 4 presents the consumer trends and perceptions related to the development of the milk ATM market segment. Chapter 5 explores the business ecosystem that surrounds the ATM milk market segment in Kenya and simulates the potential scenarios and their expected effect on development of the ATM milk segment. Finally, Chapter 6 provides some conclusions and recommendations derived from this study. 


\section{Methodology}

\section{Chapter 2 overview}

This chapter describes the study area and how the research was designed, including sampling and data collection methods. The chapter provides details of the approach applied in studying the trends, consumer perspectives, business ecosystems and in development of possible scenarios based on the past and current trends in the ATM milk market segment.

\section{$2.1 \quad$ Study area}

The study was conducted in six counties with the highest density of registered milk ATMs, according to 2018 KDB-supplied data (2019): Nairobi County (48\% of all ATMs), Kiambu County (15\%), Nakuru County (11\%), Kajiado County (7\%), Uasin Gishu County (6\%) and Machakos County (5\%). Th rest of the counties not included in this study accounted for $9 \%$ of the ATMs. In each county, areas with high ATM concentration were then selected, informed by KDB data on registered milk ATMs.

The selected areas within each county were:

1. Nairobi county: Kariobangi, Kayole, Kawangware, Langata, Hurlinghum, Karen, Imara Daima, Umoja 11, Kahawa West, Roysambu, Pangani, Nairobi West, Nairobi CBD and Zimmerman

2. Kiambu County: Githurai, Juja, Kikuyu town, Thika CBD, Phase 10, Witeithie, Ngoingwa and Makongeni

3. Nakuru County: Nakuru CBD, Free area, Kaptembwa, Langa Langa, Olive Inn, Shabab, London and White House

4. Uasin Gishu County: Eldoret CBD, Chepkoilel, West Indies and Maili Nne

5. Kajiado County: Kiserian, Rimpa, Ngong and Kitengela town

6. Machakos County: Athi River, Syokimau and Mlolongo.

Data was collected using mixed methods, including literature review, key informant interviews, modified Delphi technique ${ }^{1}$, a survey of ATM milk chain actors and visual techniques including photography.

\subsection{Sampling and data collection}

\subsubsection{Survey of milk ATM operators and consumers}

Two surveys were undertaken targeting consumers and milk ATM owners/operators. Quantitative and qualitative tools/questionnaires were developed, taking into consideration the study objectives and deliverables. A mobile (Android) phone data collection procedure was used for quantitative data, implemented using the Open Data Kit platform. To sample ATM operators, first towns in each county were selected using KDB-supplied data, 2019, and they were subdivided into location clusters considering the dispersion of consumers based on their income status (low-, medium- and highincome areas). After selection of the clusters in towns, milk ATM operators within the chosen clusters were interviewed using random sampling to ensure the target number in each cluster was achieved.

A total of 490 individuals identified as milk consumers were randomly selected and interviewed at the selected milk ATM sales point. For more details on the sampling technique, see Appendix 1 . The

\footnotetext{
${ }^{1}$ This involved a group of experts in the ATM market segment in a one-day meeting to validate the proposed scenarios including their likelihood impact and behaviour of the actors. The discussions were used during reporting in section 5 .
} 
number of milk consumers in each town was proportional to the number of sampled ATM machines, except in Nairobi, which was oversampled because of the higher number of survey sites across Nairobi County (Table 1).

Table 1 Sample size distribution.

\begin{tabular}{|c|c|c|c|}
\hline Counties & $\begin{array}{c}\text { No. of registered milk } \\
\text { ATMs* }\end{array}$ & $\begin{array}{c}\text { No. of sampled ATM } \\
\text { operators }\end{array}$ & $\begin{array}{c}\text { No. of sampled } \\
\text { consumers }\end{array}$ \\
\hline Nairobi & 420 & 84 & 292 \\
\hline Nakuru & 101 & 20 & 52 \\
\hline Kajiado & 58 & 12 & 31 \\
\hline Uasin Gishu & 49 & 10 & 26 \\
\hline Kiambu & 132 & 27 & 66 \\
\hline Total & 805 & 162 & 490 \\
\hline
\end{tabular}

*Source: KDB-supplied data, 2019

Note that only questionnaires where the respondent had identified themselves as being a household head (352) were used for analysis, since they could provide the most complete information. Out of the 352, 286 (representing about 81\%) had bought ATM milk while 66 consumers (representing about 19\%) did not consume ATM milk in 2019.

\subsubsection{Key informant interviews}

Key informant interviews were conducted with suppliers of milk to ATMs, suppliers of ATM machines, KDB inspectors at county levels, KDB officials at the headquarters and county public health officials. Literature review and secondary data were used to establish the ATM milk quality and safety attributes. Interview guides were used to interview key informants who were selected purposively based on their acquaintance with the milk ATM supply chain. A summary of milk ATM stakeholders interviewed is presented in Table 2.

Table 2 Overview of key informants interviewed.

\begin{tabular}{lc} 
Stakeholder type & Number of interviews \\
\hline KDB (headquarters) & 1 \\
\hline KDB (inspectors at county levels) & 5 \\
\hline Suppliers of milk to milk ATM operators & 17 \\
\hline Suppliers of milk ATM machines & 9 \\
\hline County public health officials & 6 \\
\hline Total & $\mathbf{3 8}$
\end{tabular}

\subsection{Scenario analysis method}

Scenario analysis was undertaken to consider future development of the ATM milk segment (research question 4). It involved integration of secondary data from relevant institutions (KNBS, FAOSTAT, KDB) and primary data from the surveys. After data collection and analysis, the scenarios were developed and subjected to further discussions and validation using a modified Delphi technique, with a small group of experts being used to validate the scenarios.

The scenarios were developed based on literature (MoALF, 2010; van der Lee et al., 2016; Ndambi et al., 2018; GoK, 2019; Kenya Markets Trust, 2019) and the primary data that was collected. They are anchored on the premise that the future is still in the making and is shaped by megatrends in existing 
opportunities and threats that will trigger development of the market segment. Based on the findings from primary data, literature review and the stakeholder engagement (see Appendix 1, section A), three scenarios were developed and simulated in MS Excel. See Appendix 1 section B for a description of how the variables were generated.

\section{Scenario 1: Business as usual}

The business-as-usual scenario was determined and used as a starting point for other scenarios. This scenario involved simulation of future trends, based on the current status of the ATM milk market segment. The population demanding ATM milk and the number of ATMs were predicted using a logistic growth function. Logistic growth was used because it is bounded by the carrying capacity, unlike exponential growth that increases without limits.

\section{Scenario 2: Stronger regulatory framework leading to increased compliance with KDB regulations}

The growth of the ATM market segment has taken off in an environment of inadequate regulations and inadequate enforcement by KDB. Further, owing to the large amount of milk that is marketed unprocessed and the weak monitoring of markets, there are concerns about public health risks consequently undermining the emergence of a competitive dairy sector (Alonso et al., 2018; Makoni et al., 2014; Ndambi et al., 2018). The regulator (KDB) is in the advanced stage of reviewing regulations and the code of practice, which is likely to be a game changer in the industry in the near future. With the impending approval of the regulations that will also govern the milk ATM market segment, the scenario where the regulator would have a stronger basis for enforcement is likely, therefore increasing compliance that could translate to higher consumer confidence in the quality and safety of milk products. On the other hand, to comply, operators will need to increase investment costs and operational costs, which are likely to be passed on to consumers.

\section{Scenario 3: Public ban on the sale of raw milk in urban areas, leading the ATM market segment to encroach on the informal market segment}

It is estimated that currently, $30 \%$ of marketed milk is formal and $70 \%$ informal. One of the proposed measures in the KDB regulations is a public ban on informal marketing of milk in urban areas. This would mean that more of the informal milk traded would shift to formal milk, implying a demand shift, which will subsequently trigger a supply shift. A public ban should come with a strong regulatory framework as well, otherwise sales in the informal market would probably continue, regardless of the ban. This means the ATM milk segment would start encroaching on the $70 \%$ of milk marketed informally, which would be distributed between the processed packaged and processed ATM milk. 


\section{Trends and development of milk ATMs}

\section{Chapter 3 overview}

This chapter answers the first research question about trends in the development of the ATM milk market segment in Kenya. The growth by number of ATMs over time, by business model and by geographical region is presented to paint a picture of the segment while highlighting the sales patterns of ATM milk in the retail market.

The establishment of milk ATM businesses has been growing in Kenya, as shown by KDB-supplied data (Figure 1). The data reveal that the licensed milk ATM business started in 2005 and that growth in the numbers gained momentum in 2010, peaking in 2018.

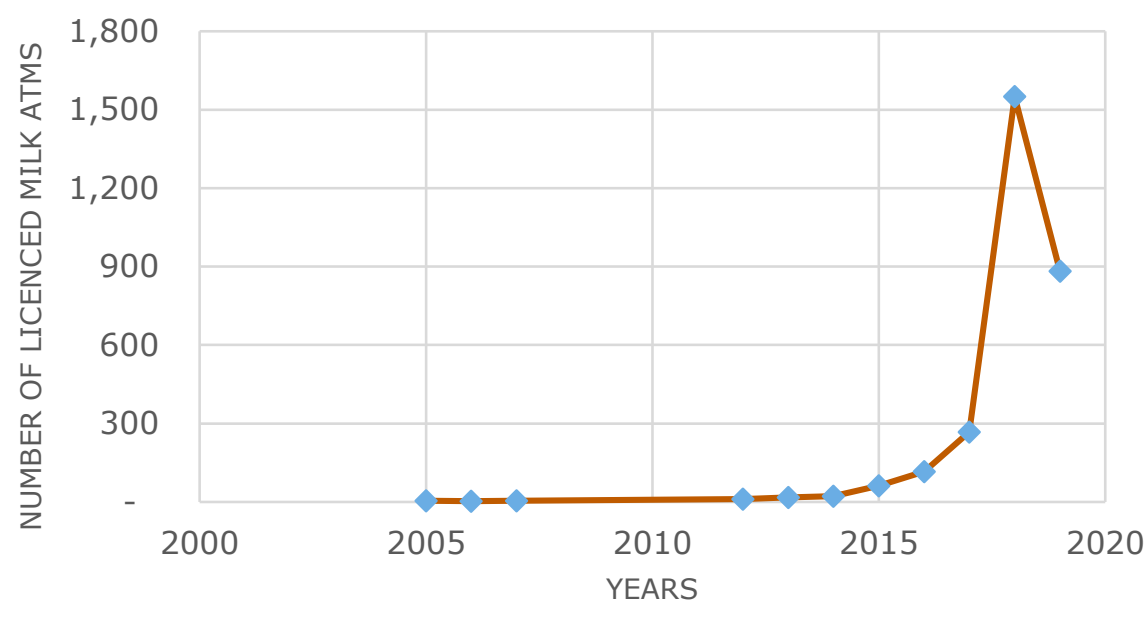

Figure 1 Trend in setting up of licensed milk ATMs across Kenya.

Source: KDB-supplied data, 2019

According to KDB-supplied data (2019), we were an estimated 1,550 milk ATMs in 2018, but only 883 were found recorded in the $2019 \mathrm{KDB}$ database that was accessed for the study. This decline in numbers may be due to KDB suspending the issue of licences for ATMs in 2018 in order to introduce revised regulatory measures for milk.

However, of the 162 ATMs surveyed in this study, approximately $24 \%$ reported not ever registering with KDB. Therefore, we extrapolate that 480 milk ATMs (representing $24 \%$ of 1,550 ) were not registered in 2018. Therefore, the study estimates that in reality 2,030 ATMs were operational at the start of 2019 nationally. A caveat is that there is lack of reliable and consistent data from KDB on the ATM market retail outlets.

\subsection{Geographical distribution of milk ATMs}

From the survey data we note some geographical patterns in how milk ATM business has grown over time. The general trend is that there is a higher concentration of ATMs in Nairobi, the densely populated capital city, and the neighbouring Kiambu County (Figure 2). Nairobi County was the early adopter of milk ATMs, before they spread into the other counties, and recently Kiambu County has recorded significant growth in number of ATMs. Entrepreneurs tend to establish ATM businesses in densely populated areas. Milk ATMs grew exponentially in 2017 across the different counties but decreased from 2018, which confirms the initial findings in Figure 1. 


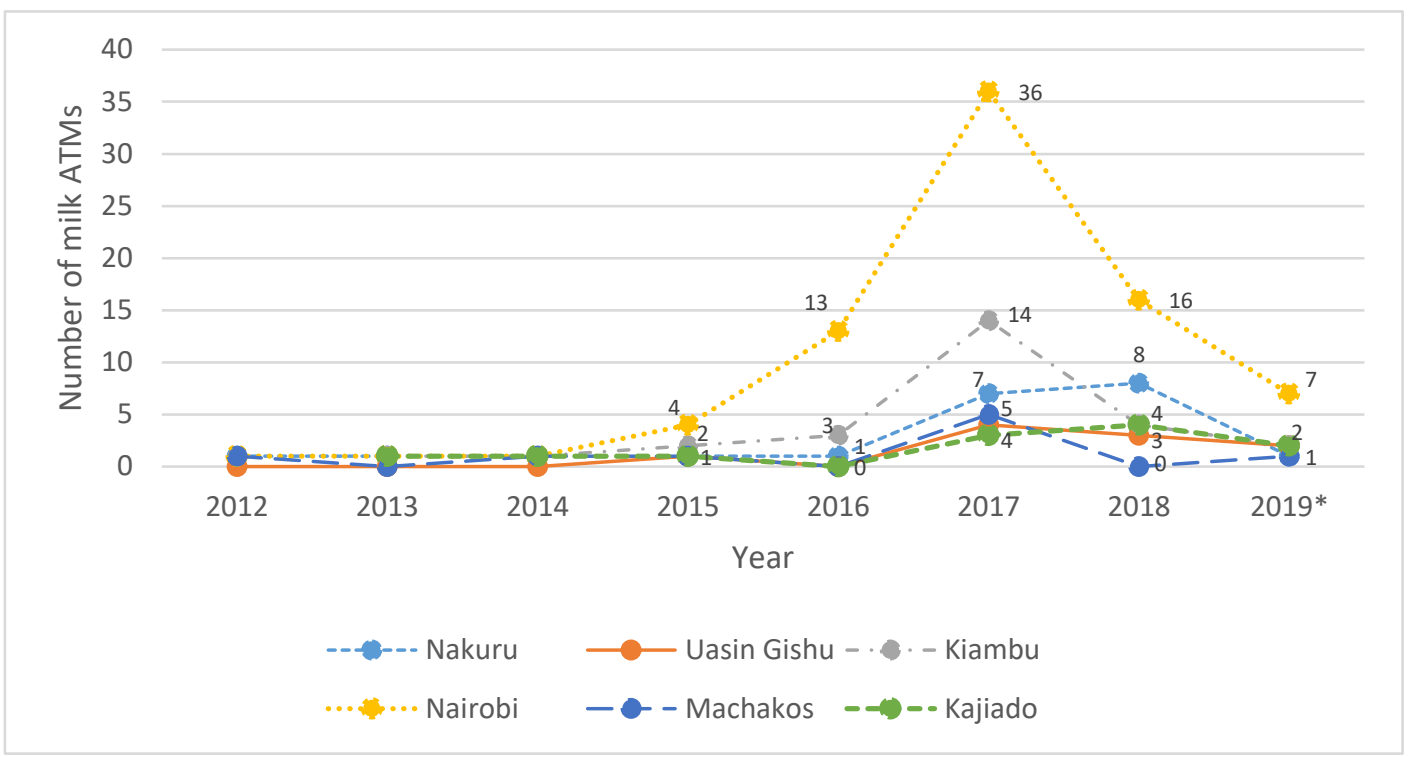

Figure 2 Geographical distribution of milk ATMs.

Source: ATM operators survey data $(n=162)$

* means the data is representing a part of the year

\subsection{Location of milk ATMs and related business models}

The survey data provides an overview of where milk ATM businesses are located. About $21 \%$ are located in supermarkets, and $79 \%$ are in other business premises (either stand-alone or as part of a mixed retail shop). The majority (86\%) operate from rented premises, while a few (7\%) operate from their own premises. Different rental arrangements were used, where some businesses paid a fixed amount of rent and others paid a commission on sales volume.

The business models of milk ATM enterprises vary in relation to ownership structure, type of business products and scale of operation (Table 3). The ownership structure of milk ATM businesses was very diverse with the majority (79\%) owned by sole proprietors, $17 \%$ owned by companies, $3 \%$ owned by partnerships and $1 \%$ by cooperatives. Partnerships include individuals coming together to establish the milk ATM business. On scale of operation, some milk ATM owners operated several machines in different locations, but most $(82 \%)$ ran a single machine.

Table 3 Business models for milk ATM businesses in Kenya.

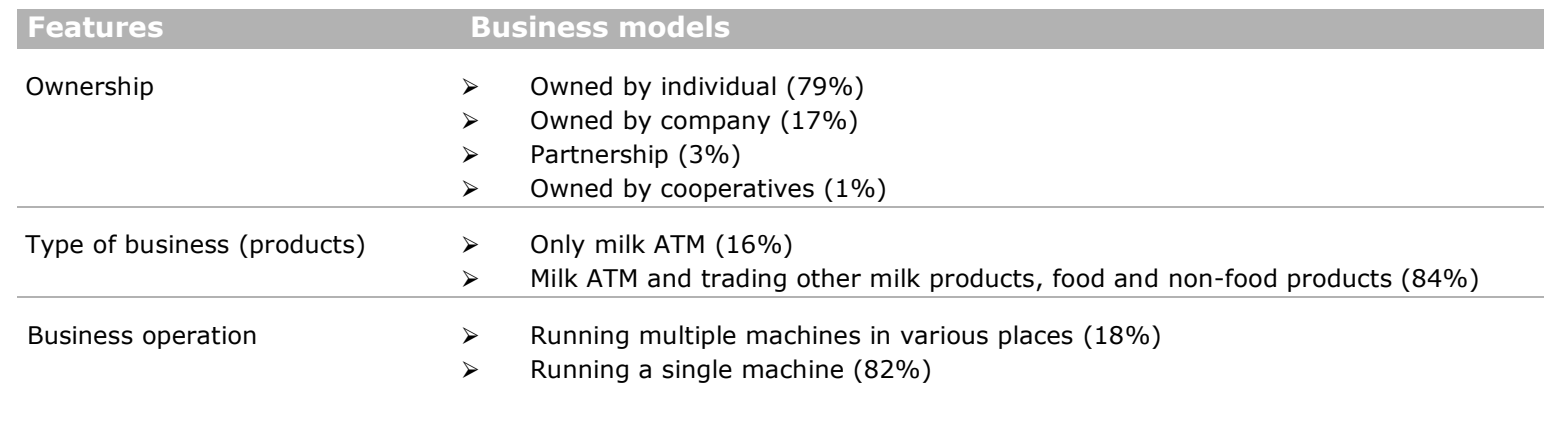

Source: Key informants, ATM operators survey data

Related to type of business, a few outlets sell ATM milk only (16\%), but most ( $84 \%)$ have integrated dairy products (such as yoghurt and buttermilk, locally known as "mala"), non-dairy food products (such as eggs and bread) and non-food products (such as financial services and small electronic devices like mobile phone accessories). 

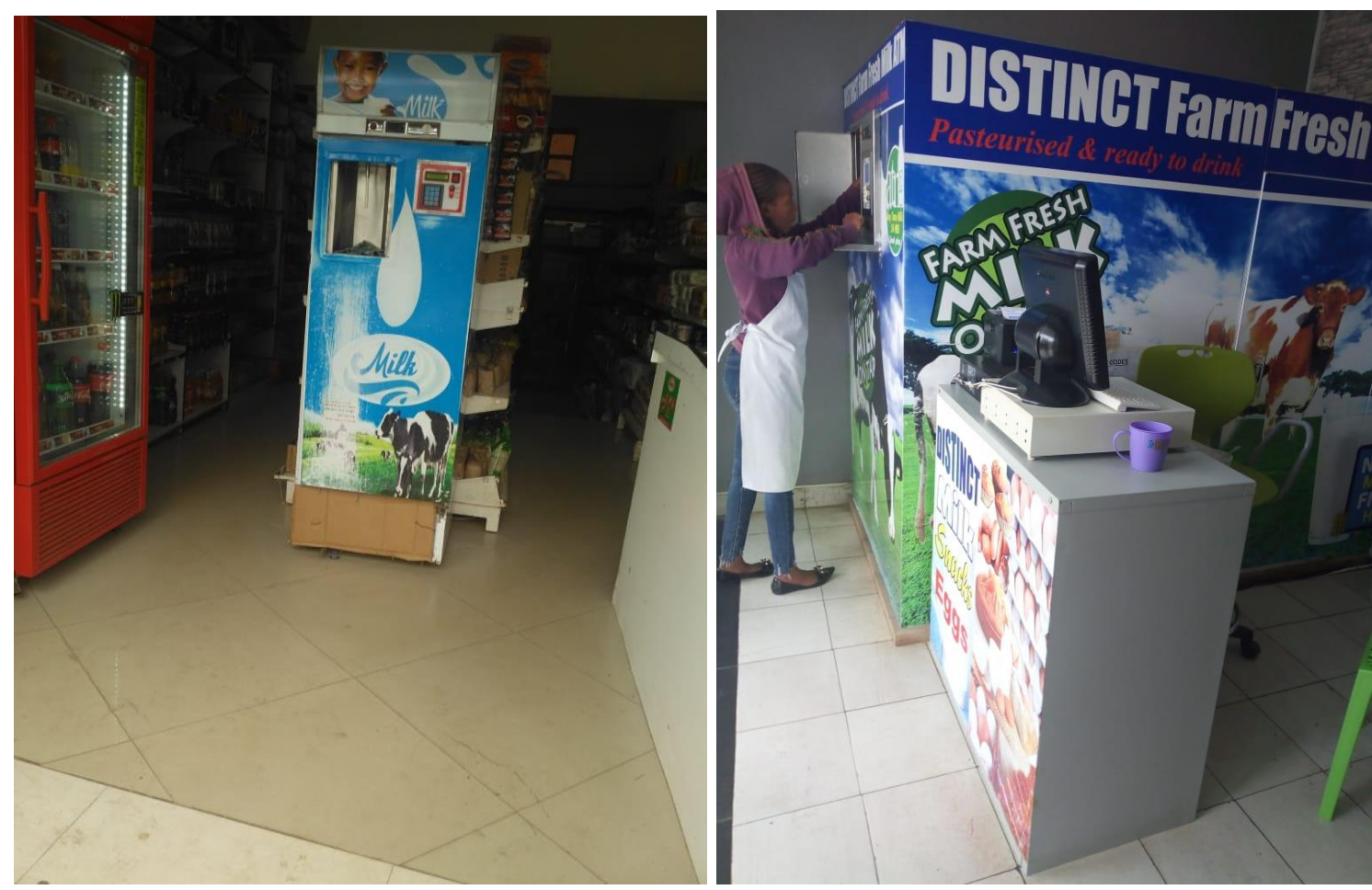

Photo 1 Milk ATM in a mini supermarket (left) and stand-alone milk ATM business (right).

On business financing, most milk ATM operators (93\%) acquired milk ATMs on cash payment, while others used other means: credit (2\%), acquired from various financial institutions; cost-sharing ( $1 \%)$, which was done with other parties; leasing (1\%) from the supplier or a different machine owner; hire purchase (1\%); and getting them as a gift (1\%).

\subsection{ATM milk sales}

The results show that each ATM sells approximately 140 litres of milk daily (Table 4). Based on this average, we can infer that an estimated 102 million litres of milk are sold through the ATM outlets annually (average of 140 litres per day from approximately 2,030 milk ATMs nationally, assuming sales on 360 days in a year). This represents about $16 \%$ of the formal processed milk (102 million litres of 634 million litres marketed formally in 2018), thus contributing to expanding the formal milk market in the country by about $5 \%$ of the total milk marketed.

Table 4 Milk ATM sales patterns.

\begin{tabular}{ll} 
Sales characteristics & Mean \\
\hline Average daily sales (in litres) & 140 \\
\hline Average sales to individuals (\% of total) & 84.32 \\
\hline Average sales to institutions (\% of total) & 12.78 \\
\hline Average milk consumed in the business or by the owner (\% of total) & 2.89
\end{tabular}

Source: ATM operator survey data $(n=162)$

About $84 \%$ of the ATM milk volume is sold to individual customers, while $13 \%$ of the volume is sold to institutions such as hotels, schools and hospitals (Table 4). Additionally, $3 \%$ of the volume is used by the business for consumption (as tea or for drinking by employees at work) and by the owner for home consumption.

Table 5 presents the quantity of ATM milk sold at different time periods by ATM operators. Milk is not evenly demanded throughout the year, as indicated by seasonal peak volumes. On average, stable normal milk demand runs for seven months with an average demand of 147 litres per day. 
Table $5 \quad$ Quantity of ATM milk sold at different periods.

\begin{tabular}{ll}
\hline Characteristic & Mean \\
\hline Average number of normal months (number) & 7.25 \\
\hline Average number of off-peak months (number) & 1.76 \\
\hline Average number of peak months (number) & 2.99 \\
\hline Average volume sold in normal months (in litres per ATM per day) & 146.94 \\
\hline Average volume sold in off-peak months (in litres per ATM per day) & 99.22 \\
\hline Average volume sold in peak months (in litres per ATM per day) & 175.72 \\
\hline
\end{tabular}

Source: ATM operator survey data $(n=162)$

\subsection{ATM milk pricing and margins}

Milk sold through ATMs is priced differently across the geographical regions, with price ranging between KES 50 and KES 80 and a mean of KES 63.4 per litre (Table 6 and Table 7). Milk pricing differed significantly across the counties. In Machakos County, ATM milk was priced the highest (KES 70.6). This could be because most of the milk sold within the county is produced and processed outside the county, as reflected by a high purchase price of KES 57 per litre from the supplier and the longer distances (210 driving minutes) to ATM milk suppliers.

Table 6 Geographical patterns in ATM average pricing and distance by ATM operators

\begin{tabular}{|c|c|c|c|c|c|c|c|c|c|c|c|}
\hline & $\begin{array}{l}\frac{3}{2} \\
\frac{y}{10} \\
\frac{10}{2}\end{array}$ & & 듬 $\frac{2}{0}$ & $\frac{2}{\frac{2}{2}}$ & & $\frac{2}{\frac{2}{2}}$ & $\frac{\frac{8}{2}}{\frac{9}{0}}$ & $\frac{}{ㅇ ㅡ ㅁ ~}$ & $\frac{7}{\frac{10}{10}}$ & & 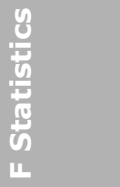 \\
\hline $\begin{array}{l}\text { Average selling price of ATM milk } \\
\text { per litre }\end{array}$ & & 63.2 & 62.5 & & 61.8 & 63.9 & 70.6 & 60.5 & & 63.4 & 1.54 \\
\hline $\begin{array}{l}\text { Average distance to main milk } \\
\text { supplier (driving minutes) }\end{array}$ & & 41.2 & 25.0 & & 61.3 & 90.4 & 210.0 & 106.7 & & 78.3 & $\begin{array}{r}8.51 * * \\
*\end{array}$ \\
\hline
\end{tabular}

Source: ATM operator survey data $(n=162)$

$* * *$ Indicate a statistical difference at the $\mathrm{p}=0.01$ level.

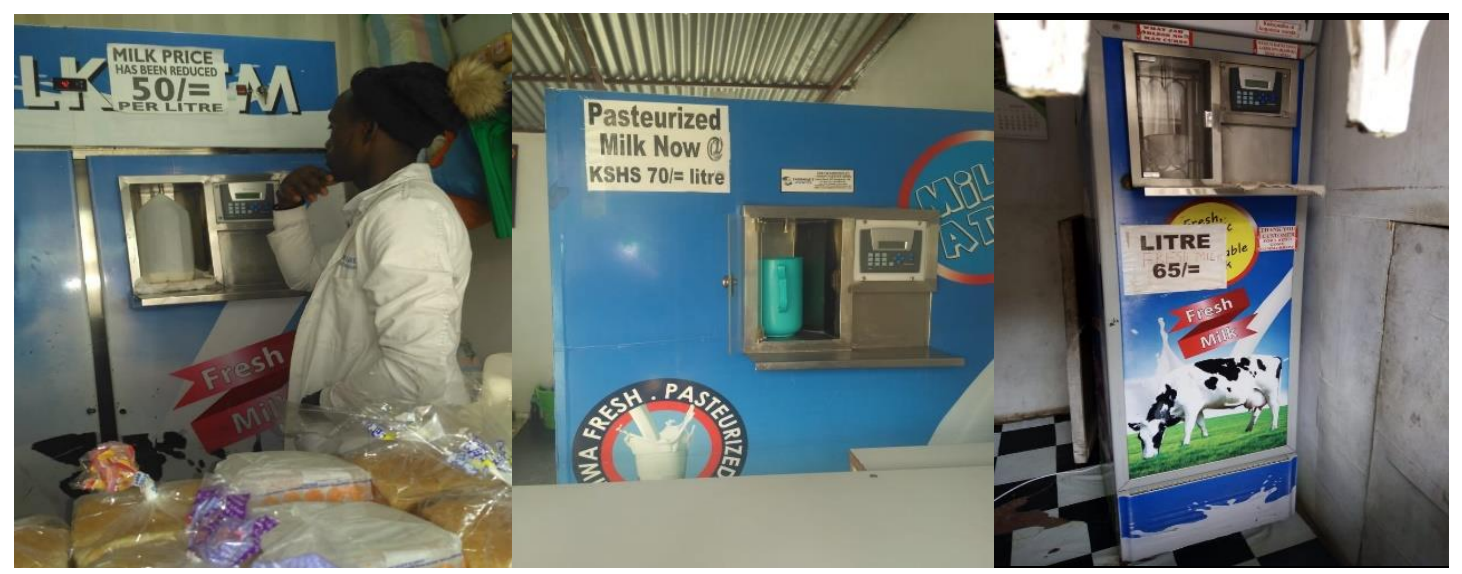

Photo 2: Illustration of the different ATM milk prices across operators

The retail prices of ATM milk differed in comparison with other milk products (Table 7). The price of ultraheat treated (UHT) milk was the highest at an average of KES 109.7 per litre, while that of pasteurized packaged milk was KES 92.9. This makes UHT and packaged pasteurized milk on average respectively $73 \%$ and $48 \%$ more expensive than ATM milk (KES 63.4). On the other hand, raw milk sold informally by traders to consumers was sold at an average of KES 53.8, which makes ATM milk $18 \%$ more expensive than raw milk. This confirms what was noted by some ATM operators: raw milk remains their major price competitor and impediment for growth. 
Table $7 \quad$ Price comparison between ATM milk and other milk market segments.

\begin{tabular}{lrr} 
& & Minimum Maximum \\
Price of UHT milk per litre & 109.7 & 94.0 \\
\hline Price of packaged pasteurized milk per litre & 92.9 & 150.0 \\
\hline Retail price of raw milk per litre & 53.8 & 88.0 \\
\hline Price of ATM milk per litre & 63.4 & 35.0 \\
\hline
\end{tabular}

Source: ATM operator survey data $(n=162)$

Table 8 presents an indicative gross margin based on a case study of an ATM business in Nakuru County. The business sources raw milk and pasteurizes it before taking it to the milk ATM outlet located in Nakuru central business district (CBD). On average the business sells about 270 litres per day at an average price of KES 55 per litre. The cost items are also indicated; they include purchase of milk, transportation costs, labour, rental, utilities (electricity and water), licensing (County trade permit, advertisement permit, County public health permit for the premise, milk-handling certificate for the operators from County public health and the KDB permit).

Table 8 Indicative gross margin of milk ATM business.

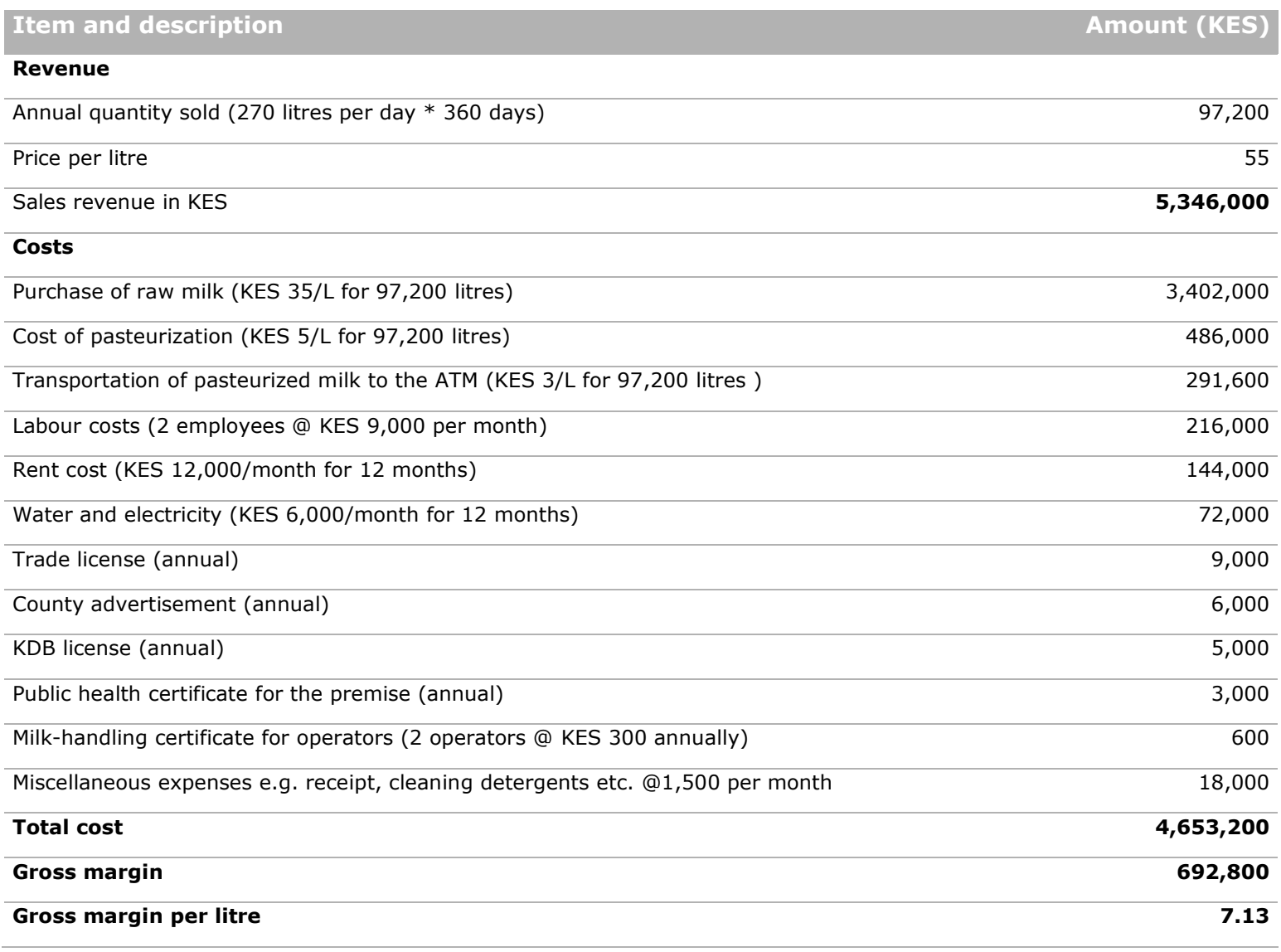

Source: Case of a milk ATM business in Nakuru County

The main cost driver for the ATM business is acquisition of pasteurized milk, which takes about $90 \%$ of the total variable costs (Table 8 ). Notably, most of the licensing costs from the county offices vary based on the business and location. The advertisement cost varies not only by location but also by the size of the signage. The milk ATMs give an estimated gross margin of approximately KES 7 per litre. However, the gross margin will vary based on volume traded (influenced directly by business positioning and population, among other factors) and pricing. To improve viability, milk ATM businesses need to reduce the cost of pasteurized milk through strategies such as vertical integration by investing in building their own supply chain and reducing transportation cost.

Milk ATM businesses also incur fixed costs that include business establishment costs (e.g. goodwill, furniture and fittings, branding, plumbing works, painting works) and the cost of purchasing and 
installing the ATM machine. The cost of establishment varies with location, and the cost of the ATM will vary with the features of the machine. For the case presented in Table 8, the establishment cost was estimated at KES 400,000 and the ATM milk machine cost around KES 350,000, implying that the cost can be recovered within two years of business operation.

\subsection{Milk ATM businesses and employment}

The milk ATM business has created jobs. The sampled ATM business employed is 1.65 (approximately two operators) on average. An analysis by gender indicates that majority (59\%) of the employed operators are male compared to females (41\%) Our projections estimate that milk ATMs businesses are currently employing 3,350 operators nationally. The average age of the operators was 28 years, indicating that most workers employed in these businesses were youth. The majority (54\%) of the employees had secondary education, $6 \%$ had primary education and $40 \%$ tertiary education as the highest level. Further, the operators had approximately two years of working experience, which is due to the relatively recent establishment of many businesses.

A large proportion of the ATM operators indicated that they had been trained in various activities and operations of the milk ATM (Figure 3). All operators were trained in the basic operations: dispensing milk, cleaning, replacing milk cans and regulating temperature. Furthermore, $93 \%$ of the operators were trained in hygienic milk-handling practices. About $60 \%$ of the operators were trained in calibration of the machine, ensuring the machine dispenses exact volumes of milk and payment calibrations. Calibration could not be carried out by all employees, being password protected. To ensure consistency and accountability of the system, only some staff are mandated to carry out calibration.

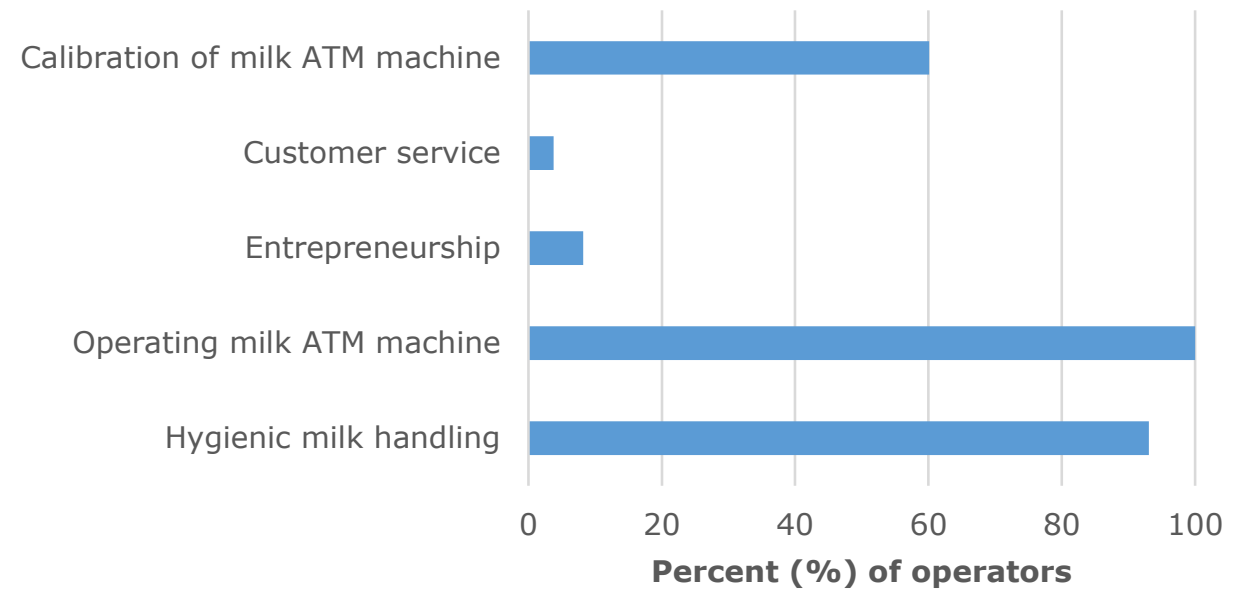

Figure 3 Trainings received by milk ATM operators.

Source: ATM operator survey data $(n=162)$ 


\section{$4 \quad$ Consumer perceptions and quality aspects of ATM milk}

Chapter 4 overview

This chapter gives answers to the second research question: What are the key consumer patterns, and quality and food safety issues related to the development of the milk ATM market segment in Kenya? It also gives insights into some best and worst practices in the market segment.

\subsection{Consumers' milk purchasing patterns}

The consumer survey revealed that milk consumption decisions were made mostly by women (56\%). Approximately $95 \%$ of all households bought milk regularly, with $97 \%$ of female decision makers in the households buying milk slightly more regularly than male decision makers (92\%). Most (80\%) milk purchasing decision makers had attained secondary and above level of education. About $16 \%$ had dropped out in secondary school, and the rest had primary as the highest level of education achieved.

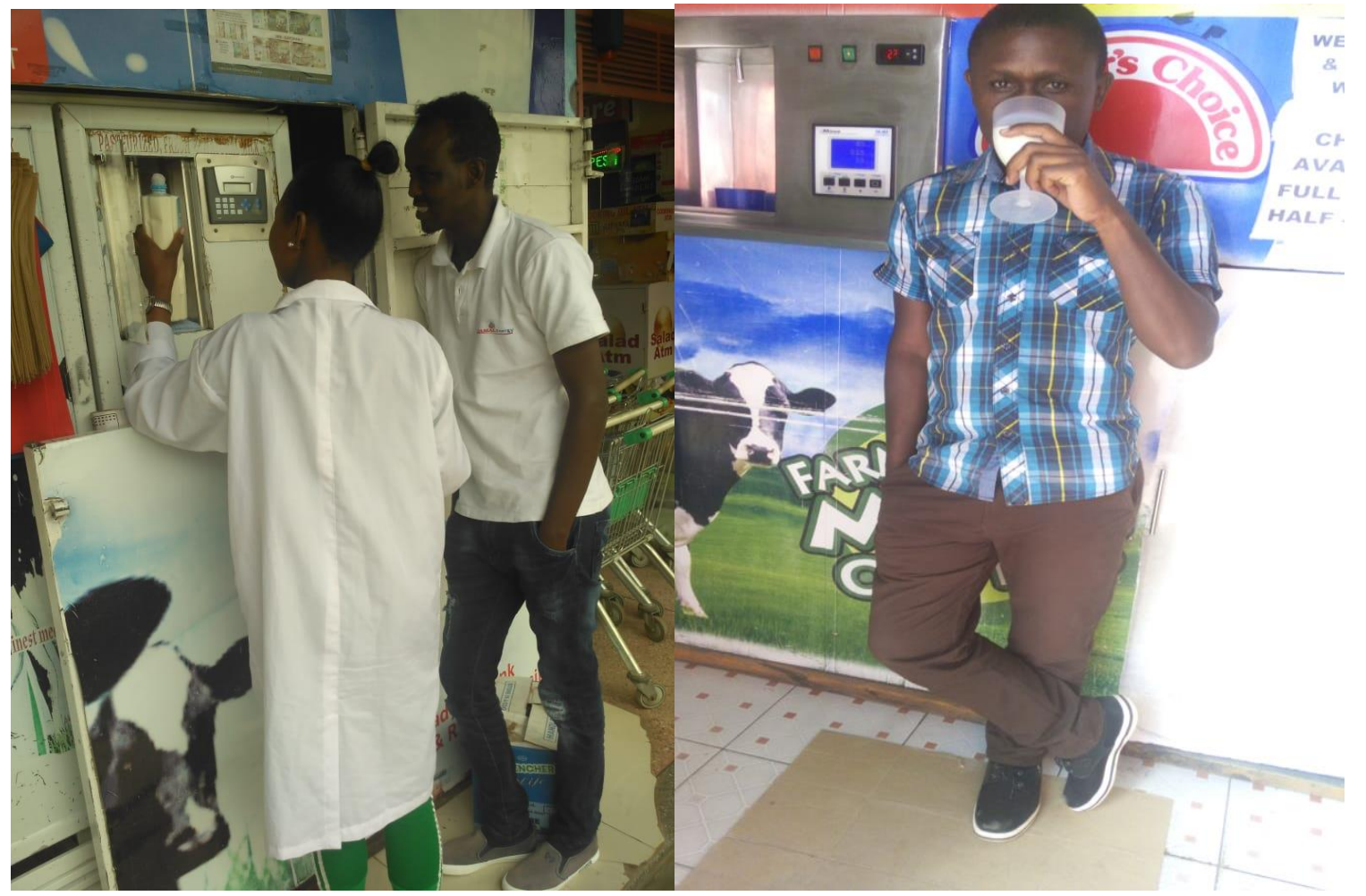

Photo 3 Consumer purchasing ATM milk for home consumption (left) and a customer consuming at milk ATM point (right).

To understand household milk consumption patterns, the consumers were classified according to the monthly income of the household head. Households earning below KES 19,999 per month were classified as low income, those earning KES 20,000 to KES 49,999 were classified as middle income, and those earning above KES 50,000 were classified as high income. With the above income classification, $52 \%$ of consumers interviewed $(n=139)$ were low income earners, $42 \%(n=110)$ were middle-income earners and $6 \%(n=15)$ were high-income earners. The income bands were derived from an overview of salary guidelines provided by Kenyan labour laws and regulations of wages, which differ by sector and location. Table A in Appendix 2 provides a summary of key variables by income bands. 
Figure 4 presents results of consumption patterns of different types of milk by households in varying income categories in the past year. Those categorised as high income only purchased packaged and ATM milk, while those in low and middle income categories bought all milk types. In all income categories, ATM milk is consumed alongside processed packaged milk. From the overall sample, about ATM milk was the most consumed by about $70 \%$ of the sample and only $17 \%$ of the population had consumed raw milk.

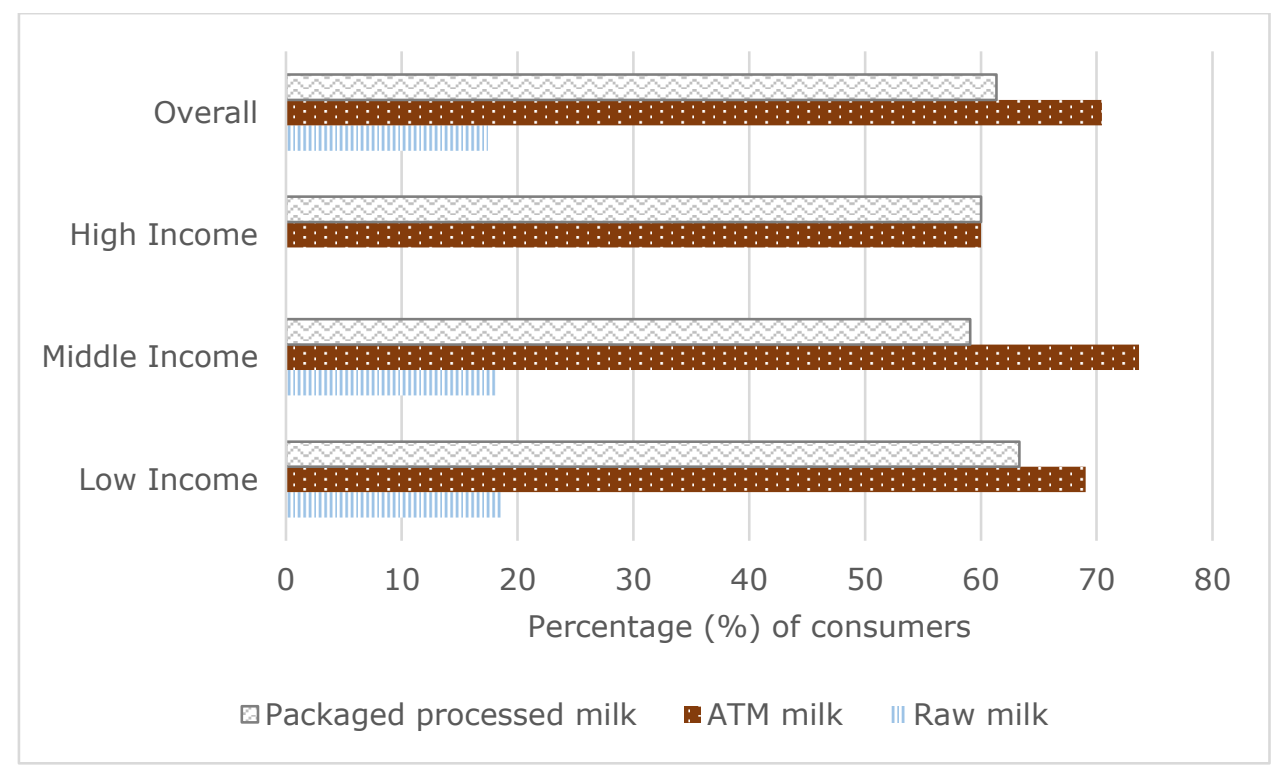

Figure 4 Type of milk consumed in the past year (\%) by income category.

Source: Consumer survey $(n=352)$

The consumption patterns of milk varied based on the gender of the household decision-maker for milk consumption (Figure 5). More households with female decision makers (68\%) consumed ATM milk anytime in the past year compared to $59 \%$ of households with male decision makers. On contrast, $20 \%$ of households with male decision makers consumed raw milk compared to $16 \%$ in households with female decision makers. However, the average total quantity of milk purchased per household was about 1 litre per day and did not vary significantly with the gender of the household decision-maker (Table 9).

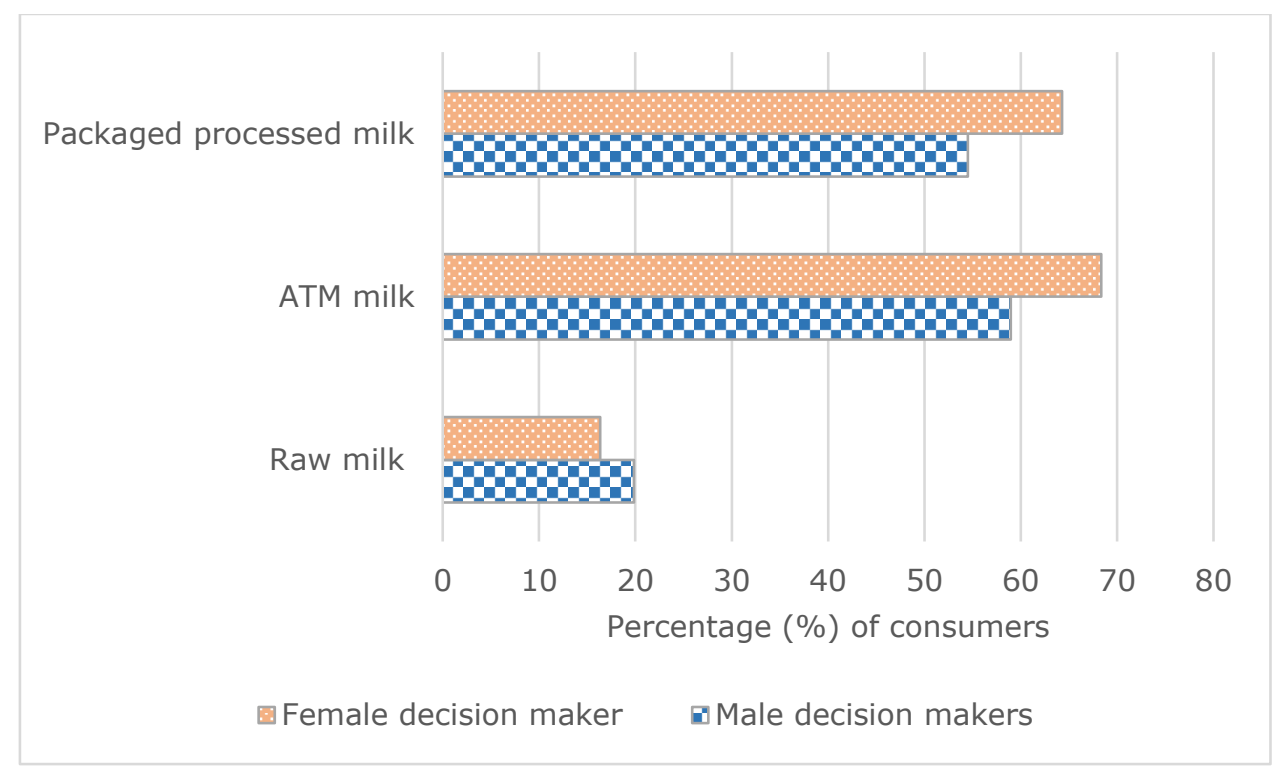

Figure 5 Type of milk consumed in the past one year (\%) by gender.

Source: Consumer survey $(n=352)$ 
The purchasing patterns of ATM milk were further broken down by income bands (Figure 6). The figure shows that the number of consumers who currently buy ATM milk is lower than those who have ever bought ATM milk, and that this is true across all income brackets, indicates a problem with product retention. It was observed that high-income earners had the lowest (64\%) retention rate, and that the highest retention rate was observed among medium income earners. Consumers who had ever bought ATM milk but currently no longer buy it, attributed it to low quality, as they mostly reported that the milk had gone bad. Respondents also observed poor hygiene of the ATM operator.

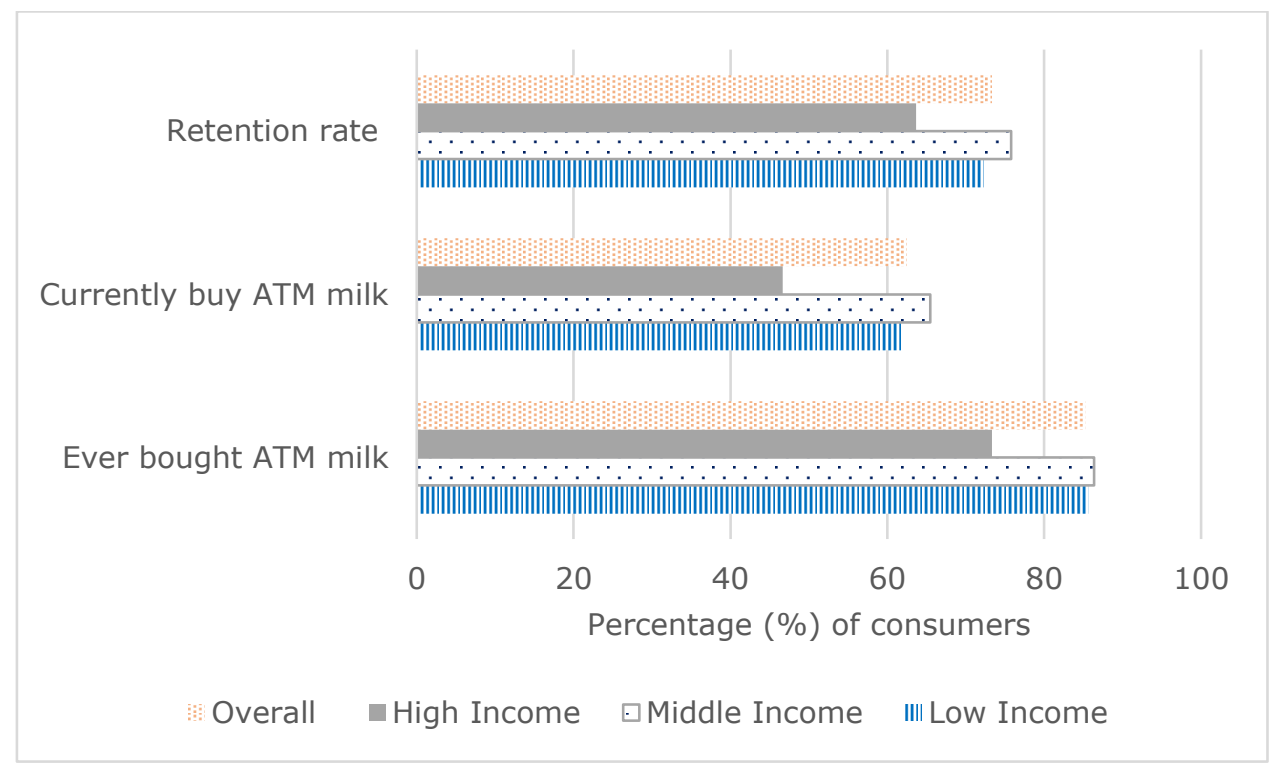

Figure 6 Consumer purchasing patterns of ATM milk (\%) by income bands.

Source: Consumer survey $(n=352)$

The amount of milk purchased and the distance consumers cover in walking minutes to the milk ATM they usually frequent is presented in Table 9. Consumers bought an average of 1.05 litres of milk per purchase. Consumers tend to take about eight minutes on average to walk to the milk ATM they use most frequently.

Table 9 Milk purchases and distance to ATM by male- and female-headed consumer households.

\begin{tabular}{|c|c|c|c|c|c|}
\hline & $\begin{array}{c}\text { Male- } \\
\text { headed }\end{array}$ & $\begin{array}{l}\text { Female- } \\
\text { headed }\end{array}$ & Total & t-statistic & p-value \\
\hline Amount of ATM milk bought daily (litres) & 1.09 & 1.02 & 1.05 & 0.5779 & 0.564 \\
\hline Distance to ATM (walking minutes) & 6.95 & 8.57 & 7.90 & -1.1922 & 0.2342 \\
\hline
\end{tabular}

Source: Consumer survey $(n=352)$

For consumers who currently buy ATM milk, the most (43\%) notable reason for this purchase choice was the affordability of ATM milk (Figure 7). Other important reasons are its availability (17\%), as ATM machines are positioned in strategic locations for consumers; flexibility in quantity purchasable (15\%); and consumers' preference for the taste of ATM milk. 


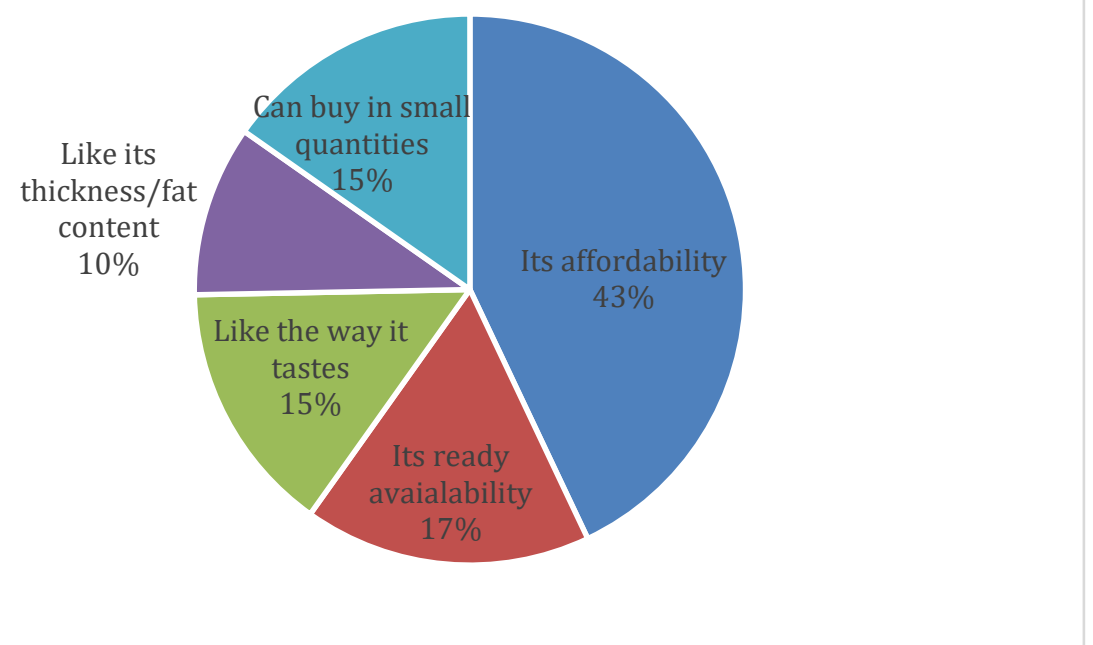

Figure 7 Reasons why consumers purchase ATM milk.

Source: Consumer survey $(n=286)$

Figure 8 presents the reasons why some consumers do not buy or stopped buying ATM milk. A majority (56\%) of milk consumers who do not purchase ATM milk perceive it to be adulterated, and $19 \%$ of the consumers consider that it is not clean. This implies that about $75 \%$ of consumers who do not purchase ATM milk are making this decision because of quality issues. Addressing quality issues in ATM milk outlets is imperative to enhance the retention rate and attract potential customers.

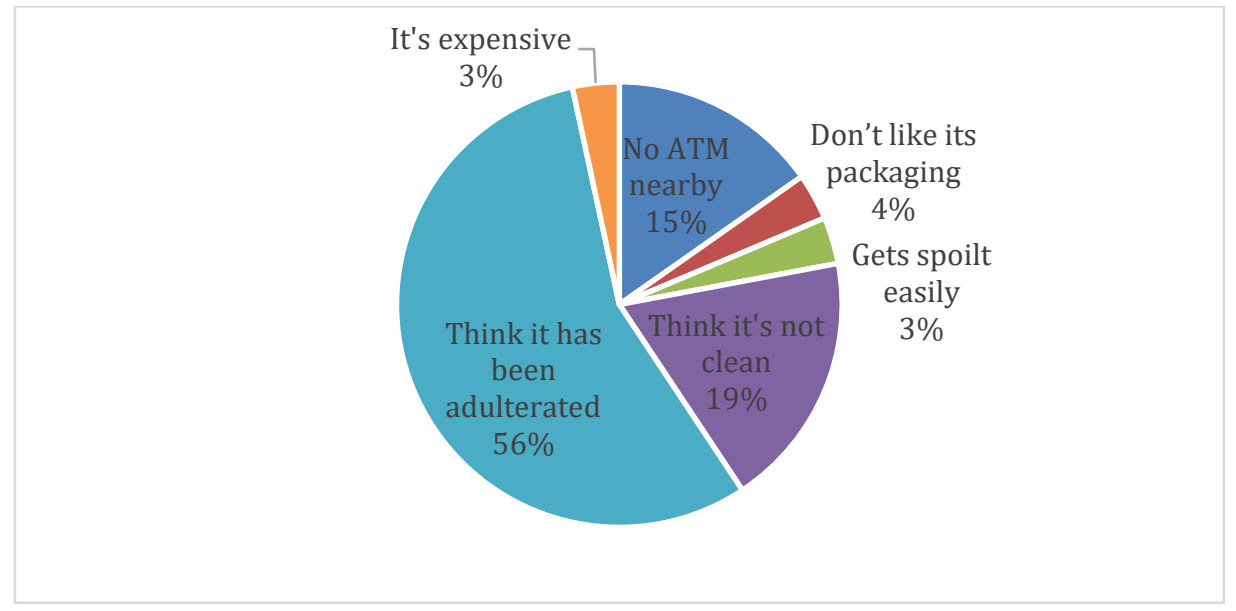

Figure 8 Reasons why some consumers do not buy ATM milk.

Source: Consumer survey $(n=66)$

Figure 9 presents factors that consumers consider in choosing which point to purchase ATM milk from. Most consumers consider reliability in availability of milk $(51 \%)$ (that is, the ATM always has milk in stock) and perception of high quality (48\%). Consumers are also attracted (42\%) to a specific milk ATM whose hours of operation suit their daily schedules. For ATM operators, it would be advisable to assure continuous availability of milk and to have flexible opening hours based on consumer convenience, in order to meet consumer needs. 
Favourable operation hours

Reliability in availability of milk supply

High quality of milk

Favourable prices

Nearest location

Cleanliness of the premises

Good customer service

One-stop shop

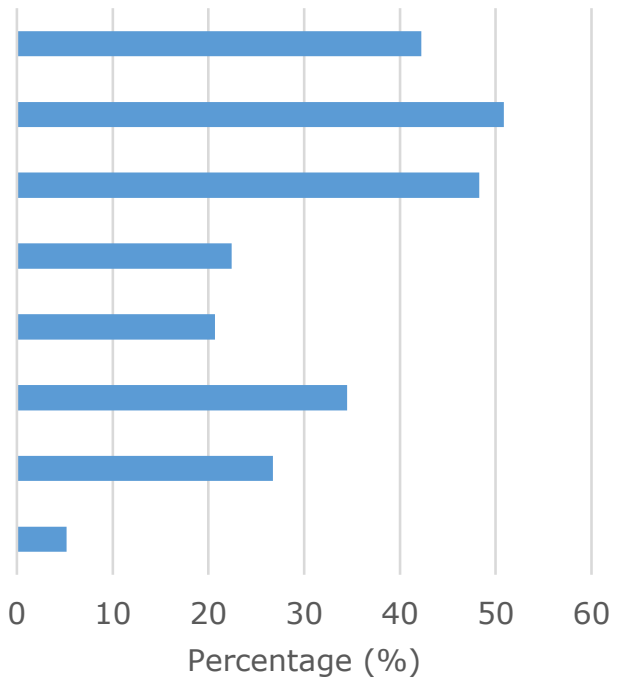

Figure 9 What consumers prefer when choosing the point of ATM milk purchase. Source: Consumer survey $(n=352)$

\subsection{Quality perception of ATM milk by consumers}

Respondents were also asked about their perception of quality issues related to ATM milk (Table 10). Perception of adulteration of milk was the most reported (28\%) closely followed by cleanliness of the ATM machines, premises and the milk handler (22\%). Consumers were also concerned that they did not know or trust the milk source implying that information on the source (the supplier) of the milk could boost consumers' confidence of ATM operators. Considering that the ATM milk sector is growing, building trust among stakeholders can help increase milk demand. Sale of unpasteurized milk was also raised as a concern about ATM milk, especially because it is difficult for consumers to differentiate between pasteurized and raw milk.

Table 10 Quality perception of ATM milk by consumers.

\begin{tabular}{lc} 
Quality concern & Percentage \\
ATM milk does not last long / easily gets spoiled & 5 \\
\hline ATM milk has a bad taste & 7 \\
\hline ATM milk has preservatives and chemicals & 15 \\
\hline ATM milk is adulterated & 28 \\
\hline Cleanliness of ATM machine, premises and handler & 22 \\
\hline Lack of trust (not knowing milk source, not trusting operators) & 6 \\
\hline Hygiene in handling & 16 \\
\hline Uncertainty if ATM milk is pasteurized & 1 \\
\hline
\end{tabular}

Source: Consumer survey $(n=352)$

The key informants interviewed voiced additional quality concerns, such as ATM milk operators selling milk that has gone beyond the 24 hour allowable limit for ATMs, which has health implications especially if the right temperatures are not maintained during storage. The operator's survey revealed that ATM milk is maintained at approximately 4.9 degrees Celsius at the ATM machine. However, when supplied with larger volumes of milk than the machine can hold, operators use alternative storage facilities and $31 \%$ of the milk operators had stored ATM milk at higher temperatures than recommended. 


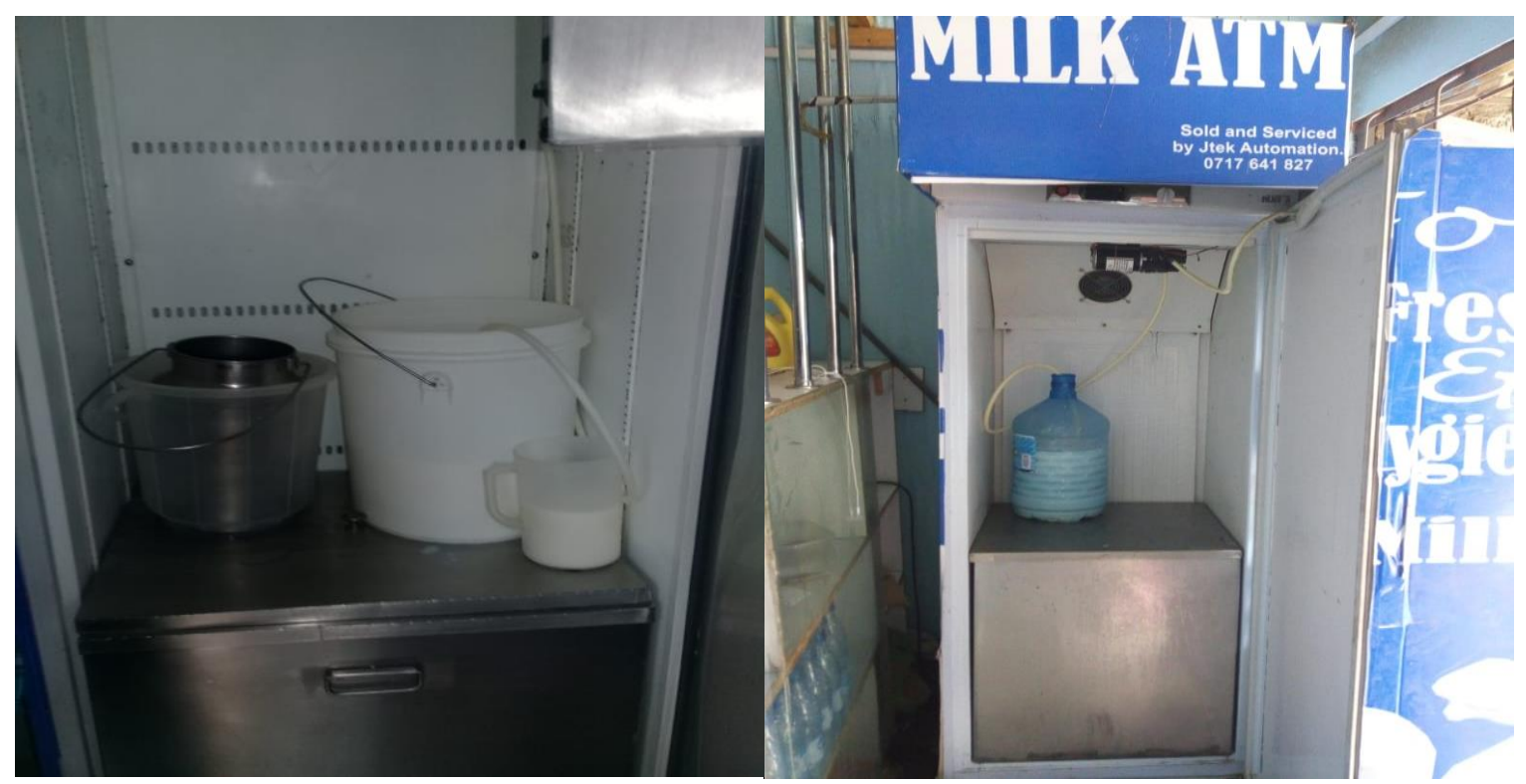

Photo 4 ATM milk operators using non-recommended milk cans in the ATM machine.

\subsection{Quality and safety assessment of milk dispensed in ATMs}

The study also sought to understand the extent to which milk sold through ATMs met established regulatory standards for quality and safety. We did not undertake analysis of milk samples but relied on secondary sources that included surveillance data on sampled milk ATMs from the KDB and the results of several recent studies. The Kenyan Dairy Standards for various milk quality and safety parameters are stipulated by the Kenya Bureau of Standards (KEBS). Some of the standards, including those for pasteurized milk, are harmonized with the East African Community (EAC) Standards and linked to the Codex Alimentarius for some parameters. The EAC standards for raw and pasteurized milk were revised in 2018 and published in 2019. These standards added aflatoxin M1 residues as an additional requirement. Table 11 provides a summary of the standards for the various parameters for raw and pasteurized milk.

Table 11 EAC/Kenyan Standards for pasteurized and raw milk (2018).

\begin{tabular}{|c|c|c|}
\hline & Pasteurized milk & Raw milk \\
\hline No added water or preservatives & Yes & Yes \\
\hline \multicolumn{3}{|c|}{ Limits established by Codex Alimentarius Commission } \\
\hline Pesticides & Yes & $*$ \\
\hline Veterinary drug residues & Yes & Yes \\
\hline Minimum milk fat $\%^{+}$ & 3.25 & 3.25 \\
\hline Maximum coliform plate count $(\mathrm{CPC})^{ \pm}$ & 10 & 50,000 \\
\hline Escherichia Coli Per ml & Absent & $\mathrm{n} / \mathrm{a}$ \\
\hline Mycobacterium Tuberculosis per ml & Absent & $\mathrm{n} / \mathrm{a}$ \\
\hline
\end{tabular}

*Pesticide limits for raw milk are explicitly included in the EAC Standards.

+Applies to whole milk; lower for fat-reduced and fat-free milk.

tRaw milk maximum TPC refers to Grade 3. The maximum for Grade 2 is $1,000,000$ and for Grade 1 is $200,000$.

\pm Raw milk maximum CPC refers to "good" quality milk; the maximum for "very good" quality milk is 1000 .

Source: Brown et al., 2018

\subsubsection{Results of quality and safety of milk sampled for KDB surveillance}

The KDB surveillance data from a sample of 60 milk ATMs across the country in 2018 (Figure 10) reveals compliance of this market segment with some of the set standards. About $19 \%$ of the milk samples failed the alcohol test, an indication of milk spoilage as a result of bacterial fermentation. Further, $15 \%$ of the samples had butter fat content below accepted levels. This is an indicator of adulteration but can also be affected $y$ by the breed of the cow. Aflatoxin and antibiotic residues were 
detected in some samples, with about $11 \%$ of the samples testing positive for tetracycline and another $7 \%$ testing positive for sulphonamides, both of which are antibiotics. About $11 \%$ of the samples tested positive for aflatoxin M1.

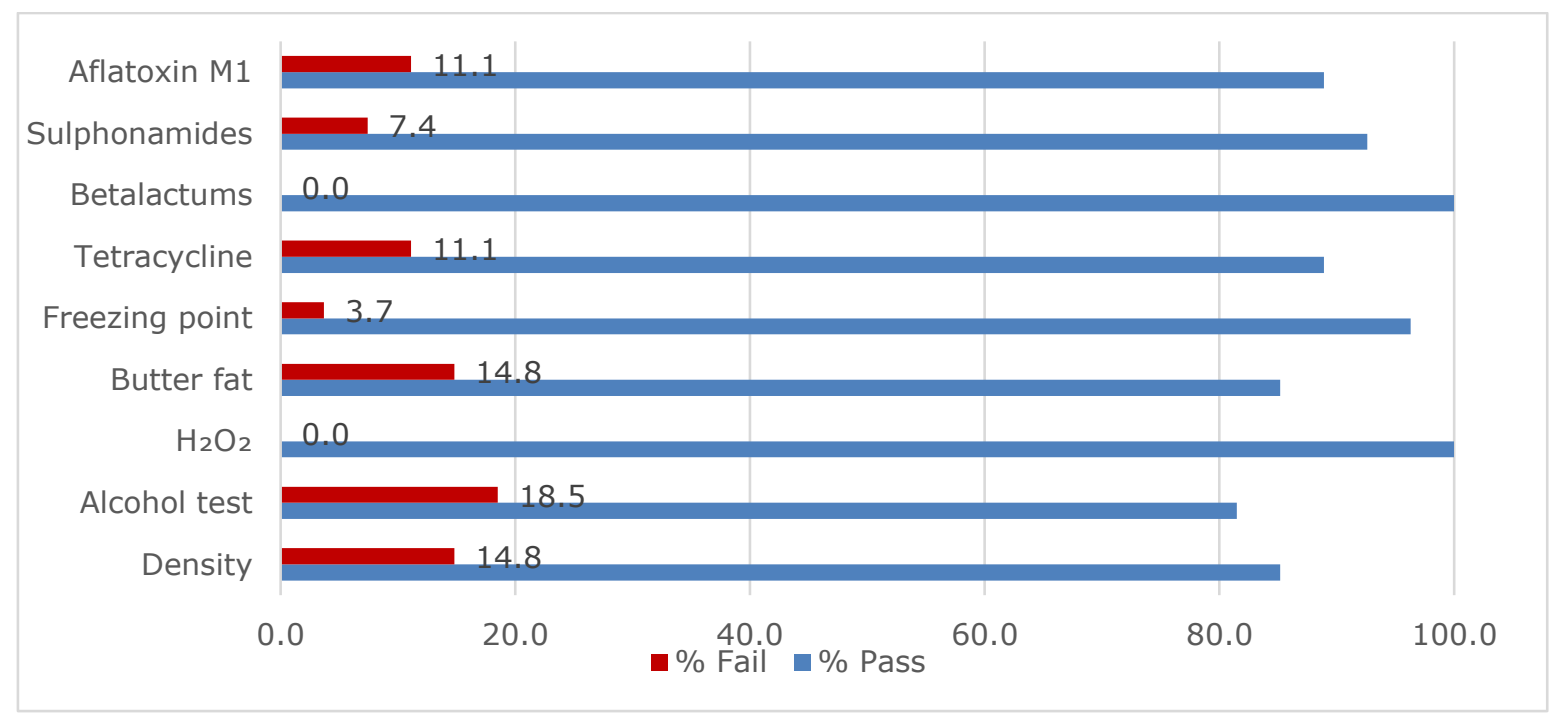

Figure 10 Milk test results of KDB surveillance data.

Source: KDB-supplied data, $2019(n=60)$

\subsubsection{Selected studies on quality and safety of ATM milk}

A study by Bebe et al. (2018b) assessed the quality of milk marketed through three retails options: ATM; plastic containers, including the improved Mazzicans (raw); and packaged milk. The study was conducted in Nairobi, Nakuru, Eldoret and Kisumu in 2017 and sampled 39 ATMs, 32 packaged milk sachets and 29 raw milk from plastic containers sold in informal markets). The study analysed the density, solids not fat (SNF), total bacterial counts (TBC), total coliform counts (TCC), aflatoxins, hydrogen peroxide and antibiotics levels of the milk.

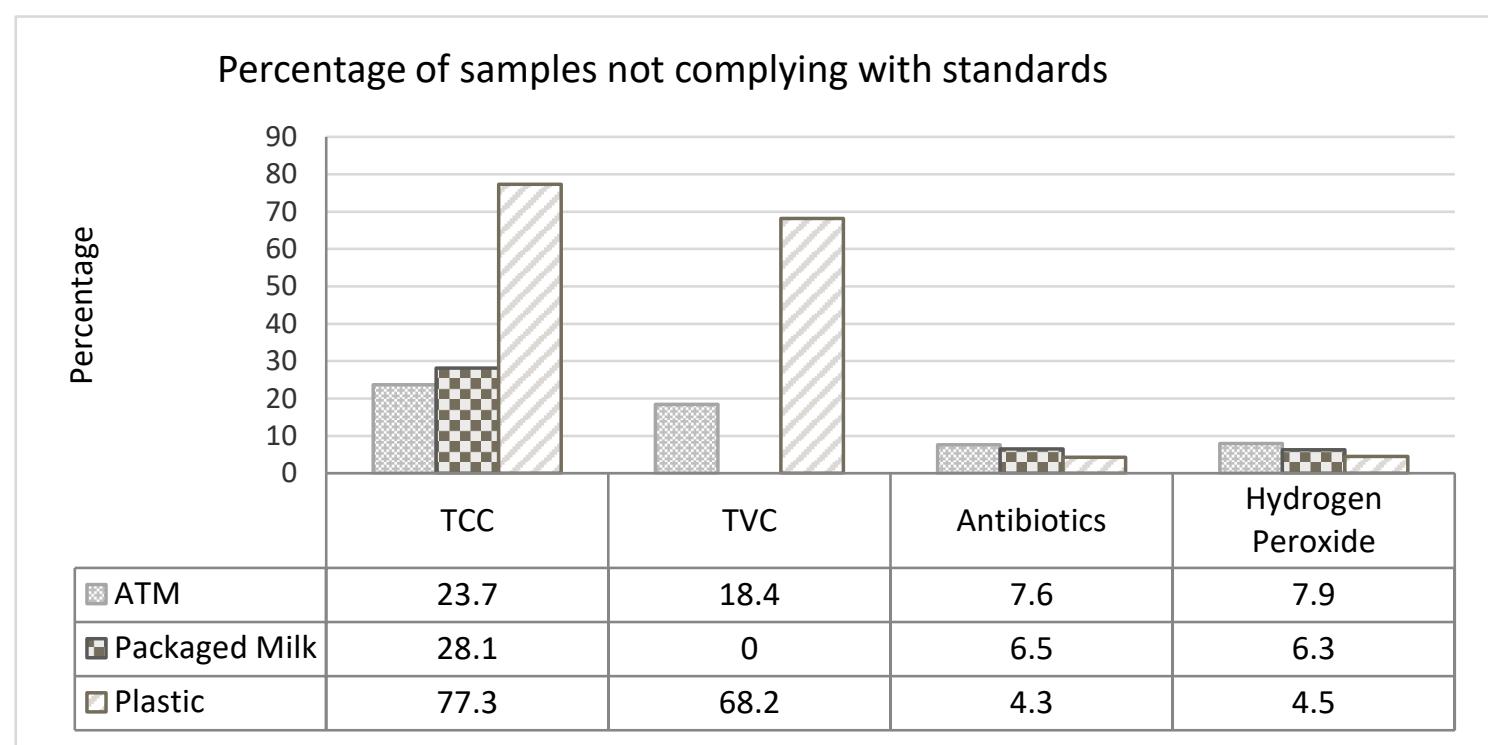

Figure 11 Percentage milk of samples that do not meet standards.

Source: Bebe et al., $2018(\mathrm{n}=100)$

Figure 11 provides a summary of the findings on the quality of milk marketed through ATM, packages and plastics. On TCC, results show that $24 \%$ of the sampled ATM milk did not meet KEBS standards for pasteurized milk. The results were comparable to packaged milk, as about $28 \%$ of those samples also did not meet the standards. For other parameters, sampled ATM milks that did not meet the standards were slightly above that of packaged milk. Milk sold in plastic containers, which is sold raw, had many more samples that did not meet the various standards (Bebe et al., 2018b). 
Another study, conducted by Kosgey et al. (2018) in Eldoret town focused on assessing the prevalence of antibiotic residues from packaged milk, ATM milk and raw milk sold by informal traders (street vendors). The study was conducted on 80 milk samples: 25 pre-packaged milk (commercial brands), 34 milk samples from ATMs and 21 milk samples from informal traders (Table 12). The study found different types of antibiotic residue in some of the ATM milk and raw milk (about $24 \%$ of samples for each).

Table 12 Prevalence of detectable levels of antibiotic residues in milk from Eldoret.

\begin{tabular}{|c|c|c|c|c|c|}
\hline & $\begin{array}{l}\text { Tetra- } \\
\text { cycline }\end{array}$ & $\begin{array}{l}\text { Sulfa- } \\
\text { methazine }\end{array}$ & $\begin{array}{l}\text { Beta- } \\
\text { lactams }\end{array}$ & $\begin{array}{l}\text { Genta- } \\
\text { micin }\end{array}$ & Antibiotic \\
\hline Sample type & $\pm(\%)$ & $\pm(\%)$ & $\pm(\%)$ & $\pm(\%)$ & $\pm(\%)$ \\
\hline Commercial packaged milk & $0 / 25(0)$ & $0 / 25(0)$ & $0 / 25(0)$ & $0 / 25(0)$ & $0 / 25(0)$ \\
\hline Milk-vending machine (ATM) & $2 / 34(5.9)$ & $1 / 34(2.9)$ & $2 / 34(5.9)$ & $3 / 34(8.8)$ & $8 / 34(24)$ \\
\hline Raw milk from street vendor & $3 / 21(14)$ & $0 / 21(0)$ & $0 / 21(0)$ & $2 / 21(9.5)$ & $5 / 21(24)$ \\
\hline
\end{tabular}

Source : Kosgey et al., $2018(n=80)$

Another independent assessment was conducted on six milk ATMs businesses in various locations in Nairobi (Anonymous, 2018). The assessment focused on understanding the different contamination points of milk sold through the ATM. This was in consideration that one of the main challenges faced at the ATM point of sale is post-pasteurization contamination. The results (Figure 12) show that total viable count (TVC) in the milk ATM tanks (cans) excessively exceeded the allowable limit under the KEBS standards. More revealing was that samples taken at the dispensing taps of the same ATMs show a further increase in the TVC beyond the allowable limit, with some samples having a TVC of 60 million (units) which is above the EAC Standard of 30,000. This is an indication of the challenges of cleaning and maintaining the ATM machines in a hygienic manner.

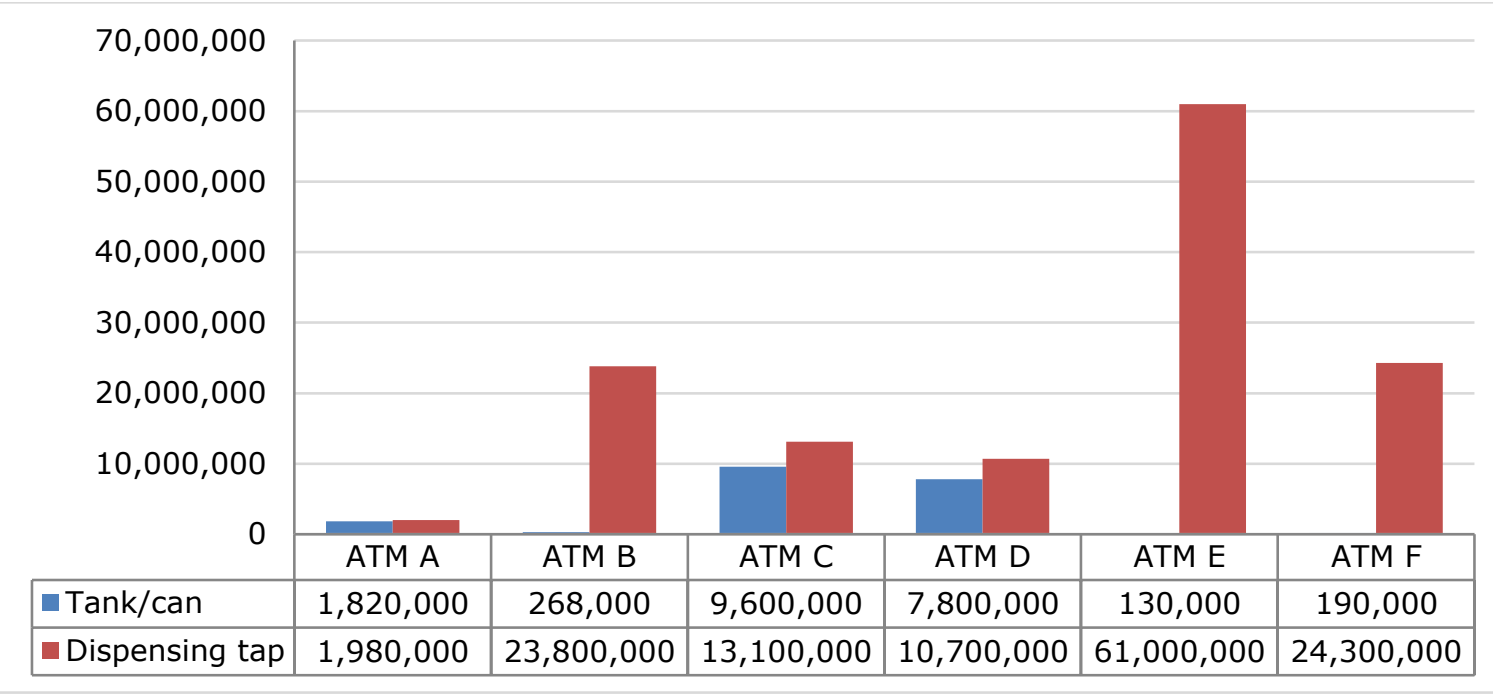

Figure 12 Assessment of total viable count (TVC cfu/ml) at different points of the ATM.

Source: Anonymous, 2018

\subsection{Best and poor practices along the milk ATM supply chain}

The best and poor practices as described by the stakeholders are outlined in Table 13. The only poor practice mentioned was use of non-food-grade materials in the fabrication of ATM machines. 
Table 13 Best practices and poor practices along the milk ATM supply chain.

Best practices Poor practices

Design and fabrication of milk ATM technology

- Use of food-grade materials

- Use of non-food-grade materials

- Provision of after-sales service

- $\quad$ CIP system

- $\quad$ Adherence to KEBS standards

- $\quad$ Provision of a user manual with proper cleaning schedules

\section{Milk-handling practices}

- Use of sealed cans

- $\quad$ Sale of pasteurized milk

- $\quad$ Storage of ATM milk at recommended temperature

- Use of adulterated milk

- Good inventory management of milk (record keeping First In First Out; FIFO)

- $\quad$ Sanitization of milk cans

- Traceable source of milk

- $\quad$ Adding non-approved preservatives or chemicals

- Sale of raw unpasteurized milk

- Unregulated independent pasteurizers

- Poor temperature control

- $\quad$ Sale of spoiled milk as value-added product (e.g. mala)

- Infrequent inspection and licensing

- Use of transport means not conforming with requirements, e.g. lacking permits, refrigeration for long distances, or insulation

- Use of unsealed and plastic containers

\section{Operational practices}

- Observing hygiene practices (protective clothing, cleanliness, clean running water, sanitary facilities, painting walls)

- Medical certificate of milk handlers

- $\quad$ Frequent milk ATM machine servicing

- Proper waste water disposal e.g. septic tanks, connection to sewerage system etc.

- Accurate calibrations

- Adequate ventilation
- Improper waste disposal e.g. pouring on

roads/pavements.

- Corruption by some stakeholders (licensing, inspection, milk handling)

- $\quad$ Corrupted calibrated systems

- Use of non-approved cleaning agents

- Infrequent cleaning

- Mounting ATMs in poorly ventilated places

- Lack of standard cleaning schedule (temperature of water, type and concentration of detergent, recirculation time)

At the ATM operation level, the best and poor practices centred around milk-handling practices, certification of milk handlers, servicing of ATM technologies, waste disposal and calibration of equipment. The best practices in terms of product quality were in the use of the recommended milk cans and sale of pasteurized milk, while poor practices were in the adulteration of milk, sale of raw milk and not having the required permits and licences among others.

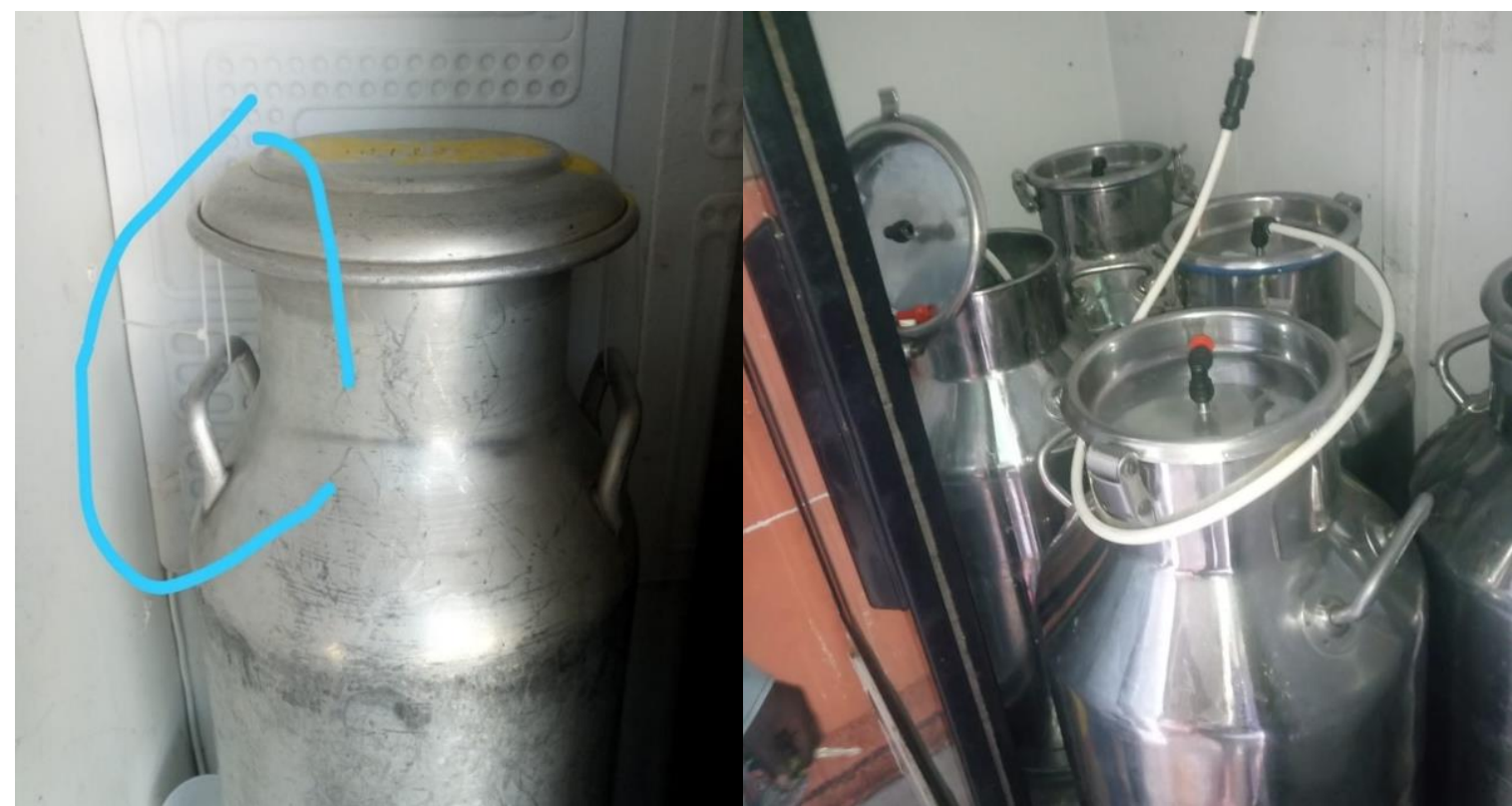

Photo 5 Sealed cans(left) and tamper-proof cans (right) used by some enterprises to secure the ATM milk. 


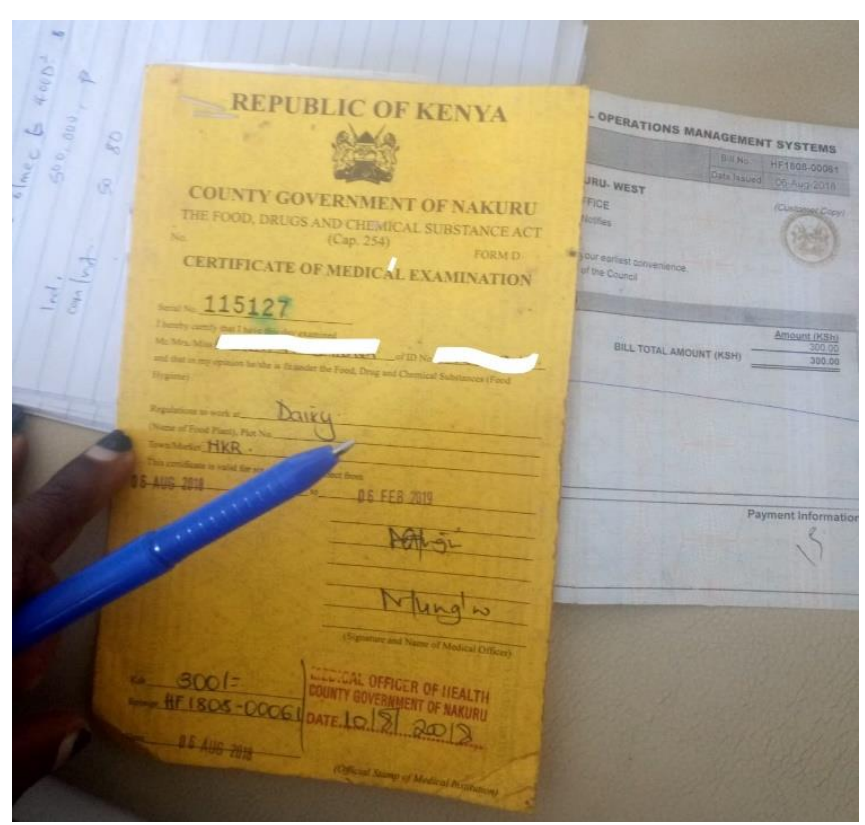

Photo 6

Medical certificate issued by county government to milk ATM operators.

The KDB, in a bid to address the poor practices, developed guidelines that have been incorporated into the proposed revised dairy draft regulations currently undergoing stakeholder consultations. They look at four different aspects of the ATM:

1. Construction and design requirements, which focus on product contact surfaces, inbuilt product-holding area, bulk milk tanks, removable dispensing nozzle, inbuilt refrigeration system, temperature monitoring and displaying device, exterior construction and routine maintenance

2. Product requirements, which focus on location and layout, product handling and personnel

3. Operational requirements, which look at temperature, holding time and labelling of the product

4. Key recording requirements, which look at milk procurement records (quantity and volumes), cleaning schedule and records, maintenance schedule and records, calibration schedule and records (for volume and temperature-measuring devices), relevant licences, personnel medical and training records and rinse and swab test results. 


\section{Business ecosystem in the ATM market segment}

\section{Chapter 5 overview}

This chapter answers the third research question: What businesses have emerged around the ATM milk market segment in Kenya? Specifically, the chapter addresses the effect of ATM introduction on business development and resultant employment creation effects in view of giving an idea on the contribution of the market segment to the economy. It also gives insights on suppliers of ATM milk and ATM business licencing.

\subsection{Milk ATM technology business}

The ATM technology is the core of the new milk market. Out of the nine milk ATM suppliers interviewed, most (eight of the nine) of these businesses are located in Nairobi and one in Nakuru, and have been established within the last eight years. Only one milk ATM supplier was importing fully assembled milk ATMs for customers; the other eight import parts of the machine and fabricate the milk ATMs locally. Some of the parts imported included refrigeration units, calibration units, milk pumps, tamperproof cans, flow sensors and food-grade pipes. Some suppliers were converting standard fridges into milk ATMs.

All milk ATM suppliers were involved in other businesses such as supplying other equipment and machinery (e.g. refrigeration units, microwaves, water and fuel pumps, washing machines coolers, solar technologies, pasteurizers, chillers, milk cans, milking machines and milk tanks). All milk ATM suppliers (both importers and local fabricators) offered training with the purchase of the ATM machines, some after-sales services and warranty after purchase (Appendix 2, Table B). The most common after-sales service was delivery and transportation of the machine and provision of machine installation and maintenance. Maintenance service was either offered directly by the supplier or through third-party technicians subcontracted by the supplier, especially in cases where the supplier did not have an office in the same town where the ATM was operating.

From the nine ATM supply businesses interviewed, about 56 employees are involved in one way or another in the ATM business. They noted that due to declining demand for milk ATMs and growth in the number of ATM suppliers, the number of workers per business has decreased. Most suppliers are currently maintaining some contractual workers who are called up whenever a milk ATM assembly contract arises. According to one of the key informants, the emergence of ATMs offers opportunities for developing a pool of skilled personnel to fabricate and maintain milk ATMs. The enabling/regulatory environment for milk ATM supply is supported by several government bodies, among them the KDB, KEBS, public health offices, Kenya Revenue Authority and County governments.

\subsubsection{Types of Milk ATM technologies offered by suppliers}

Based on ATM suppliers' interviews and field observations, Table 14 summarizes characteristics and design features of the milk ATM technology in the Kenyan market. 
Table 14 Technology characteristics of milk ATMs supplied in Kenya.

\begin{tabular}{|c|c|}
\hline Characteristic & Variation observed \\
\hline Holding capacity & $\begin{array}{l}\text { - Varies from } 50 \text { to } 700 \text { litres } \\
\text { - Some have fixed volumes, while others customize the size during assembly }\end{array}$ \\
\hline Milk-holding vessel material & $\begin{array}{l}\text { - Stainless steel } \\
\text { - Aluminium }\end{array}$ \\
\hline Dispensing unit & $\begin{array}{l}\text { - One nozzle } \\
\text { - More than one nozzle (rare cases) }\end{array}$ \\
\hline Automation of temperature control & $\begin{array}{l}\text { - Automated temperature control unit } \\
\text { - Not automated }\end{array}$ \\
\hline Cooling & $\begin{array}{l}\text { - Inbuilt refrigeration system } \\
\text { - External cooling system (e.g. deep freezer) }\end{array}$ \\
\hline Piping and pumps & $\begin{array}{l}\text { - Food grade } \\
\text { - Non-food grade }\end{array}$ \\
\hline Calibration options & $\begin{array}{l}\text { - Accepts coins } \\
\text { - Accepts notes } \\
\text { - Generates a receipt } \\
\text { - Volume calibration } \\
\text { - Calibration is password-protected }\end{array}$ \\
\hline Cleaning & $\begin{array}{l}\text { - } \text { Automated cleaning } \\
\text { - Non-automated cleaning }\end{array}$ \\
\hline Portability & $\begin{array}{l}\text { - Portable machine } \\
\text { - Fixed machine }\end{array}$ \\
\hline
\end{tabular}

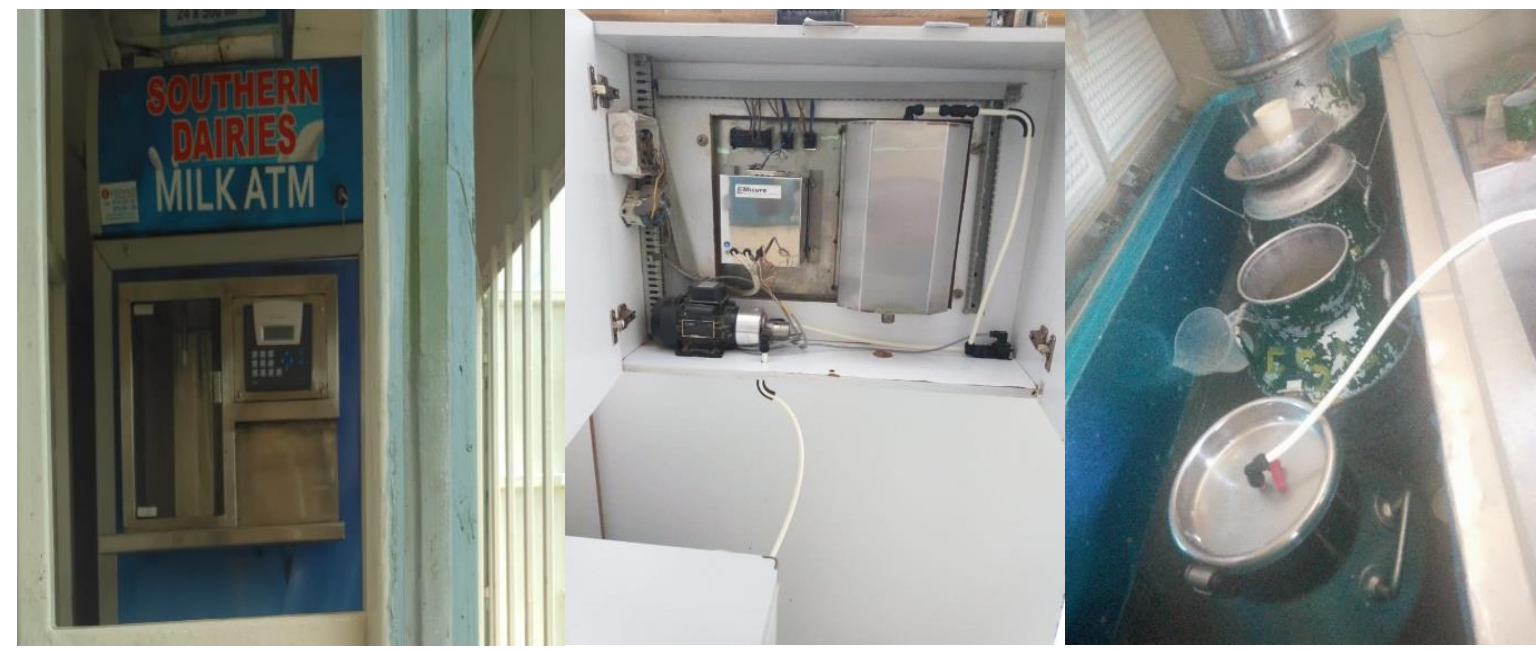

Photo 7 Selected features in milk ATM retail market.

Milk ATMs available in Kenya vary from 50 to 700 litres in holding capacity (the volume of milk that can be stored in the ATM inbuilt tank at a time). Imported ATM machines costs about KES 1.2 million, while locally fabricated machines cost between KES 120,000 and 700,000, depending on specifications. Some suppliers have fixed-volume machines (pre-installed tanks of varying capacities), but others have the option of customizing the volume of the machine during assembly. Some ATMs do not have inbuilt tanks; their refrigeration holding space can accommodate several (1-4) 50 litre cans. KDB regulations require that all surfaces in contact with milk be food-grade materials. However, some suppliers deceive customers who may not know which materials are food-grade, and they supply nonfood-grade components in the milk ATM. In some instances, non-food-grade pumps, which are not suited for pumping milk and are difficult to clean, are used because they are cheaper.

Temperature control is critical for the milk ATM to be efficient in terms of power consumption, while still providing a quality product. Suppliers offer automated temperature control units, semi-automated units and non-automated machines. The automated temperature control is most preferred, since it improves power efficiency (non-automated units require the operator to switch power on and off to control milk temperatures). Moreover, the cooling system also uses temperature control. Some machines have an inbuilt refrigeration system, while others have external cooling systems. In the external cooling system, the dispensing units and the cooling system run separately.

The milk ATMs supplied have various calibration units, the most common being coin calibration, where the machine differentiates coins based on weight, diameter and width; note calibration, where the machine differentiates different currency notes based on the size and weight; and volume calibration, where the system is set to dispense a fixed volume of milk within a certain time frame. In many 
cases, volume is calibrated by timing how many seconds milk is flowing, which was identified to be a problem in cases where the pipes may swell after cleaning with hot water. Some machines have fixed volumes calibrated in them, such that they can only dispense milk in those amounts, but others can dispense any volume of milk. Some other machines are calibrated to generate a sales receipt upon dispensing the milk. The majority of the calibration units are protected with a password, which is held by a responsible operator in the business or by the owner. However, some suppliers do not give the operators the calibration password, prompting them to be called every now and then to change the calibrations. Automated cleaning of the machine is a common feature sought by customers. Some suppliers have machines that are cleaned manually and others that are automated. Different types of automation exist, where some machines have a fully functional CIP module, while most of the machines do not. The common automation is where the machine operator replaces the milk system with water and runs the cleaning modules for some minutes. The cleaning modules are preprogrammed by the suppliers. Another feature of interest is the portability of the machines, with suppliers offering machines that can be moved from one place to another as well as fixed machines that cannot be moved after installation.

Other technological improvements would add value to milk ATMs. Suppliers reported that there is an increased demand for machines installed with "running empty sensors" to notify operators when milk is running low. Machines with a sales record memory are also in high demand, since they help owners do the milk business accounting. The same was true for machines with GSM messaging systems, which send short sales text messages periodically, for example, at close of business and to summarize periodic performance of the milk ATM sales. This would help in monitoring the business, especially by absent "telephone entrepreneurs". Other technological aspects in demand include card payment facilities, more accurate calibration units, fully automated CIP and all materials being of food grade. For fabricators, adding value to current machines by incorporating these demands from operators may determine future differentiation within the ATM market.

\subsubsection{Business development in the ATM milk supply chain}

The ATM milk market segment has led to business development and employment creation ranging from the supplying the machine to the various support services emerging around the technology. The businesses can be visualized as having three facets: ATM technology supply, milk supply to the ATM operators and ATM milk retail operations (Figure 13). On the ATM technology supply side, the main business support has been around the transportation of ATMs to the retail outlets, periodic servicing of the ATM machines, branding of the ATMs, sale of other milk equipment such pasteurizing equipment as milk cans, including the new tamperproof milk cans that have been recommended by KDB as meeting the regulatory standards. Various informants were wary of this push to adopt the tamper proof can as a requirement in ATM milk market noting the high cost of the cans that would affect viability of business.

On the milk supply side, businesses have developed around milk supply, transportation and pasteurization services. Where milk comes from a processing company, the milk is pasteurized at the processing plant before delivery to the retail outlet by the processor. New milk pasteurization businesses have emerged where independent pasteurization units or pasteurization partnerships (copasteurization) are set up to offer pasteurization at KES 5-6/litre. In the case of co-pasteurization, milk ATM operators buy milk directly from farmers and transport it to a co-pasteurization location before taking it to their retail unit for sale. One of the challenges with this model is the issue of postpasteurization contamination, especially when using cans which are not properly cleaned. The findings reveal that only $1 \%$ of the businesses use the recommended tamperproof cans (Photo 5 ) that have been introduced recently in the Kenyan market. About $84 \%$ of suppliers use sealed aluminium cans to ensure quality of milk. Sealing cans is seen as a substitute for use of tamperproof cans. The remaining $15 \%$ of suppliers used unsealed aluminium cans, which could risk compromising the quality of the milk supplied. That is, unsealed cans pose a risk for contamination and adulteration of milk. 


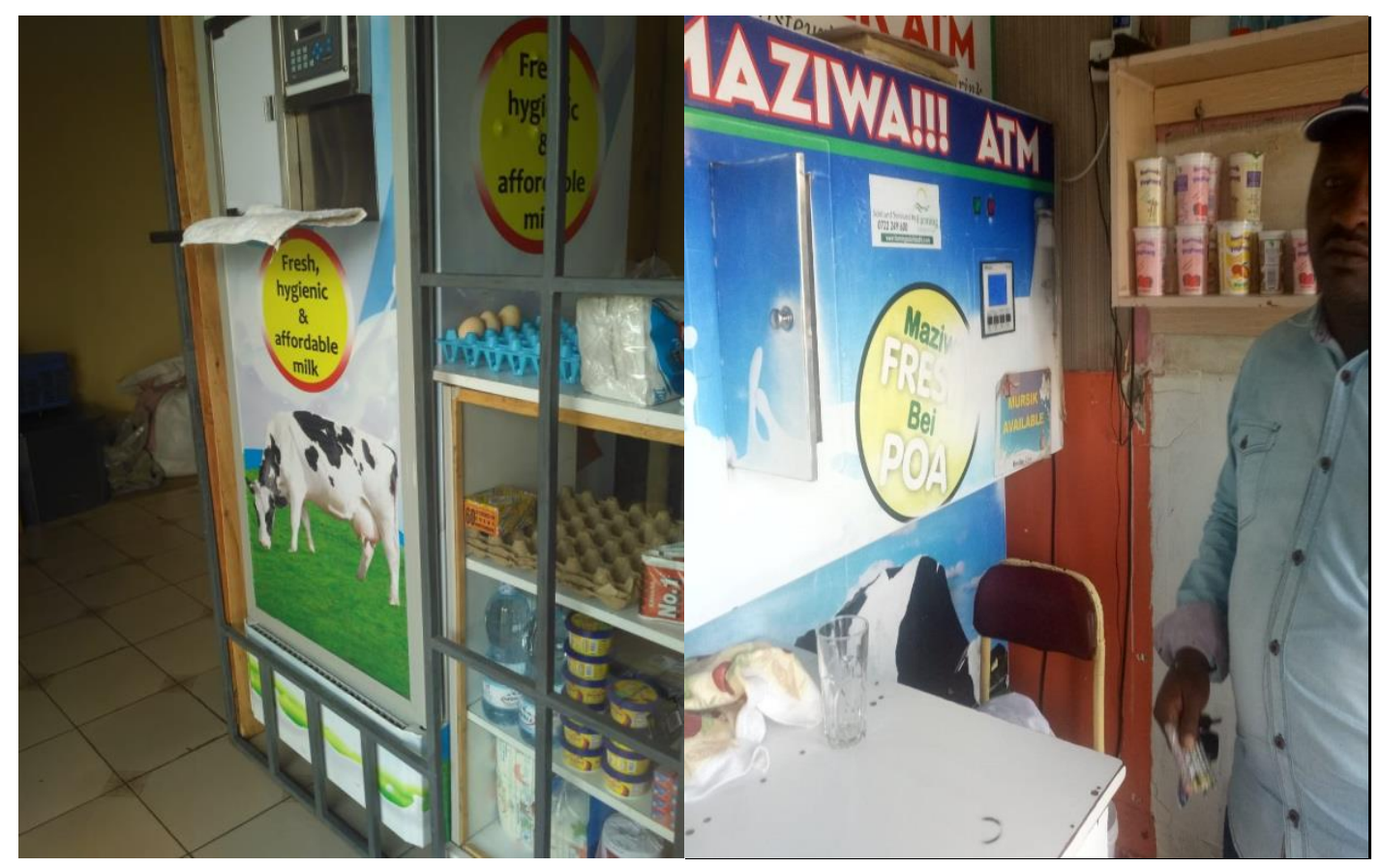

Photo 8 Businesses selling non-dairy products (left) and dairy products (right) together with ATM milk.

\subsubsection{Suppliers of ATM milk}

According to the survey of milk ATM businesses, their pasteurized milk is supplied by mini dairies/processors (40\%), major processors (26\%) and farmer cooperatives (29\%) (Figure 14). The major processors are large dairy firms with extensive penetration of the national domestic market, while mini -processors are small but growing firms concentrating their business in small markets with limited penetration. A majority (95\%) of ATM operators source their milk from mini-processors, major processors and farmer cooperatives. A smaller proportion (about 3\%) of ATM operators get their milk directly from farmers, while $2 \%$ get it from their own farm. 


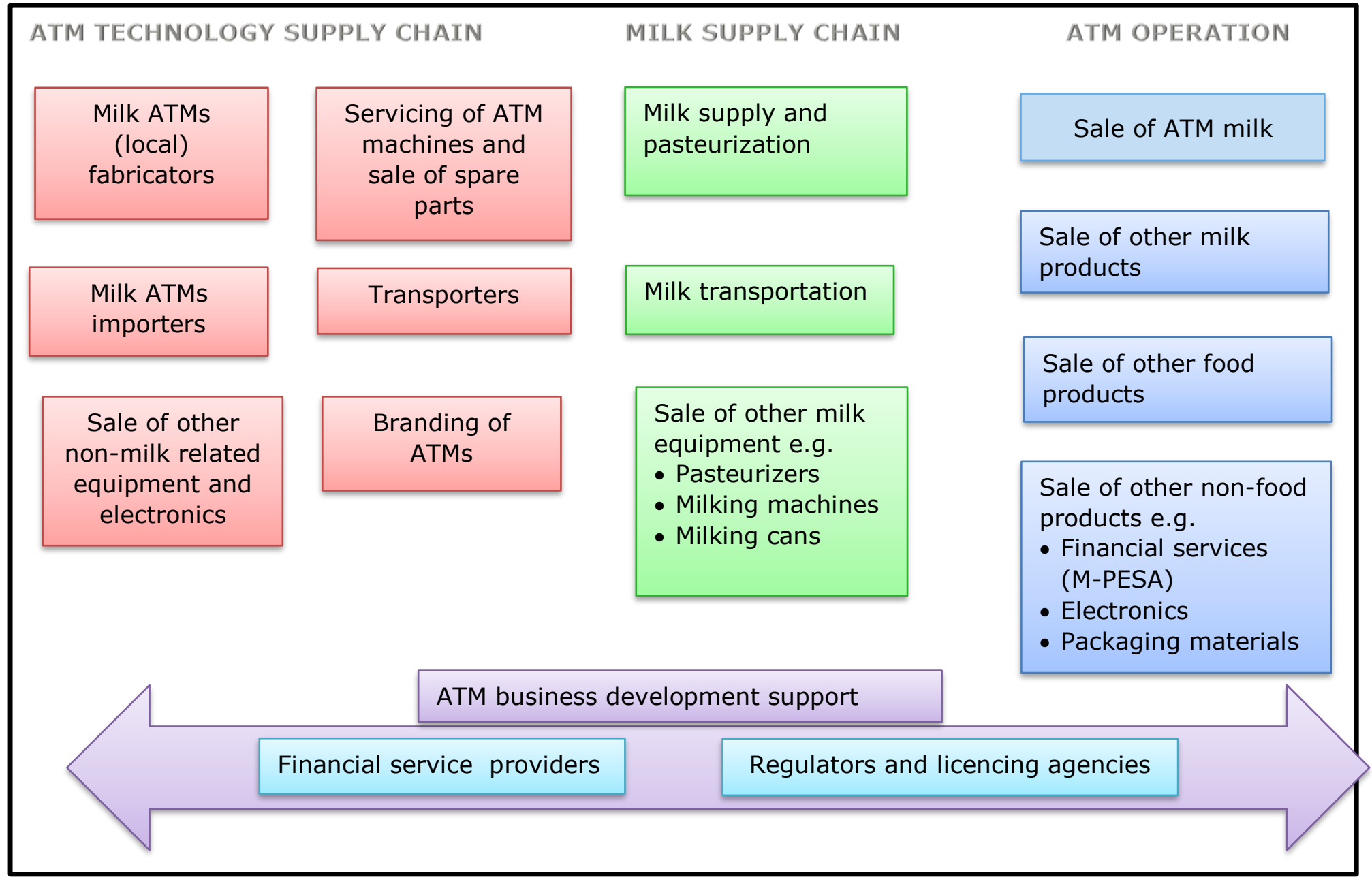

Figure 13 Business ecosystem around the ATM market segment. 


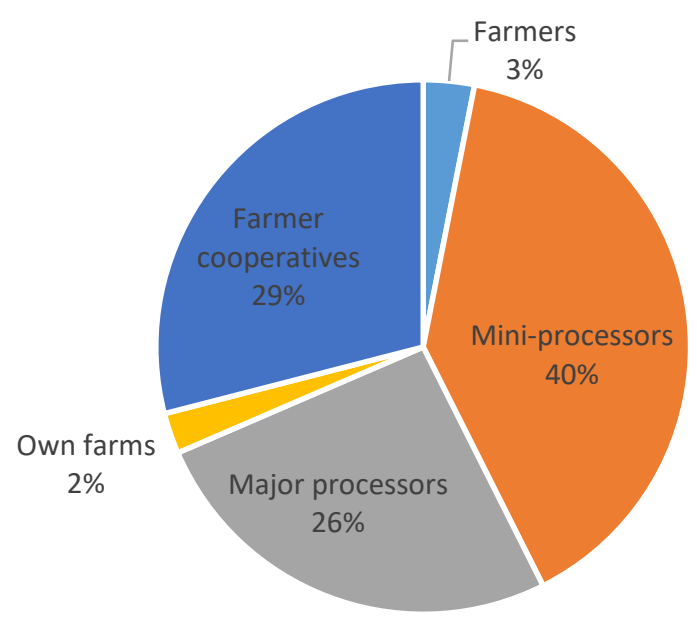

Figure 14 Source of milk for ATM businesses.

Source: ATM operator survey data $(n=162)$

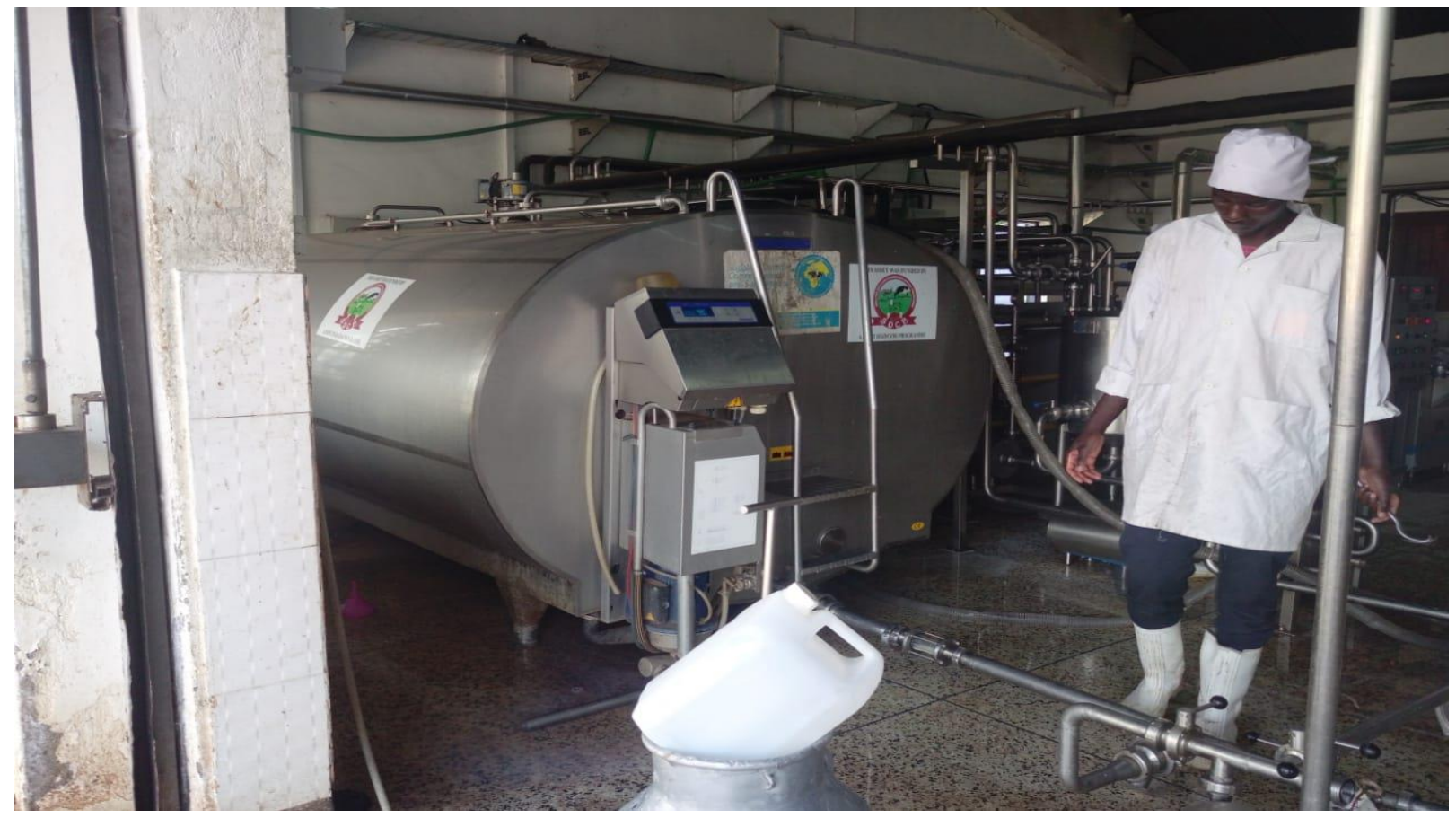

Photo 9 Suka dairies cooperatives one of the suppliers of ATM milk in Nakuru.

KDB requires that milk sold in ATMs is pasteurized, hence we asked ATM operators about compliance levels with this regulation. The findings reveal that $99 \%$ of the businesses reported that they sell pasteurized milk, with only $1 \%$ selling raw milk (Figure 15 ). Regarding the sourcing of milk, majority (95\%) of the ATM operators purchase pasteurized milk (from mini-processors, major processors and farmer cooperatives), while only about $2 \%$ do their own pasteurization and another $2 \%$ have a copasteurizing arrangement. Co-pasteurization is where a milk ATM retailer purchases raw milk and hires the pasteurization services of an independent pasteurizer. It was evident that there is growing business of using small pasteurizers, which might not be regulated by KDB. 


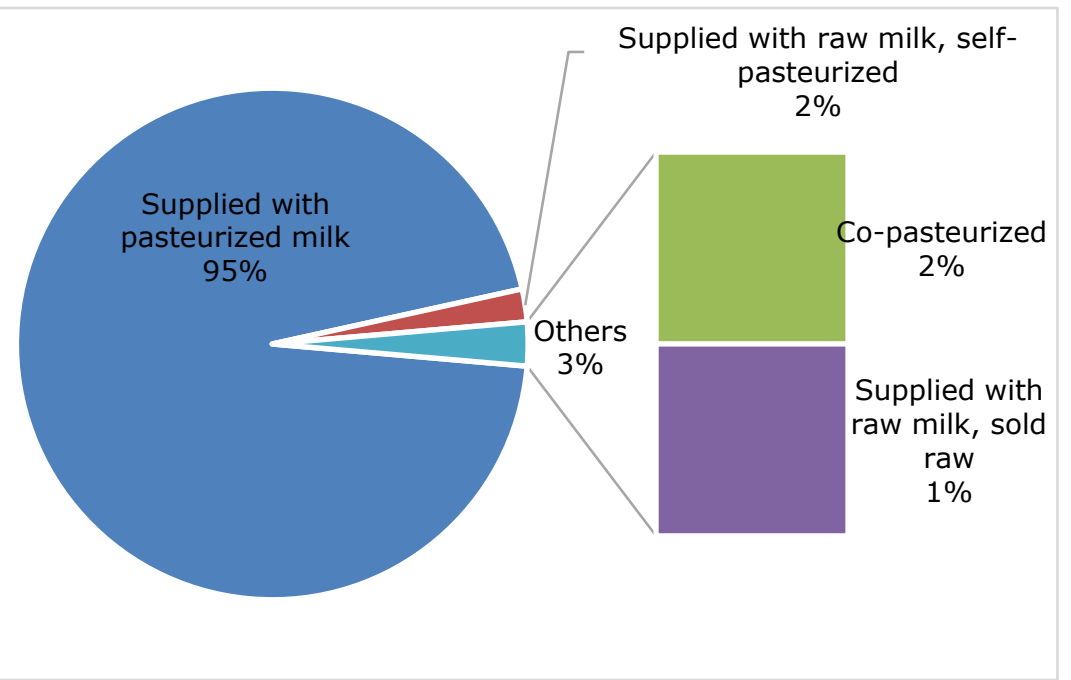

Figure 15 Nature of milk supplied to ATM operators.

Source: ATM operator survey data $(n=162)$

Findings show that about 54\% of the businesses put the milk cans in the ATM machine directly after supply. A further $33 \%$ of the businesses use a refrigerator connected to the ATM where they put the cans once supplied with milk. Approximately $22 \%$ of the businesses pour the milk directly into the refrigerator, which could pose a risk if the milk is not fully sold within 24 hours or goes bad in the refrigerator. About $4 \%$ of the businesses store the milk in cans outside the dispenser and not in a freezer, which implies the milk is at room temperature and could be a medium for growth of microbial organisms.

As shown in Figure 16, two thirds (67\%) of the ATM business had contracts with the milk suppliers. Contracts for supply of milk are important in ensuring consistency in milk supply and quality. In Uasin Gishu County, milk ATM businesses are supposed to get into contracts with pasteurized milk suppliers before they are licensed to operate. This is also a requirement for licensing by KDB but is being enforced differently across counties.

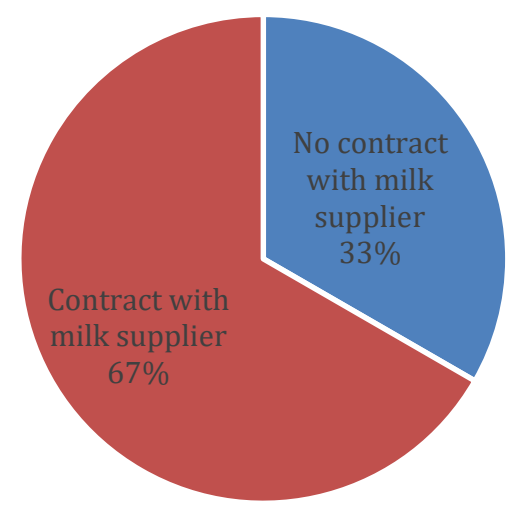

Figure 16 Contractual arrangements for supply of milk.

Source: ATM operators survey data $(n=162)$

\subsection{Milk ATM business licensing}

The basic requirements to operate milk ATM businesses in Kenya are the County Business Permit, KDB licence, Public Health Certificate (premise), and Medical Certificate issued by the public health department to operators. Some counties require a proof of contract between the supplier of pasteurized milk and the milk ATM business and an advertisement licence for businesses intending to advertise their milk ATM products. 
Figure 17 shows that approximately $94 \%$ of the businesses had a valid business licence, $75 \%$ had a KDB licence, and $79 \%$ had a Public Health Certificate for the premise and food handling. Most of the KDB licences had expired, as new requirements by KDB had not been met. However, at the time of the study, some businesses did not have the KDB licence because its issuance had been suspended as regulations around its use are being developed. About $94 \%$ of the businesses had a valid business permit.

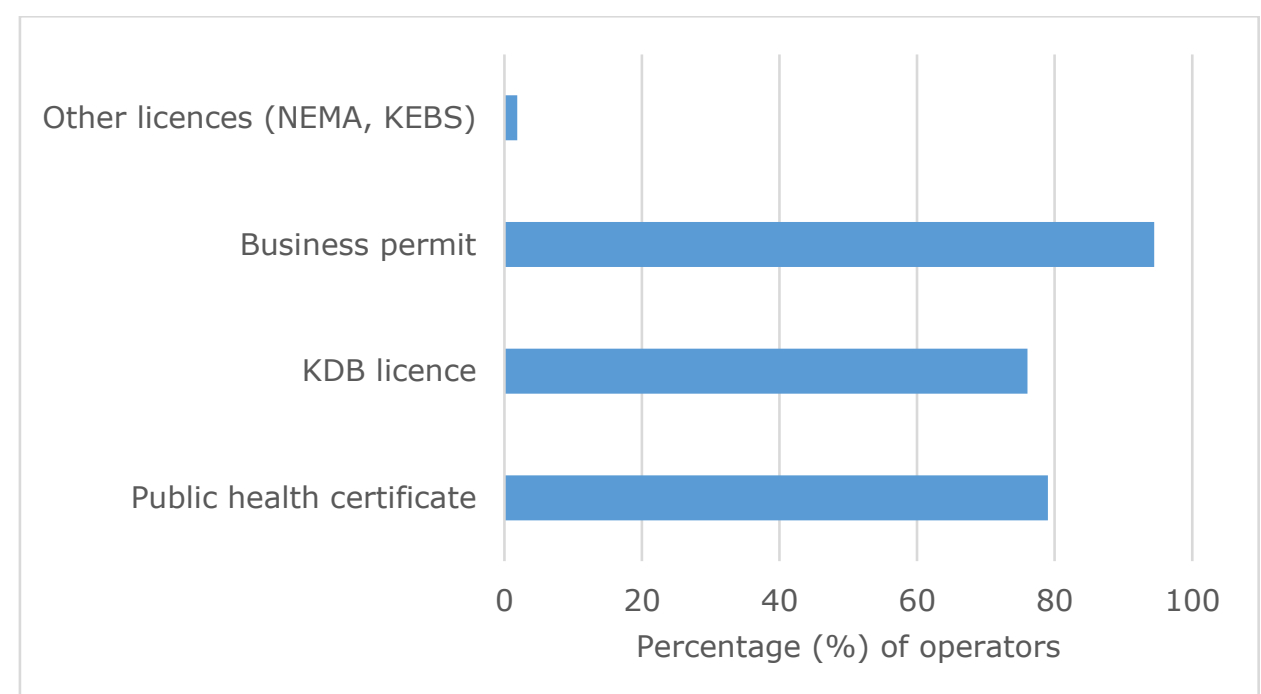

Figure 17 Licensing of milk ATM businesses.

Source: ATM operators survey data $(n=162)$ 


\section{6 Future development of the milk ATM supply chain: A scenario analysis}

Chapter 6 overview

This chapter answers the fourth research question regarding potential scenarios and their expected effect on development of the ATM milk segment. Scenarios are plausible snapshots of the future that help focus thinking on key factors driving performance of the ATM milk supply chain while considering potential emerging opportunities, challenges and threats. The scenarios under consideration were constructed through stakeholder's engagement during a roundtable meeting organized by the research team. The chapter presents three scenarios that could inform potential future growth trajectories in the market segment: business as usual; changes in compliance to quality standards; and a public ban on trading of raw milk in urban areas, which would result in an advantage for ATM milk in the competition with informally traded milk.

\subsection{Enablers and disablers of ATM milk sector growth}

The data presented in the preceding sections indicate exponential growth of milk ATM businesses, contributing to the growth in market share in the processed milk market. To what extent will this growth trajectory continue? During the stakeholders' roundtable meeting, we elicited perspectives on important enablers and disablers of growth of the ATM milk sector, which could affect future developments (Table 15). The enablers and disablers are categorized into demand for ATM milk, supply of ATM milk and ATM machines, and regulatory aspects.

On the consumption side, increased consumer awareness of the quality of ATM milk Key interventions include branding of the machines on the theme of selling pasteurized milk to build consumer trust, as some consumers still perceive ATM milk as raw milk; enhancing accuracy of calibration to ensure that consumers get value for money; technological breakthroughs in cheaper packaging materials to address the increased cost of packaging on dairy products due to the national ban on use of plastic bags. In terms of disablers, as discussed in Chapter 4, some studies have reported incidences affecting the quality and safety of purchased ATM milk (e.g. raw milk, milk spoilage, adulteration and high usage of preservatives) which could impede growth of the sector. These can be rectified by enhanced testing and compliance monitoring by KDB and other agencies, such as public health agencies.

The growth of independent pasteurizers and co-pasteurization in the proximity of retail outlets will play an important role in future development of the ATM supply chain. They reduce milk transportation costs thereby increasing margins, and might also reduce milk spoilage due to a shorter duration of exposure of the milk to higher temperatures since transportation is often done without cooling. However, stronger linkages between the ATM operators and pasteurizers in terms of contracts would guarantee reliable quality and safe milk supply to final consumers through increased traceability. Preventing adulteration of milk could also be achieved through adoption and proper use of tamperproof cans and seals during transportation.

Further automation of the milk ATM machines is an enabler of growth in the ATM milk supply chain. It leads to multiple dividends: reduced losses due to poor hygiene and temperature control and reduced costs for labour and electricity (through improved energy efficiency). These increase the margins for ATM machine operators, thus stimulating growth in the sector. Examples of automation systems that could be considered include CIP, temperature regulators, volume calibration and bank note calibration.

Capacity-building of ATM personnel will increase the quality of the product and of the service, instilling trust in consumers. This will need to include training of ATM suppliers in requirements for the milk ATM machines and of ATM operators in operational issues such as hygienic milk handling and disposal of wastewater.

Disablers on the supply side of ATM milk and ATM machines include contamination through adulteration and unhygienic milk handling, as well as use of high levels of preservatives to extend the 
buy-sell period of milk. Milk contamination discourages consumers, affecting demand and limiting growth of the sector. Further, some ATM machine suppliers fabricate substandard machines, for example using non-food-grade materials in efforts to reduce costs, with implications for food safety and lifespan of the machines. The high prices of good quality ATM machines impede growth of numbers.

In terms of the regulatory dimension, a stronger and more conducive framework would strengthen the ATM milk supply chain by ensuring that appropriate standards are set, approved and implemented. This addresses the disabler of inadequate regulation in the ATM milk supply chain. Lobbying for a total ban on trade of raw milk, or a partial ban for urban areas, would stimulate the sector, as would lobbying for reduction of taxes on imported components of milk ATM machines, such as refrigeration units, calibration units, milk pumps and food-grade materials.

Table 15 Enablers and disablers of future development of ATM milk supply chain.

\begin{tabular}{|c|c|c|}
\hline & Enablers & Disablers \\
\hline $\begin{array}{l}\text { Demand } \\
\text { (consumer) side }\end{array}$ & 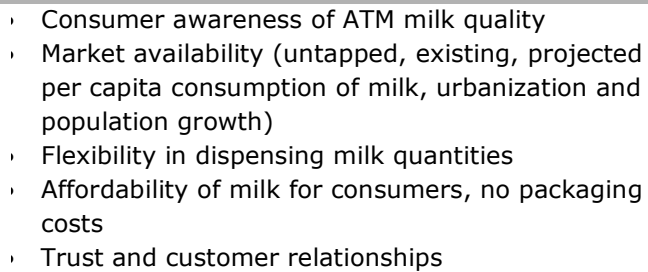 & $\begin{array}{l}\text { - Cases of milk spoilage } \\
\text { - Low trust levels regarding sourcing of milk } \\
\text { - Perception that ATM milk is of low quality }\end{array}$ \\
\hline
\end{tabular}

\begin{tabular}{|c|c|c|}
\hline $\begin{array}{l}\text { Supply side of ATM } \\
\text { milk and ATM milk } \\
\text { machines }\end{array}$ & $\begin{array}{l}\text { Accessible and affordable technology and services } \\
\text { for co-pasteurization and independent } \\
\text { pasteurization } \\
\text { Strong market linkages between processors and } \\
\text { ATM operators } \\
\text { efficiency of the machines (hygiene, temperature } \\
\text { and energy reduction) }\end{array}$ & $\begin{array}{l}\text { - Milk contamination, for example by adulteration } \\
\text { or by high levels of usage of preservatives or } \\
\text { chemicals } \\
\text {, Competition from continued sale of raw milk } \\
\text {, Unhygienic conditions around ATMs } \\
\text {, Fluctuating milk supply and milk prices } \\
\text {, Substandard ATM machines } \\
\text {, Long distances and poor transportation } \\
\text { equipment }\end{array}$ \\
\hline Regulatory aspects & $\begin{array}{l}\text { Strong and conducive regulatory framework, for } \\
\text { example: } \\
\text { - Ban on trade of raw milk sale in urban areas } \\
\text { - Ease and affordability of accessing business } \\
\text { licences } \\
\text { - Introduction of regulations to reduce risk of milk } \\
\text { contamination (tamper-proof cans, hygiene, } \\
\text { inspection) }\end{array}$ & $\begin{array}{l}\text { - Continued sale of raw milk } \\
\text { - Taxation on ATM milk equipment, such as } \\
\text { refrigeration units, calibration units, milk pumps } \\
\text { and food-grade materials } \\
\text { - Inadequate regulations (still in draft stage). }\end{array}$ \\
\hline
\end{tabular}

Source: Key informant interviews; $\mathrm{n}=38$

\subsection{Scenario analysis}

This section presents results for possible scenarios in the milk ATM supply chain and the implications for sector growth (expressed as demand for milk, supply of milk and employment over the next 10 years). Scenarios are plausible snapshots of the future that help focus thinking on key factors driving performance of the ATM milk supply chain while considering potential emerging opportunities, challenges and threats. Scenarios were built on the premise that the future is still in the making and can be actively shaped by anticipating emerging opportunities, challenges and threats and by taking strategic action today that supports performance of the ATM milk supply chain. The scenarios under consideration were constructed through consultation with experts from different relevant parties involved in the milk ATM supply chain. The parameter choices and detailed methodology are presented in Appendix 1.

\subsubsection{Scenario 1: Business as usual}

The key assumptions for the business-as-usual scenario are summarized below: 
1. The population demanding ATM milk and the number of ATMs were predicted using a logistic growth function ("S-curve"). Logistic growth was used to model the data because it is bounded by the carrying capacity, unlike the exponential growth that increases without limits. The logistic growth function used assumes that growth begins slowly, then increases rapidly and eventually levels off because of restrictions that place limits on the size of the underlying population.

2. Employment in the ATM businesses was estimated by multiplying the average number of employees per ATM (1.65; see Appendix 1 ) by the estimated number of ATMs.

3. The relative growth rate of the ATM sector was projected from the historical annual growth rate. For 2019 the growth rate of milk ATMs in Kenya was estimated at 31\% per year for the normal case. For the worst-case growth rate, we took the lowest growth rate of $23 \%$ recorded in 2014 (Appendix 1, Table C). We assume a fairly conservative best-case growth rate of 39\% (the normal growth plus the difference between the normal and worst growth rate), as the highest growth rate ever recorded in the past, of $481 \%$, seems unrealistic for the future. However, it is more likely that the growth would surpass the $39 \%$ in the best case scenario.

4. A projected intercensal growth of $2 \%$ as an indicator of population is assumed. An intercensal estimate is an estimate of population between official census in this case 2019 to 2029

5. The ATM milk market share of $16 \%$ of the formal milk market are assumed.

6. The current compliance level is estimated at 33\%; if the trend continues, 50\% compliance level is assumed to be attained in the fourth year.

Table 16 presents a business-as-usual situation including normal-, best- and worst-case scenarios for the next 10 years. If all conditions remain constant, the results reflect positive growth of the milk ATM market segment. In this case, demand for ATM milk would increase by a growth factor of 3.36 and the quantity supplied by 3.2 in 10 years. The change in quantity demanded exceeds change in quantity supplied because the ATM market segment exhibits demand-led growth. Thus, suppliers of ATM milk will lag their supply decisions, such that the market stabilizes, before committing more resources. Further, operators prefer to clear the stock daily, instead of having surplus stock which increases risk of incurring losses resulting from milk going bad. The increase in quantity demanded will be accompanied by a 1.83 growth factor in the number of milk ATMs. The higher number of milk ATMs implies growth in the sales of the machines by the suppliers, translating into further expansion of local ATM machine fabrication, leading to expansion in indirect and direct employment (workers selling the ATM milk machines and those selling ATM milk). The increased supply of ATM milk implies increased pasteurization and thus more business. This trend may trigger further growth in co-pasteurization and more investment in capacity to ensure compliance with KDB standards.

Table 16 Future projections in demand and supply of ATM milk in a business-as-usual scenario.

\begin{tabular}{|c|c|c|c|c|}
\hline \multirow[t]{2}{*}{ Variable } & \multirow[t]{2}{*}{ Status quo } & \multicolumn{3}{|c|}{ In 10 years } \\
\hline & & Normal case & Best case & Worst case \\
\hline Quantity demanded ('000 litres) & 102,205 & $343,307(336 \%)$ & $447,233(438 \%)$ & $\begin{array}{r}217,297 \\
(213 \%)\end{array}$ \\
\hline Number of ATMs & 2,030 & $\begin{array}{r}3,710 \\
(183 \%)\end{array}$ & $\begin{array}{r}3,971 \\
(196 \%)\end{array}$ & $\begin{array}{r}2,904 \\
(143 \%)\end{array}$ \\
\hline
\end{tabular}

Note: Figures in parenthesis represent \% change from status quo

In a best-case scenario (Table 16), projections show an increase by a factor of 4.38 for ATM milk demanded and of 4.13 for ATM milk supplied. The findings suggest that the quantity would grow fourfold in the best-case scenario and twofold in the worst scenario. In the best case, the number of milk ATM machines will grow by a factor of 1.96; in the worst-case scenario, by a factor of 1.43 . The trend diagram for the changes in demand and supply in 10 years is presented in Figure 18. In the short run, demand growth will outstrip supply growth, but later on oversupply would be a threat. This may be because changes in demand trigger changes in supply. In conclusion, in the short run it is likely that there would be minimal changes in demand and supply and thereafter the market segment will grow steeply, demonstrating a bright outlook for the ATM market segment. 


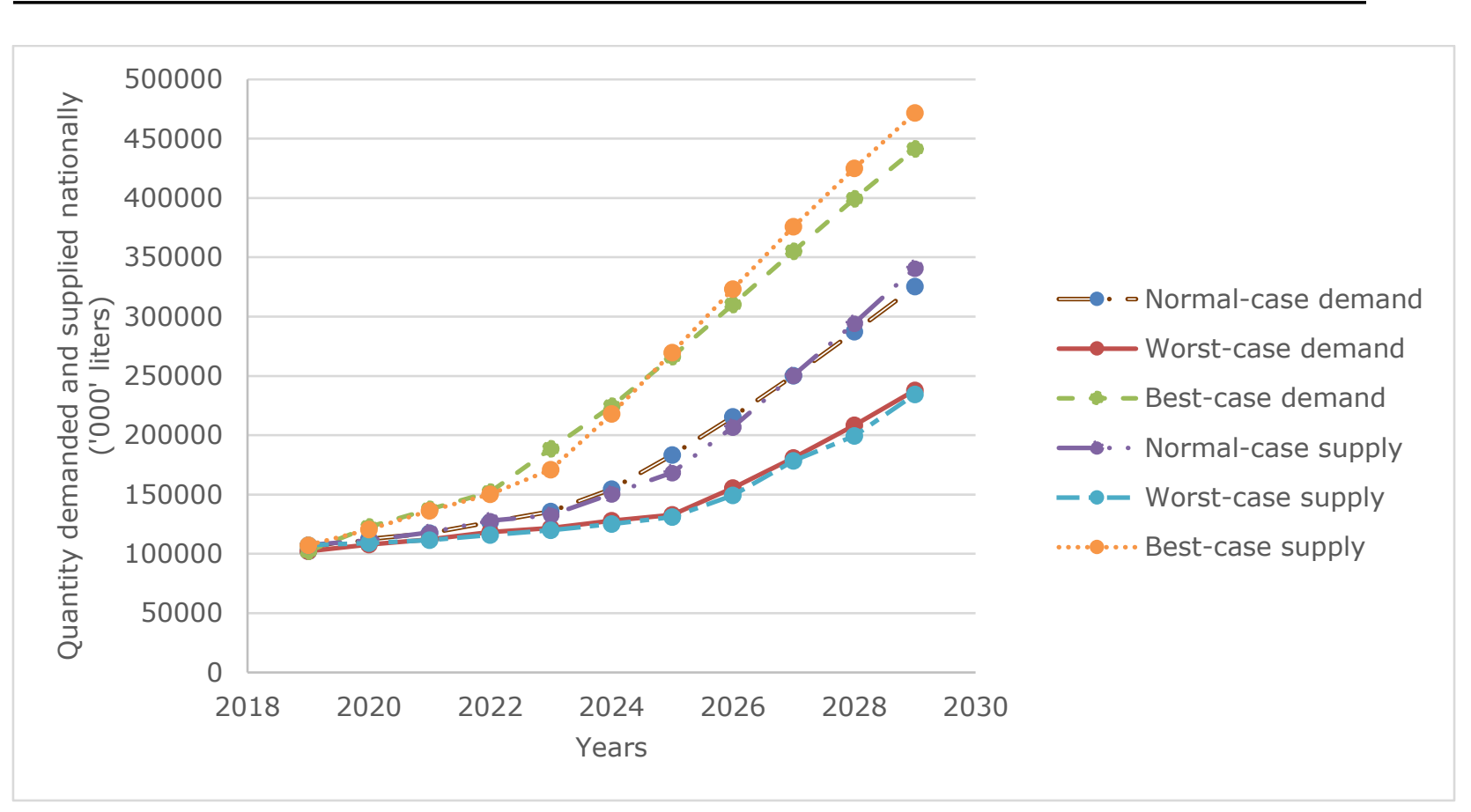

Figure 18 Trends in supply and demand of ATM milk over 10 years in business as usual scenario.

\subsubsection{Scenario 2: Stronger regulatory framework leads to increased compliance with $\mathrm{KDB}$ regulations}

With the impending approval of the regulations that will govern the milk ATM market segment, a scenario is likely where the regulator will have a stronger basis for enforcement. Based on KDBsupplied data (2019), of the estimated 1,550 ATM machines in 2018, about 436 were compliant with KDB measures and were issued with KDB certificates, which gives a $28 \%$ compliance rate.

Benchmarking against the $80 \%$ compliance rate estimated by KDB under the current dairy sector regulations and public health act, we make an assumption that the maximum compliance rate of the proposed ATM market segment will be $80 \%$. The possible scenario could involve tightening compliance for ATM machines (e.g. use of food-grade materials) and for the milk supply chain (e.g. use of tamper-proof cans). To comply, operators will need to increase investment costs and operational costs, which have to be covered by the consumer to ensure sustainability of the ATM milk enterprise. It is hypothesized that such a trend would lead to increased consumer prices of ATM milk to absorb the investment costs. On the other hand, increased compliance would assure consumers of the quality of ATM milk, which would build consumer trust in the product, which in turn would increase the quantity demanded. However, competition from cheap imported milk from neighbouring countries also may affect the price competitiveness of ATM milk.

As mentioned above, in 2018, the compliance rate was $28 \%$. By 2019 it was estimated at $33 \%$ according to KDB-supplied data. The relatively low level of compliance is a result of inadequate and non-specific guidelines for the sector. Simulations project that if the growth in compliance observed in the past continues over the coming years, compliance will be $50 \%$ in four years (normal-case scenario). For the best-case scenario - assuming more effort, cooperation and investment by KDB and other stakeholders in the sector - it is estimated that the sector can attain $50 \%$ compliance in two years. However, with complacency in the sector (worst-case scenario), 50\% compliance would not be achieved until the sixth year. The results for this scenario are presented in Table 17. They show that the expected compliance levels for the normal-, best- and worst-case scenarios in 10 years is $70 \%$, $79 \%$ and $62 \%$ respectively.

In the best-case scenario, quantity demanded and supplied would grow by a factor of 4.71 and 4.48 respectively (Table 17). Growth in the number of ATMs would grow slightly more than in the normal case by a factor of 1.91 . The trend is explained by tightening compliance with regulations, which results in more ATMs as non-compliant ATM enterprises close down but are compensated for by new entrants. These new entrepreneurs are responding to the business opportunity triggered by increased demand due to quality assurance in the ATM retail market segment. To achieve a higher level of 
compliance, KDB would require additional human resources and investments in laboratory and equipment to monitor the milk ATM machine and ATM milk supply chains. By the tenth year, compliance would have grown to $79 \%$. This will attract more consumers who are concerned about quality and price of milk, providing a mechanism for the ATM segment to encroach on the processed packaged milk market.

In contrast, in the worst-case scenario, where enhanced compliance takes longer, quantities demanded and supplied reduce compared to the normal-case scenario (Table 17). Consumers will tend to shift to raw milk consumption because of the price and quality effect in the market, as laxity in ensuring compliance by KDB would lead to mushrooming of non-compliant milk ATMs.

For policymakers and stakeholders, strengthening compliance is justified for a better milk ATM market segment. This scenario depends significantly on the capacity of the KDB to enforce the regulations.

Table 17 Scenario with compliance rate changes through a stronger regulatory framework.

\begin{tabular}{|c|c|c|c|}
\hline \multirow[b]{2}{*}{ Variable } & \multicolumn{3}{|c|}{ In 10 years } \\
\hline & Normal case & Best case & Worst case \\
\hline \multirow[t]{2}{*}{ Quantity demanded ('000 litres) } & 343,307 & 481,276 & 272,521 \\
\hline & $(336 \%)$ & $(471 \%)$ & $(267 \%)$ \\
\hline \multirow[t]{2}{*}{ Quantity supplied ('000 litres) } & 343,446 & 481,040 & 274,977 \\
\hline & $(320 \%)$ & $(448 \%)$ & $(256 \%)$ \\
\hline Number of ATMs & 3,710 & 3,886 & 2,904 \\
\hline
\end{tabular}

\subsubsection{Scenario 3: Public ban on sale of raw milk in urban areas, leading to the ATM market segment encroaching on the informal market segment}

This scenario occurs with a public intervention in the milk supply chain. Public intervention could be implementation of the proposed partial ban on the sale of raw milk in urban areas. From the current statistics, it is estimated that $30 \%$ of the marketable milk produced in the country is traded formally and $70 \%$ informally (Argwings-Kodhek et al., 2005). In this scenario, the ATM milk supply chain targets to expand into the $70 \%$ of milk traded informally, facilitated by a partial ban that will enhance trade in pasteurized milk and lead to higher demand for ATM milk. For raw milk consumers, in terms of cost, ATM milk is the next best alternative and thus there would be a shift in quantity supplied and consumed. The market share of ATM milk in the next 10 years is assumed to grow from $16 \%$ to $30 \%$ of formal marketed milk in urban areas with the remaining estimated $70 \%$ being taken by packaged processed milk. We created two scenarios: in the best-case scenario, ATM milk supplies $30 \%$ of total milk marketed; in the worst-case scenario it remains at $15 \%$ of the total milk marketed in the urban areas. The results of this scenario are presented in Table 18.

Table 18 Scenarios with public ban of raw milk in urban areas.

\begin{tabular}{|c|c|c|c|}
\hline \multirow[t]{2}{*}{ Variable } & \multicolumn{3}{|c|}{ In 10 years } \\
\hline & Normal case & Best case & Worst case \\
\hline \multirow[t]{2}{*}{ Quantity demanded ('000 litres) } & 343,307 & 593,004 & 475,782 \\
\hline & $(336 \%)$ & $(580 \%)$ & $(466 \%)$ \\
\hline \multirow[t]{2}{*}{ Quantity supplied ('000 litres) } & 343,446 & 575,286 & 477,891 \\
\hline & $(320 \%)$ & $(536 \%)$ & $(445 \%)$ \\
\hline Number of ATMs & 3,710 & 4,749 & 3,945 \\
\hline
\end{tabular}

The demand for ATM milk grows by a factor of 5.8 in the best-case scenario (Table 1 ). The additional growth factor of 2.44 growth (5.80-3.36) can be attributed to consumers who were previously consuming raw milk. Similarly, the supply of ATM milk grows by a factor of 5.36 up from 3.2, triggered by increased demand. The growth in supply is projected to be less than that of demand because suppliers speculate that since ATM milk is more expensive than raw milk, not all consumers will change over to ATM milk. Further, the number of ATMs in the country will increase, since the former raw market presents an extra opportunity to expand the milk ATM businesses.

In the worst-case scenario, ATM milk demand grows by an extra factor of 1.3 from the normal projected 3.36. In this case, the ATM milk market segment does not grow fully because there a black market to trade raw milk that is cheaper than ATM milk may develop. Overall, banning the sale of raw 
milk in urban areas would imply more ATMs being fabricated and installed in the market, which would also require more effort and investment by KDB to enforce and monitor compliance levels. Such a policy on banning of raw milk will increase the market size of pasteurizing enterprises. Farmers who supplied raw milk to the urban areas would be required to join the formal milk segment either through joining cooperatives or co-pasteurization. Due to the existing food safety concerns of raw milk, the public ban is more likely to happen in the urban areas of Kenya. In conclusion, future growth of the ATM milk sector is anchored on encroachment into the informal market segment rather than competing with packaged processed milk.

The findings suggest that a combined intervention with a ban on the sale of raw milk and proper monitoring systems in the ATM milk supply chain, leading to enhanced compliance, will result in a market share of ATM milk of more than $30 \%$ of the milk marketed in urban areas. 


\section{$7 \quad$ Conclusions and recommendations}

From this study of the ATM milk market segment, the following can be concluded:

1. The Kenyan ATM milk market is growing but concentrated in a few towns, mainly in Nairobi County and neighbouring counties. However, there is a likely general trend of the market segment spreading to other urban areas if the sector is supported. The future potential of the ATM market segment is in targeting growing urban areas across the different counties and targeting all categories of income earners.

2. The ATM milk market is expanding based on affordability of milk compared to pasteurized packaged milk and has the potential of expanding the formal milk market share beyond the current $30 \%$. to more consumers.

3. The flexibility in quantity of milk that is sold through milk ATM market segment has enabled consumers to access pasteurized and potentially safe milk thus contributes to household nutritional security. However, the finding indicate that some ATM milk does not meet the safety standards that comprise its value proposition to consumers and the industry.

4. Consumer perceptions of milk quality $\mathrm{h}$ were most important in making decisions about where to purchase ATM milk.

5. The growth of the milk ATM market is linked to a shift from the initial reliance on imported technology towards more locally fabricated machines, which has reduced reduce the cost of the machines. This has stimulated the development and expansion of fabrication and manufacturing industrial cluster. However, this has led to unregulated fabrication that is compromising the quality of these ATM machines.

6. The business ecosystem around the milk ATM retail market is expanding opportunities for job and business creation. In addition to fabrication of milk ATMs, other businesses that have emerged include milk pasteurizing, transportation, cooling systems, milk-handling equipment, servicing of the machines and sale of spare parts.

7. Future growth of the ATM milk supply chain is anchored on i) enhancing design of cost-effective, locally fabricated, automated quality assured machines (including calibration, CIP and improvement in energy efficiency); ii) building consumer awareness on quality of ATM milk as pasteurized milk since some consumers perceive it as raw milk, and iii) a stronger, well-thought through regulatory framework that are more enabling and supportive of expanding milk ATMs a quality-oriented market segment. The gaps in regulations for ATM machines and ATM milk (with regulations still in the draft stage) have implications for consumers and the regulator, in terms of food safety concerns as well as opportunistic behaviour of some fabricators, for example use of non-food-grade materials so machines are cheaper to make. With the relevant policy and regulatory framework being in limbo, there has been a rise of food safety issues in the ATM milk market segment.

8. In terms of future outlook of the milk ATM market segment, the following can be concluded, based on scenarios built:

- The business-as-usual scenario (status quo) projects the future potential growth of the ATM milk market segment by factors of 2.1-4.4 over the next 10 years.

- The ATM milk market segment is likely to grow in the future, but it is sensitive to policy and market changes. It has the potential to encroach on the informal milk market segment, offering an alternative source of milk to consumers and resulting in maximum growth by a factor of 5.8 of ATM milk volume supplied over the next decade.

\section{Recommendations}

- The milk ATM market segment has the potential to be a game changer in the process of formalization of the milk marketing sector if supported with relevant policy and regulations. GoK could fast-track policy and regulations to address unsafe operations and improve consumer confidence in the ATM milk product in order to utilize its potential, mainly linked to its price competitiveness, to be a game changer in the process of formalization of the milk marketing sector.

- Despite ATM milk price competitiveness, food safety issues along the supply chain must be addressed. To enhance safe milk handling along the ATM milk supply chain the ATM business operators supported by Government of Kenya, consumer organisations and other stakeholder need to: 
- Enhance responsible behaviour along the supply chain through labelling and effective traceability systems, which will enhance consumer trust of pasteurized milk. This will require development and deployment of standard operating procedures at the different nodes of the supply chain.

- Enhance capacity of the operators through a training programme. KDB can involve other parties to assist in this process, such as the public health department and consumer and food safety lobby organizations. This relates to development appropriate training curriculum and identifying effective means of delivery.

- Work with other agencies, such as the Kenya Revenue Authority to enhance access to cheap food-grade materials, and with KEBS to development and ensure compliance with fabrication standards, to address the quality issues in ATM milk machines. This also calls for working with industry actors to build capacity for innovation in developing quality, affordable technology that meets the required standards.

- Encourage private sector investment in expanding the ATM milk market, to develop a strong and robust chain that supplies pasteurized milk to ATM market retail outlets in additional towns.

- Sensitizing consumers and assuring them of quality can grow the market prospect for ATM milk while building on its price competitiveness.

- With the investments already made by operators, the upcoming regulations should facilitate improvements to the supply chain, for example a phased approach can be developed to stop the use of non-food-grade materials, to safeguard the interest of the investors and move to regulated machines. On the supply side, key enablers for the supply chain are enhancing growth of copasteurizers and building stronger linkages between milk ATM machine operators.

- GoK could enable KDB to strengthen its capacity in terms of enforcement officers, data management systems, ATM milk traceability systems and appropriate systems for registering and monitoring ATMs.

- Future growth depends on policy and market interventions in the sector by KDB that takes a less prescriptive approach but empowers the different operators along the chain. The interventions to facilitate growth in the milk ATM segment will come not only with finalizing the market and policy direction for the segment but also with meeting KDB capacity needs in terms of enforcement officers, data management systems, ATM milk traceability systems and appropriate systems for registering and monitoring ATMs. Further, increased investments in laboratory capacity and equipment as well as use of technology by KDB (e.g. using geographic information systems to map the milk ATMs and their suppliers) is required to enhance compliance rate. 


\section{References}

Alam, M.R., Sharmin, Yasin A. and Parh, M. (2015). Time Series Decomposition and Seasonal Adjustment. Global Journal of Science Frontier Research,15(9).

Alonso, S., Muunda, E., Ahlberg, S., Blackmore, E., and Grace, D. (2018). Beyond food safety: Socioeconomic effects of training informal dairy vendors in Kenya. Global Food Security 18, 86-92.

Anonymous (2018) independent assessment of some milk ATMs businesses in various locations in Nairobi.

Argwings-Kodhek, Gem \& M'mboyi, F. \& Muyanga, Milu \& Gamba, Paul, 2005. Consumption Patterns of Dairy Products in Kenya's Urban Centres: Report from an Urban Household Survey. Working Papers 202625, Egerton University, Tegemeo Institute of Agricultural Policy and Development.

Bebe, B. O. (2018a). Milk vending machine innovation for retailing milk: Operation costs, consumer perceived risks and milk quality in Kenyan markets. Sustainable Livestock Innovation and Technology: Roadmap to Improved Food and Nutrition Security. April 4-6, 2018, Sportsman Arms Hotel, Nanyuki.

Bebe, B. O, van der Lee, J., and Kilelu, C. W. (2018b). Milk retailing innovation in Kenya and consumers' perceptions of safety. 3R Kenya Project Practice Brief 010. Wageningen Livestock Research, Wageningen University \& Research, Wageningen. https://library.wur.nl/WebQuery/wurpubs/fulltext/496519.

Brown, L. H., Alonso, S., Lindahl, J., Varnell, H., Hoffmann, V., and Grace, D. (2018). Regulatory compliance in the Kenyan dairy sector: Awareness and compliance among farmers and vendors. Project Note. Washington, DC: International Food Policy Research Institute (IFPRI). http://ebrary.ifpri.org/cdm/ref/collection/p15738coll2/id/133046Fink-Gremmels, J., 2008. Mycotoxins in cattle feeds and carry-over to dairy milk: A review. Food Additives and Contaminants 02, 172-180.

Gachango, F. G., Anderson, L. M., and Pedersen, S. M. (2014). Adoption of milk cooling technology among smallholder dairy farmers in Kenya. Tropical Animal Health and Production 46, 179-184.

GoK-Government of Kenya. (2019). National livestock policy. Republic of Kenya Ministry of Agriculture, Livestock, Fisheries and Irrigation-State. Department for Livestock, Nairobi, Kenya.

KDB--Kenya Dairy Board. (2016b). Kenya Dairy Board Strategic plan 2017-2022. Kenya Dairy Board. Nairobi, Kenya. https://www.kdb.go.ke/wp-content/uploads/2019/06/KDB-strategic-plan-Final2017-to-2022.pdf

Kenya Markets Trust. (2019). Dairy sector at a glance. Available at: https://www.kenyamarkets.org/research/

KNBS-Kenya National Bureau of Statistics. (2019). Economic Survey 2019. Nairobi, Kenya.

Kosgey, A., Shitandi, A., and Marion, J. W. (2018). Antibiotic residues in milk from three popular Kenyan milk vending machines. The American Society of Tropical Medicine and Hygiene 98, 5, 1520-1522.

Makoni, N., Mwai, R., Redda, T., Zijpp, A., and van der Lee, J. (2014). White gold: Opportunities for dairy sector development collaboration in East Africa. Centre for Development Innovation report CDI-14-006, Wageningen University \& Research.

MoALF (2010). Kenya National Dairy Master Plan - A situational Analysis of the Dairy Sub sector, Volume I. Situational Analysis. Ministry of Agriculture, Livestock and Fisheries, Republic of Kenya, Nairobi. https://www.kdb.go.ke/download/kenya-national-dairy-master-plan-vol-i/

Ndambi, A., Njiru, R., van Knippenberg, C., van der Lee, J., Kilelu, C., Ngigi, M., Muliwa, M., Asher, D., Mbera G., and Mwangi, W. (2018). Enhancing milk quality and safety: Towards quality-based milk payments in Kenya. 3R Kenya Practice brief 011. Wageningen University \& Research.

Ndambi A, Kilelu CW, van der Lee J, Njiru R and Koge J (2019). Making milk quality assurance work on an unlevel playing field; Lessons from the Happy Cow pilot. Wageningen University \& Research, 3R Kenya research report 008/Wageningen Livestock Research Report 1165.

van der Lee, J., Bebe, B. O., and Oosting, S. (2016). Sustainable intensification pathways for dairy farming in Kenya; A case study for PROIntensAfrica. Wageningen Livestock Research Report 997, Wageningen University \& Research. 
Rademaker, C.J., Bebe, B.O., van der Lee, J, Kilelu, C. and Tonui, C. 2016. Sustainable growth of the Kenyan dairy sector; A quick scan of robustness, reliability and resilience. Report 3R Kenya/WLR 979.

Yamane, T. (1967). Statistics: an introductory analysis. New York: Harper and Row. 


\section{Appendix 1 ATM sampling technique and extended scenario methodology}

\section{ATM sampling technique}

The milk ATMs sample was determined using the following formula by Yamane (1967) for known population:

$$
n=\frac{N}{1+N(e)^{2}}
$$

Where $n$ is the desired sample size in the target population and $e$ is the acceptable margin of error ( $e$ $=0.07$ ). Replacing the above variables with known values where ( $N=806$ registered milk ATMs, we ended up with a sample of 162 milk ATM operators. The sample distribution is presented in Table 1.

The sample of milk consumers was determined for unknown population using the formula (Yamane, 1967):

$$
n=\frac{Z^{2} \cdot p \cdot q}{e^{2}}
$$

Where $n$ is the desired sample size in target population, $Z$ is the standard normal deviate at required confidence level of $95 \%(Z=1.96), \mathrm{P}$ is the proportion in the target population estimated to have the desired characteristics (milk ATM consumers $p=0.5$ ), $q$ is the proportion in the target population estimated not to have characteristics (milk ATM non-consumers) being measured $(q=(1-p=0.5)$, and $e$ is the acceptable margin of error $(e=0.05)$. Replacing the above variables with known values in the equation produces 385 , which after increasing by $27 \%$ to account for contingencies (such as nonresponses) gave 490 consumers.

Note that only questionnaires where the respondent had identified themselves as being a household head (352) were used for analysis, since they could provide the most complete information. Out of the 352, 286 (representing about 81\%) had bought ATM milk while 66 consumers (representing about $19 \%$ ) did not consume ATM milk in 2019

\section{Extended scenario methodology}

\section{A. Status of the dairy sector and milk ATM supply chain today}

This section presents the current statistics in the dairy industry and in the ATM milk supply chain in Kenya. Table A presents the current trend in formal milk consumption and sources. The size of the formal milk market is estimated to be about 807 million litres, of which about 154 million litres is imported from Uganda. Uganda recently has had a comparative advantage and potential for milk production reflected from its contribution of $19 \%$ of the total traded volumes in the formal market system.

\begin{tabular}{|c|c|c|c|c|c|}
\hline Period & $\begin{array}{l}\text { Produced } \\
\text { domestically } \\
\text { All products }\end{array}$ & \multicolumn{3}{|c|}{ Imports from Uganda } & $\begin{array}{c}\text { Size of formal } \\
\text { market }\end{array}$ \\
\hline July 2018 to June 2019 & $652,315,267$ & $91,220,117$ & $63,152,862$ & $154,372,979$ & $806,688,246$ \\
\hline Formal market share & $81 \%$ & $11 \%$ & $8 \%$ & $20 \%$ & $100 \%$ \\
\hline
\end{tabular}

Table A Volume of milk traded in formal markets in Kenya by source, 2018-2019, in litres LME*).

$*$ LME $=$ Liquid Milk Equivalent

Source: KDB supplied data, 2019. 
In terms of prices for processed and packaged milk, KDB data reveals that over the years prices have had an average growth of $4 \%$ per year. The current price stands at about KES 120 per litre as presented in Figure $A$.

\section{0}

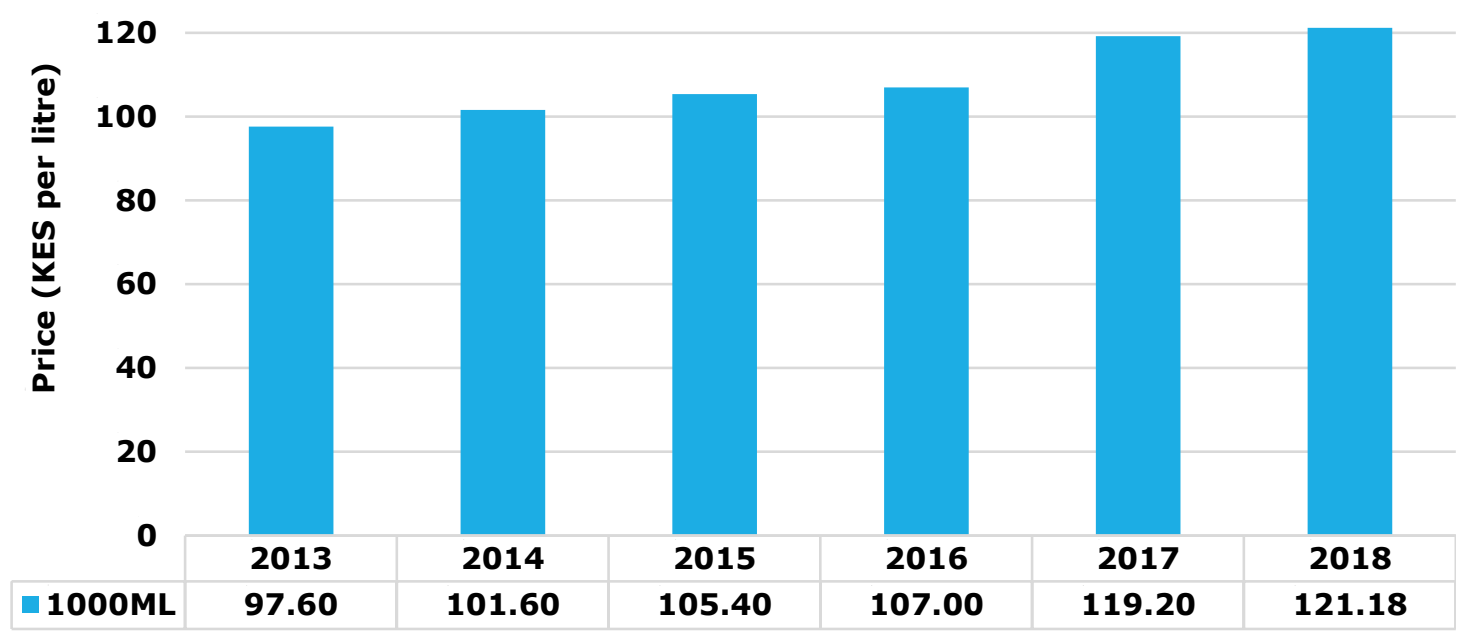

Figure A Average annual prices of UHT packaged milk.

Source: KDB-supplied data, 2019.

Table B presents other key indicators in the economy, dairy sector and the milk ATM supply chain in Kenya.

KNBS (2019) estimates that urbanization will increase to $2 \%$ intercensal growth. Urbanization has implications on milk demand, particularly on demand for pasteurized milk, as most of the processed milk is marketed in urban areas.

From the KDB-supplied data and primary data collected, the study estimates that there are 2,030 ATMs, of which about 480 ATMs are unregistered. KDB reported that in 2018 out of the 1,550 ATMs registered in Kenya, 436 had fully complied. This represented a compliance rate of about $28 \%$. KDB estimates that the current compliance rate is at $33 \%$. It is worth noting that KDB has currently suspended the licensing of the ATMs pending the passage of proposed regulations for the market segment.

Table B Current characteristics and assumptions of the dairy industry and ATM milk supply chain.

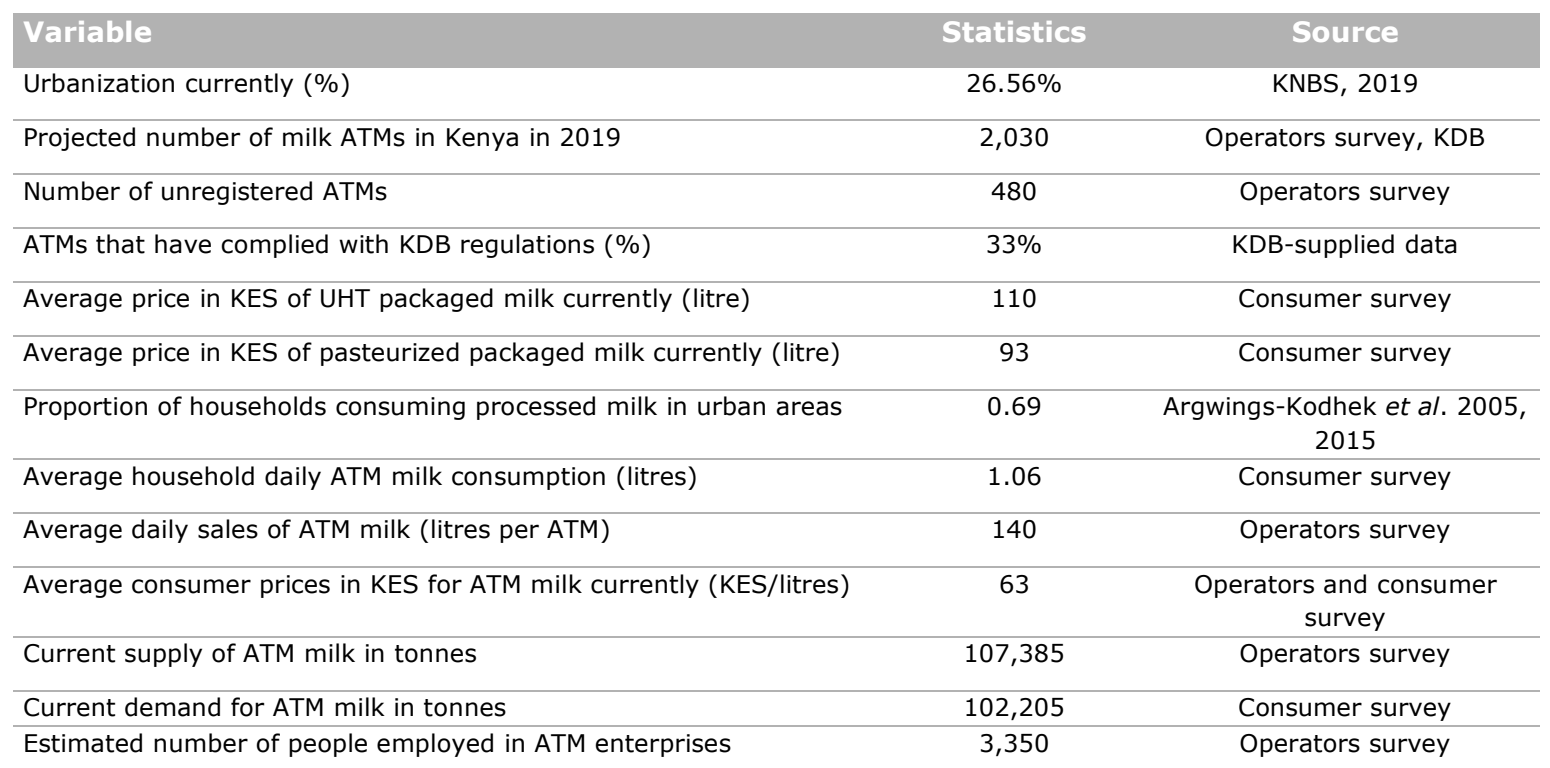

There are 3,350 people employed directly as operators in the milk ATMs. This is the total number of ATMs $(2,030)$ by the mean number of employees (1.65) from the primary data collected among operators of milk ATM machines. 


\section{B. Time series data decomposition}

Time series was done to predict the urbanization rates. Economic time series data contains four basic components which are mutually exclusive and collectively exhaustive: Trend (T)/Cycle (C), Seasonality (S) and Irregular (I). Decomposition assume that the data are made as follows:

Data $=$ pattern + error

According to Alam et al., 2015, the pattern of any data may show trends/cycles and seasonality. A trend exists when there is a long-term increase or decrease in the data. It does not have to be linear. Sometimes we will refer to a trend "changing direction", that is, it goes from an increasing trend to a decreasing trend. A seasonal pattern exists when a series is influenced by seasonal factors (e.g. the quarter of the year, the month or the day of the week). Seasonality is always of a fixed and known period. So we can give a standard form of the decomposition time series on the basis of the pattern of the data.

Data $=$ pattern + error

$=$ (trend-cycle, seasonality, error)

An element of the error or randomness is also assumed to be present in the data. It is actually the combined effect of the two sub-patterns of the series. This means the combined effect of the trendcycle, seasonality and the actual data. This is often called the "irregular" component. There are several alternative approaches to decomposing a time series, all of which aim to isolate each component of the series with great accuracy and precisely. Actually, the main substance is to remove the trend-cycle and then isolate the seasonal component. The basic time series data from the above discussion can be presented in the form:

$Y t=f(S t, T t, E t)$

Where $Y t$ is the time series value (actual data) at period $t, S t$ is the seasonal component (or index) at period $\mathrm{t}, \mathrm{t}$ is the trend cycle component at period $\mathrm{t}$, and $E \mathrm{t}$ is the irregular (or reminder) component at period $t$.

There are two main decomposition models: additive decomposition model and multiplicative decomposition model. An additive model assumes the addition of all the time series components. An additive model is usually appropriate if the magnitude or the span of the seasonal fluctuation doesn't vary with the level of the series.

$Y t=S t+T t+E t$

A multiplicative model assumes that the observed time series data is composed of all components multiplied together. A multiplicative decomposition is usually applied when the seasonal fluctuations increase and decrease proportionally with increases and decreases in the level of the series. Multiplicative decomposition is more appropriate for the economic series because most seasonal economic series have seasonal variation and may vary by day, week, month and year.

Yt $=$ St $\times$ Tt $\times$ Et

The study adopted the multiplicative model. Data on each variable was collected for the past years and, to decompose the trend-cycle component, moving averages were adopted. A five-year moving average was adopted because Kenya has a five-year government cycle. The moving averages were then used to determine the trend by use of a simple linear regression. The regression coefficients were used to determine the trend component in each observation $\mathrm{Tt}$.

To determine the seasonal component, the observed data (Yt) was divided by the trend cycle component (Tt). Mathematically this is given by:

$\mathrm{Yt} / \mathrm{Tt}=\mathrm{St} \times \mathrm{Et}$

A seasonal adjustment factor for each period was calculated by averaging the seasonal components data in order to leave the irregular component. These seasonal adjustment factors are known as seasonal indices. The data is then adjusted by the indices to remove the seasonality and retain only the trend cycle and the irregular components. This implies that the predicted trend cycle component is multiplied with the seasonal indices to have the seasonally adjusted predictions for the future time 
periods. The forecasting of the variables was done for the next 15 years from the above procedure on each key variable.

\section{Modelling milk ATM growth}

Growth can take different forms, including linear and exponential, depending on the variable under consideration. Milk ATMs could not take a linear growth form where $Y=a+b X$, since this would imply an indefinite growth and time relationship, which is not the case. However, the growth of milk ATMs could take an exponential growth form but only for a short time. This is because exponential growth assumes the milk ATMs will continue increasing exponentially to an infinite time period without reaching saturation, which is also not the case.

Therefore, the study settled for a logistic growth function that assumes that growth begins slowly, then increases rapidly and eventually levels off. Data of this type can be modelled by an "S-curve", or a logistic function. These functions, like exponential functions, grow quickly at first, but because of restrictions that limit the size of the underlying population, eventually they grow more slowly and then level off. The logistic growth function is modelled mathematically as follows:

$f(x)=\frac{c}{1+a e^{-b x}}$

Where $a, b$ and $c$ are constants. The value ' $c$ ' is called the limiting value or the upper limit of the function because the graph of a logistic growth function will have a horizontal asymptote at $y=c$. As is clear from the graph below, the characteristic S-shape of a logistic function shows that initial exponential growth is followed by a period in which growth slows and then levels off, approaching (but never attaining) a maximum upper limit. The initial population is denoted by the value ' $a$ '. The value ' $b$ ' denotes the growth coefficient, whereas ' $e$ ' is the exponent. Logistic functions are good models of population growth in variables that have grown so large that they are near to saturating their ecosystems, or of the spread of information within societies.

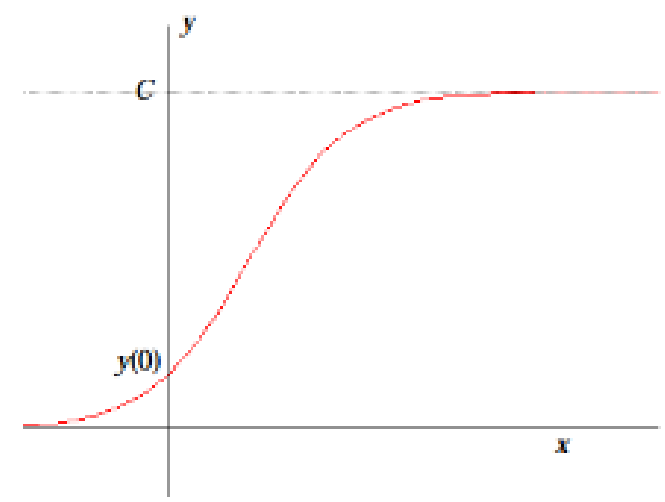

Figure B Logistic growth function.

For the case of milk ATMs, the population of machines grew slowly between 2004 and 2015, then had exponential growth up to 2017 , then the growth rate decreased from there but had not yet reached the saturation point. From the cases of exponential growth, the population reaches half when it starts increasing at a decreasing rate. Hence the current population $(2,030)$ of milk ATMs was assumed to be half of the carrying capacity. This implies that ' $c$ ' was approximated to be 4,060 milk ATMs, 'a' was assumed to be 12 and the growth rate ' $b$ ' was assumed to be 0.23 .

The ATM growth rate of 0.23 was determined by analysing the annual growth of milk ATMs from the past data provided by the KDB. The minimum annual growth was taken for the calculation because that is the least expected growth, and any other values are dependent on seasonal variations (Table C). 
Table C Number and growth of milk ATMs in Kenya.

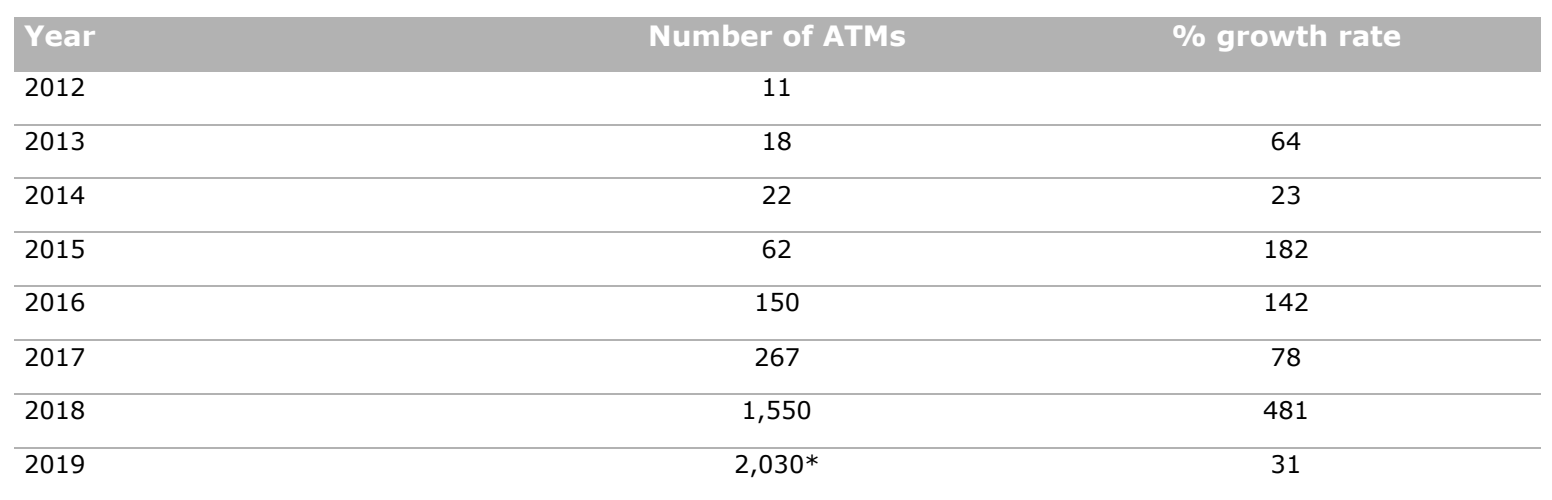

*projected number of ATMs in Kenya in 2019

The growth rate above was assumed to remain constant when modelling the growth in population demanding ATM milk, capacity utilization for milk ATM machines and the changes in compliance levels for the ATM milk market segment. In modelling growth in the population demanding ATM milk, several factors were considered. First, the study acknowledges that the ATM milk market segment is mainly in the urban areas of Kenya. Therefore, the number of urban households was calculated from the total population, and the urbanization rates were predicted from the time series data. The urban population was then adjusted to get the proportion of households demanding pasteurized milk by multiplying by a constant of $69 \%$ (Argwings-Kodhek et al., 2005).

The households demanding pasteurized milk in the urban areas and the number of households demanding ATM milk were computed by multiplying by $16 \%$, which is the ATM milk market share estimated from survey and KDB-supplied data as follows. The total urban households are estimated at urbanization rate $(27 \%)$ of $12,143,900$ households from 2019 Census data (KNBS, 2019). Therefore, the number of households demanding ATM milk is calculated as a proportion of households consuming pasteurized milk in urban areas (69\%) times the share of ATM market (16\%) giving approximately 361,985 households. Based on the consumer survey, each household consumes an average of 1.06 litres of milk, hence the total demand for ATM milk is approximately 102,205 tonnes. From KDB data, the estimated share of formal milk market is approximately 806,688 tonnes (KDB-supplied data, 2019).

The model assumes that this capacity grows at the same growth rate as the growth in demand for ATM milk. Similarly, the current compliance rate was estimated at $33 \%$ from extrapolation of KDB data on compliant ATMs in 2019. That is, 436 milk ATMs of the 1,550 milk ATMs registered in 2018 were compliant, which was approximately $28 \%$ compliance. Assuming the growth rate remains constant, then a third of the milk ATMs were compliant in 2019. However, the estimated maximum compliance rate of milk ATMs is restricted to $80 \%$, which is the highest level of compliance rate with $\mathrm{KDB}$ regulations in the dairy sector.

Supply of milk through ATMs was estimated as a function of the number of milk ATMs and the capacity utilization. The current volume supplied was calculated by multiplying the number of ATMs $(2,030)$ by the average amount of milk supplied to milk ATMs per day, estimated at 146.94 litres from the ATM operator survey data. 


\section{Appendix 2 Further analysis}

Table A Characteristics by income groups.

\begin{tabular}{|c|c|c|c|c|c|c|}
\hline & $\begin{array}{c}\text { Low } \\
\text { income }\end{array}$ & $\begin{array}{l}\text { Middle } \\
\text { income }\end{array}$ & $\begin{array}{c}\text { High } \\
\text { income }\end{array}$ & Total & $\mathrm{F}$ & Prob $>F$ \\
\hline Amount of milk bought in a day & 0.92 & 1.26 & 1.45 & 1.09 & 4.93 & 0.008 \\
\hline Price of raw milk & 55.74 & 55.19 & 55.00 & 55.47 & 0.02 & 0.982 \\
\hline Distance to ATM & 7.73 & 7.17 & 14.55 & 7.83 & 1.85 & 0.159 \\
\hline Amount of ATM milk bought in day & 1.00 & 1.04 & 1.68 & 1.05 & 1.99 & 0.141 \\
\hline Price of ATM milk & 58.87 & 63.01 & 66.43 & 61.00 & 1.20 & 0.305 \\
\hline Household size & 2.86 & 3.05 & 3.20 & 2.96 & 0.64 & 0.526 \\
\hline
\end{tabular}

Source $=$ Consumer survey $(n=352)$

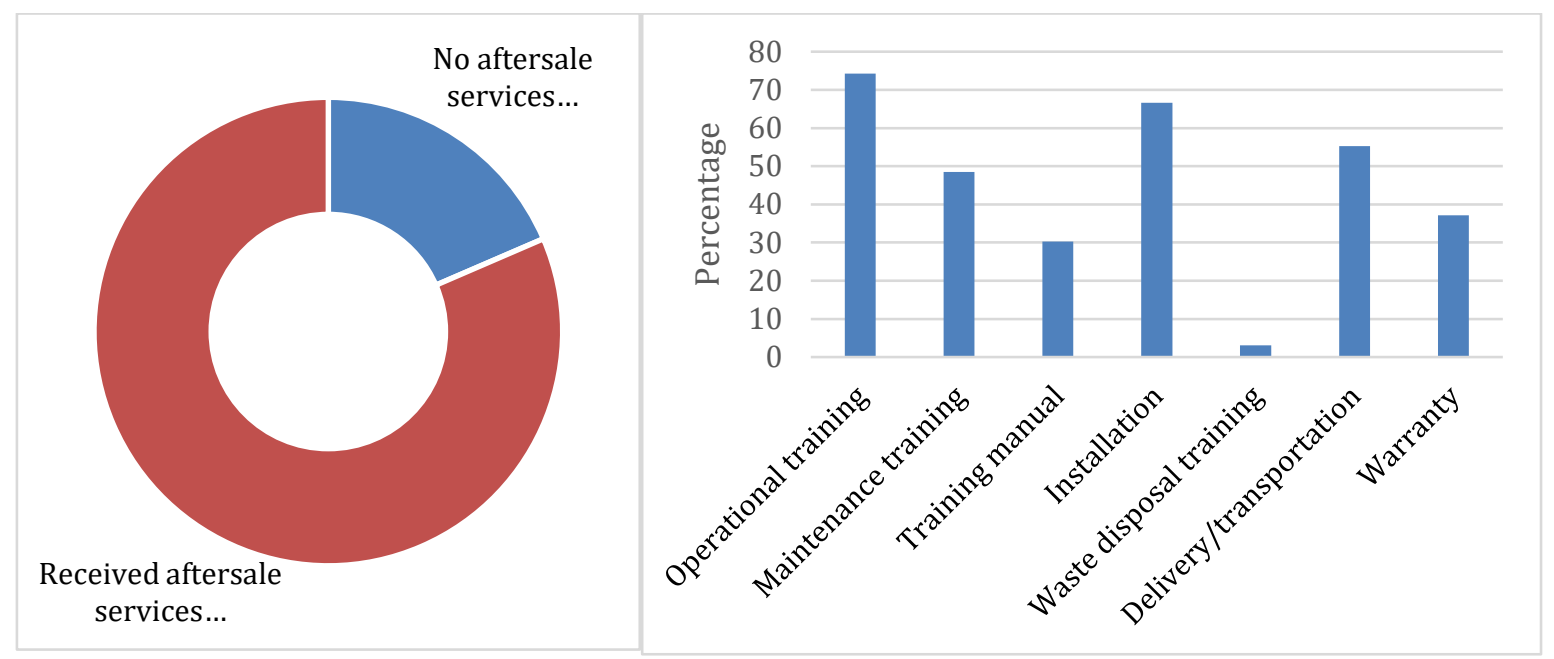

Figure A After-sales services offered after acquisition of milk ATMs.

Source $=$ Operators survey $(n=162)$ 


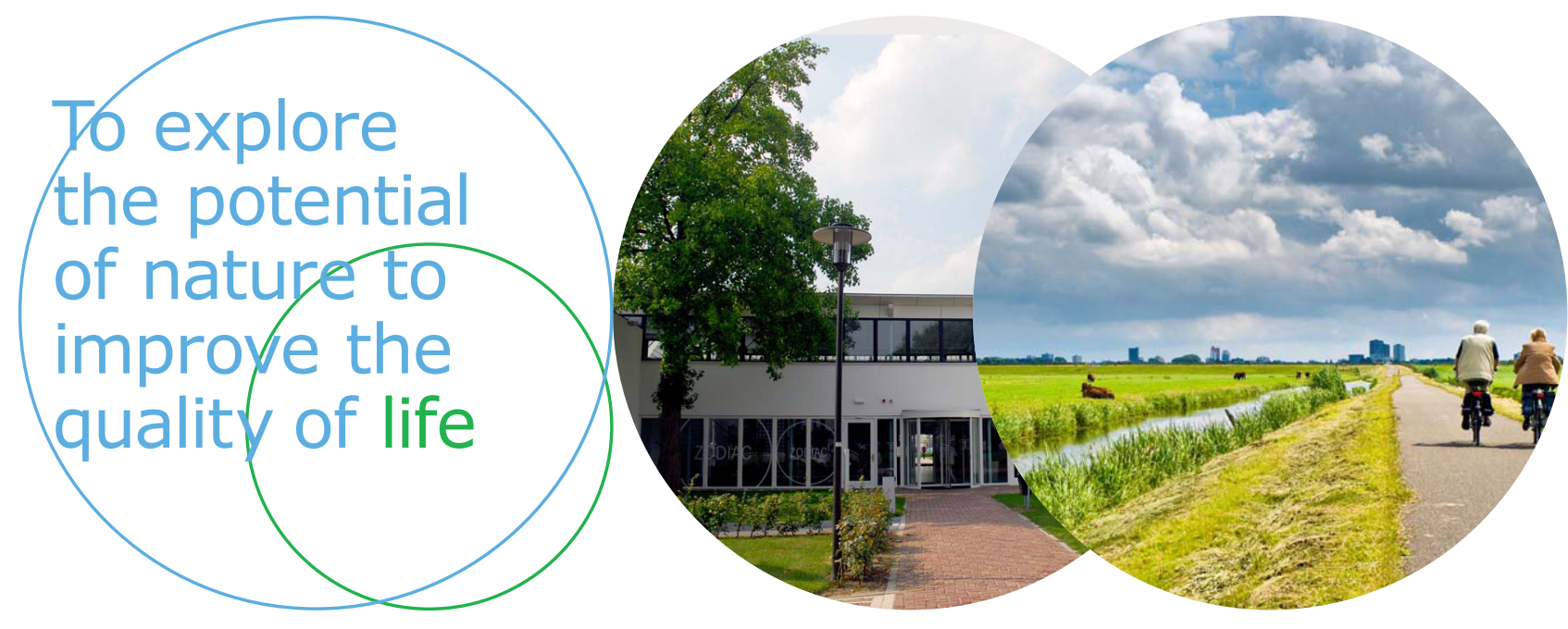

Wageningen Livestock Research P.O. Box 338

6700 AH Wageningen

The Netherlands

$\mathrm{T}+31(0) 317483953$

E info.livestockresearch@wur.nl

www.wur.nl/livestock-research

Wageningen Livestock Research creates science based solutions for a sustainable and profitable livestock sector. Together with our clients, we integrate scientific knowledge and practical experience to develop livestock concepts for future generations.

Wageningen Livestock Research is part of Wageningen University \& Research. Together we work on the mission: 'To explore the potential of nature to improve the quality of life'. A staff of 6,500 and 10,000 students from over 100 countries are working worldwide in the domain of healthy food and living environment for governments and the business community-at-large. The strength of Wageningen University \& Research lies in its ability to join the forces of specialised research institutes and the university. It also lies in the combined efforts of the various fields of natural and social sciences. This union of expertise leads to scientific breakthroughs that can quickly be put into practice and be incorporated into education. This is the Wageningen Approach. 